Florida International University FIU Digital Commons

2016

\title{
Outcomes of Transition to Adult HV Care in Perinatally HIV-infected Young Adults
}

Susan Biersteker

Florida International University, sbier002@fiu.edu

DOI: $10.25148 /$ etd.FIDC001193

Follow this and additional works at: https://digitalcommons.fiu.edu/etd

Part of the Public Health Education and Promotion Commons

\section{Recommended Citation}

Biersteker, Susan, "Outcomes of Transition to Adult HV Care in Perinatally HIV-infected Young Adults" (2016). FIU Electronic Theses and Dissertations. 3041.

https://digitalcommons.fiu.edu/etd/3041 


\title{
FLORIDA INTERNATIONAL UNIVERSITY
}

Miami, Florida

\section{OUTCOMES OF TRANSITION TO ADULT HIV CARE \\ IN PERINATALLY HIV-INFECTED YOUNG ADULTS}

\author{
A dissertation submitted in partial fulfillment of \\ the requirements for the degree of \\ DOCTOR OF PHILOSOPHY \\ in
}

PUBLIC HEALTH

by

Susan Biersteker

2016 
To: Dean Tomás R. Guilarte

R.Stempel College of Public Health and Social Work

This dissertation, written by Susan Biersteker, and entitled Outcomes of Transition to Adult HIV Care in Perinatally HIV-infected Young Adults, having been approved in respect to style and intellectual content, is referred to you for judgment.

We have read this dissertation and recommend that it be approved.

$\begin{array}{r}\text { Elena Bastida } \\ \hline \text { Virginia H. McCoy } \\ \hline \text { Mary-Jo Trepka } \\ \hline \text { Ana Garcia } \\ \hline \text { Consuelo Beck-Sagué, Major Professor }\end{array}$

Date of Defense: November 9, 2016

The dissertation of Susan Biersteker is approved.

Dean Tomás R. Guilarte R.Stempel College of Public Health and Social Work

Andrés G. Gil

Vice President for Research and Economic Development and Dean of the University Graduate School

Florida International University, 2016 


\section{ACKNOWLEDGMENTS}

No one could write a dissertation without the support of many. My special appreciation and thanks to Dr. Consuelo M. Beck-Sagué. She had my back and her prolific knowledge of perinatally HIV-infection, and compassion for underserved populations was invaluable and inspiring to me. I am also indebted to my committee members Drs Elena Bastida, Virginia McCoy, Mary-Jo Trepka and Ana Garcia. For your insightful comments and suggestions, thanks to you.

Barbara Messick invited me to conduct this research. She and Dr. Ana Garcia have supported me every step of the way. Above all, I have learned what enormous challenges they face to help patients and their families cope with the consequences of HIV-infection. I admire their dedication, compassion, and wisdom. Thanks also to Dr. Gwendolyn Scott and the staff of the pediatric Special Immunology clinic for sharing their experiences, helping me to find information, and making me feel welcome.

Extra appreciation is extended to the study participants. I hope their experiences represented in this research will be of benefit to others.

Last but not least, many thanks to my family and friends. Without their love, company, support, and without the distractions they provided, I would not have accomplished much. Special gratitude to my guys Bill and Dries. Bill, who always is seeking for the truth and social justice, inspired me to try to make a difference while acknowledging the limits of research. And to Dries, who has matured into an accomplished, creative, and dynamic young man while I was in grad school, thanks for being you! 


\section{ABSTRACT OF THE DISSERTATION \\ OUTCOMES OF TRANSITION TO ADULT HIV CARE \\ IN PERINATALLY HIV-INFECTED YOUNG ADULTS \\ by}

Susan Biersteker

Florida International University, 2016

Miami, Florida

Professor Consuelo Beck-Sagué, Major Professor

Transitioned perinatally HIV-infected patients may be at increased risk for poor outcomes, yet the impact of transition and of transition programs on health are not well understood. This research examined: (1) post-transition mortality, (2) engagement in adult HIV care, (3) transition experiences, and clinical and sociodemographic influences, including transition program exposure.

Data were collected from patients who had transitioned from a Florida pediatric clinic to adult HIV care between January 2003 and September 2012. Post-transition mortality and care engagement were assessed in a retrospective analysis of medical record data. Fisher exact and Kruskal-Wallis tests were used for significance testing. Risk ratios (RRs) were calculated to assess strength of associations. Stratified analysis controlled for confounding. Transition experiences were examined in a mixed-methods study, with qualitative data from a computer-assisted survey subjected to thematic analysis.

Of 51 transitioned patients, nine (18\%) had died by May 2014, five $(56 \%)$ in the first post-transition year. Of 42 survivors, 33 were eligible; 27 (82\%) provided consent. 
Post-transition mortality was high, particularly in those severely immunosuppressed $\left(\mathrm{CD} 4\right.$ count $\left.<100 / \mathrm{mm}^{3} ; \mathrm{RR}=6.0,95 \% \mathrm{CI}=1.88-19.19[\mathrm{P}=.005]\right)$ at transition. When controlled for CD4 count, employment was associated with decreased (adjusted RR= $0.19 ; 95 \% \mathrm{CI}=0.04-0.88[\mathrm{P}=.02])$, and high school non-completion with increased (adjusted $\mathrm{RR}=3.0 ; 95 \% \mathrm{CI}=1.37-6.40[\mathrm{P}=.07]$ ) mortality risk. The number of kept HIV appointments decreased from last pre-transition (Median $=5$, IQR 4-6) to first posttransition (Median = 2, IQR 1-10; $\mathrm{P}=.002$ ) year; the proportion of poorly engaged increased from $3 \%$ to $35 \%$ ( $\mathrm{P}=.006$ ), with no significant changes between first and second post-transition years. Non-Hispanic black and low-income participants were less likely to be regularly engaged in adult HIV care one year post-transition. Transition program exposure did not significantly affect mortality or care engagement. Most of 27 received transition services, but 59\% had trouble doing well in adult care. Needs for patient-centered care, with caring, personal patient-provider relationships and accessible HIV care, characterized post-transition experiences.

This research suggested that transitioned perinatally HIV-infected young adults are at risk for poor health outcomes. Systematic programs using a socio-ecological framework to include multi-level interventions and post-transition support may improve outcomes. 


\section{TABLE OF CONTENTS}

CHAPTER

PAGE

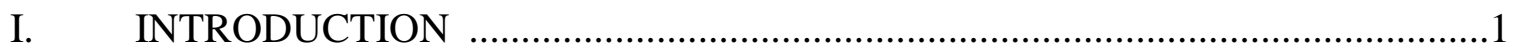

Epidemiological Changes in Perinatal HIV Cases ..................................1

New Challenges in HIV Treatment and Care ...........................................2

Transition from Pediatric to Adult Care ...................................................4

Literature Review: Transition from Pediatric/Adolescent to

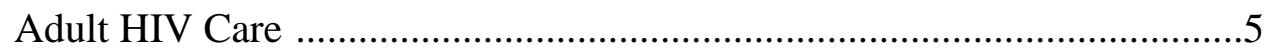

Statement of the Problem ...........................................................................

Study Context: Pediatric Clinic in South Florida ....................................10

Study Context: Comprehensive Transition Program ...............................11

Study Aims and Hypotheses ...........................................................16

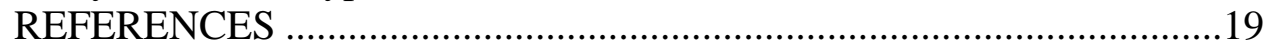

II. STUDY DESIGN AND METHODOLOGY .................................................26

Applied Research ............................................................................26

Study Design .....................................................................................26

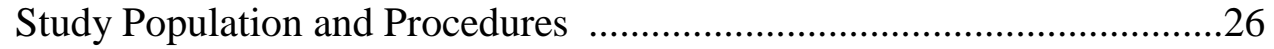

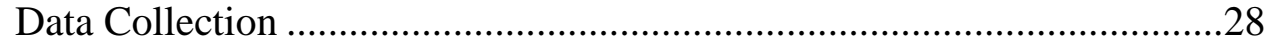

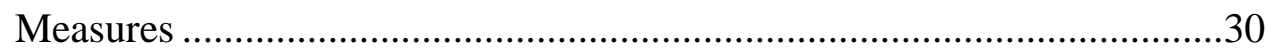

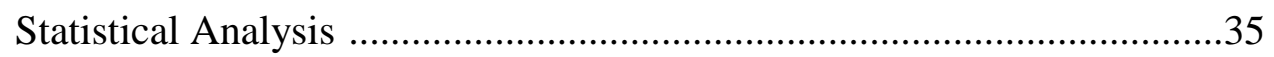

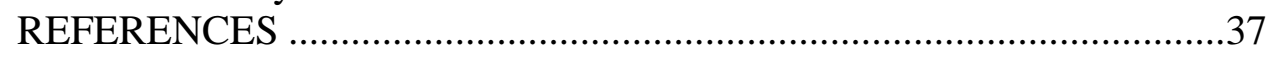

III. FIRST MANUSCRIPT Factors associated with death in perinatally HIV-infected adults after transition to adult care in Miami, Florida .....................40

ABSTRACT ..............................................................................4

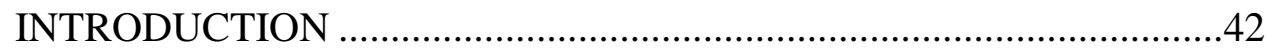

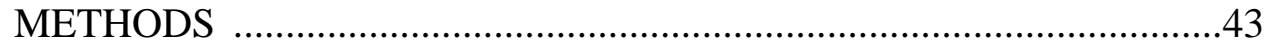

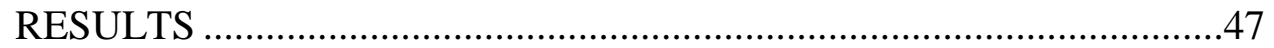

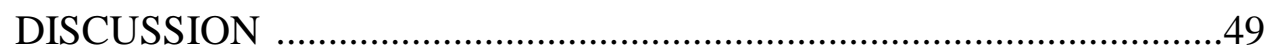

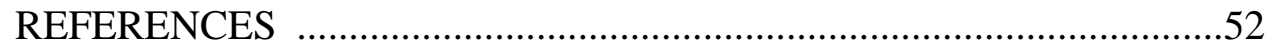

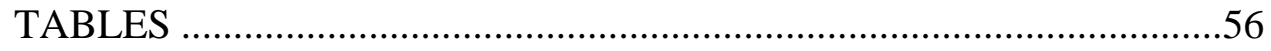

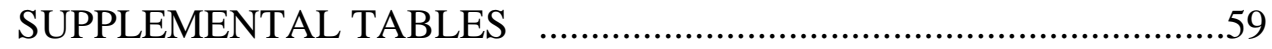

IV. SECOND MANUSCRIPT Engagement in HIV care of perinatally HIV-infected young adults after transition to adult medical care settings: Effectiveness assessment of a comprehensive transition program......................................61

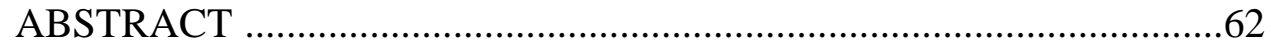

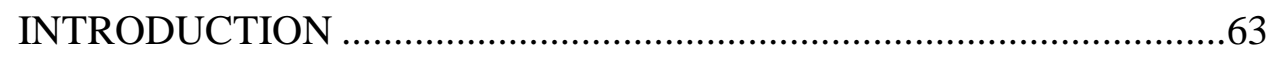

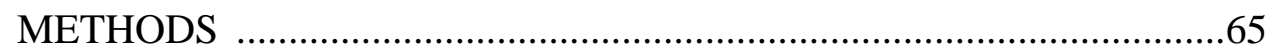

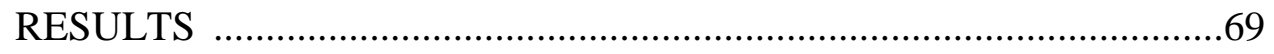

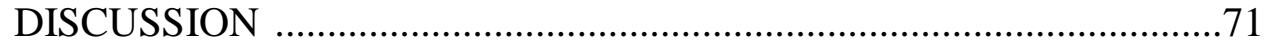

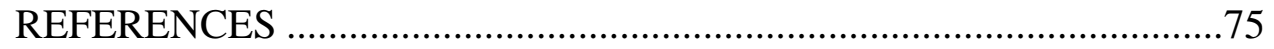


V. THIRD MANUSCRIPT "Now we are adults they do not care anymore:" Mixed-methods study of experiences of transitioned young adults with perinatally acquired HIV infection in adult care .......................................... 83

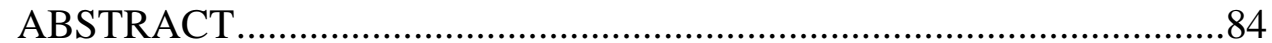

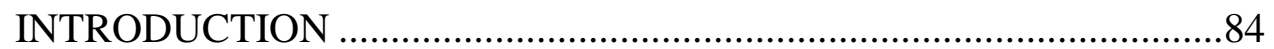

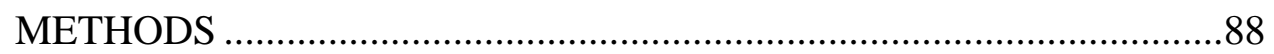

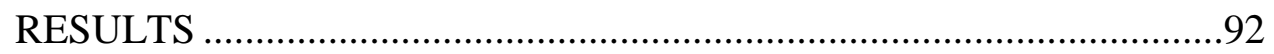

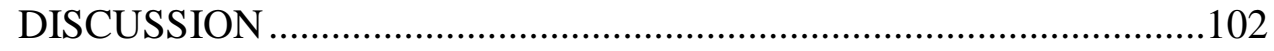

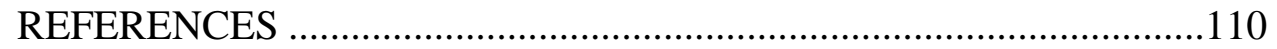

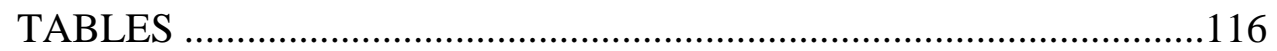

VI. CONCLUSIONS AND PROGRAM RECOMMENDATIONS .......................119

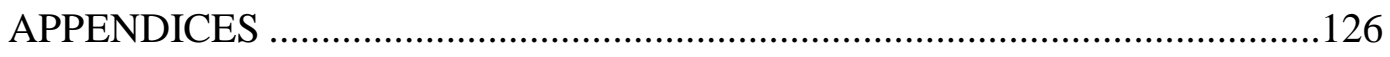

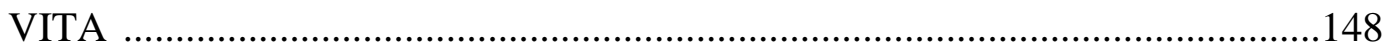




\section{LIST OF TABLES}

TABLE

PAGE

3.1 Characteristics of perinatally HIV-infected young adults at transition who died post-transition .56

3.2 Sociodemographic and clinical characteristics at time of transition $(\mathrm{N}=36)$

3.3 Factors associated with death $(\mathrm{n}=9)$ after transition to adult care $(\mathrm{N}=36)$. .58

3.4 Supplemental tables. Characteristics at transition associated with death post-transition, controlled for: a) CD4+ T-lymphocyte count $<100$ cells per $\mu \mathrm{L}$ and b) CD4+ T-lymphocyte count $<100$ cells per $\mu \mathrm{L}$ and living in poverty

4.1 Study population: Sociodemographic and clinical characteristics at time of transition to adult HIV care $(\mathrm{N}=31)$

4.2 Number of kept HIV appointments: pre-transition, one and two years post-transition .80

4.3 Visit constancy (at least one quarterly kept appointment): pre-transition, one and two years post-transition

4.4 Factors associated with regular engagement in adult HIV care, $1^{\text {st }}$ year post-transition $(n=26)$

4.5 Supplemental Table. Association of transition clinic attendance with regular engagement in care $1^{\text {st }}$ year post-transition, controlled for poverty........ .82

5.1 Characteristics of study participants $(\mathrm{N}=27)$ 116

5.2 Who/what was helpful to prepare you for transition?

5.3 Experienced problems after transition to adult HIV care 118 


\section{ABBREVIATIONS AND ACRONYMS}

AIDS

cART

CDC

FPL

GED

HIV

PHIV
Acquired Immunodeficiency Syndrome

Combination Antiretroviral Therapy

Centers for Disease Control and Prevention

Federal Poverty Level

General Educational Development Test

Human Immunodeficiency Virus

Perinatally HIV-Infected 


\section{CHAPTER I \\ INTRODUCTION}

\section{Epidemiological Changes in Perinatal HIV Cases}

Medical advances since the mid-1990s greatly improved the life expectancy of children infected with HIV early in life. ${ }^{1,2}$ With widespread access to combination antiretroviral therapy (cART) -especially in industrialized or developed countries- many perinatally HIV-infected (PHIV) children who were expected to die in early childhood, now survive into adolescence, young adulthood and beyond. ${ }^{3}$ Simultaneously, effective interventions to prevent mother-to-child transmission, including cART therapies, significantly reduced the number of children born with HIV. Without interventions, perinatal transmission rates are estimated at $18 \%$ to $32 \%{ }^{4}$ Currently, transmission rates in the United States (US) are 1-2\%; national policies aim for a reduction to $<1 \%$, which is regarded as feasible if sufficient and adequate resources are employed to deliver all recommended interventions to prevent mother-to-child transmission. ${ }^{5}$

In the US, the pediatric HIV population ${ }^{1}$ consists of a relatively stable group of approximately 10,000 infected children, adolescents, and young adults, with the addition of less than 100 new cases annually. ${ }^{6,7}$ As a consequence of epidemiologic trends, most US PHIV children are now adolescents and young adults. ${ }^{6-8}$ Significant racial/ethnic health disparities exist in PHIV, as demonstrated in the state of Florida. Black infants accounted for $75 \%$ of the pediatric HIV cases reported through 2012, while only $21 \%$ of the Florida population is Black. ${ }^{9}$ Like most HIV-infected heterosexual women and men,

\footnotetext{
${ }^{1}$ Pediatric cases include children infected with HIV prior to age $13 ; 95 \%$ of pediatric cases are perinatallyacquired HIV.
} 
most PHIV children are poor and live in urban, impoverished neighborhoods, where HIV prevalence is 20 times greater than among US heterosexuals overall. ${ }^{10,11}$

\section{New Challenges in HIV Treatment and Care}

Long term survival of PHIV children poses new care and treatment challenges. The growing cohort of adolescents and young adults with PHIV requires lifelong treatment to control for viral replication, prevent immune deterioration and transmission of HIV. ${ }^{12}$ They were infected before development of their immune systems, and most are significantly treatment experienced, often with suboptimal mono- and dual antiretroviral regimens before more effective triple regimens became available. ${ }^{7,13,14}$ Many PHIV adolescents and young adults will be in advanced stages of HIV disease and have complex medical histories, complicating treatment and limiting therapy options. ${ }^{15}$ As more PHIV children grew older, high risks of treatment failure and antiretroviral resistance, and long term complications of lifetime HIV disease, including metabolic disorders and neurocognitive impairment, became evident. ${ }^{12,13}$ With effective cART, AIDS dementia and encephalopathy have almost disappeared in the United States, but concerns regarding more subtle central nervous system and learning disabilities have emerged. ${ }^{13,16}$ Higher rates of psychiatric symptoms, particularly attention deficit-disorder and depression, were reported in HIV infected youth compared to uninfected youth from similar socioeconomic backgrounds. ${ }^{17}$ Explanatory, multifactorial, causes include biological (e.g. HIV-associated neurocognitive disorder) factors, treatment complications, including disfiguring adverse effects (e.g. lipodystrophy), and psychosocial factors, including living with a chronic illness, loss of parents, and HIV/AIDS stigma. 
With the transformation of HIV from a fatal to a chronic disease, the goal of HIV care has shifted toward achieving long-term optimal health outcomes through consistent ART adherence and responses. Continuous care is essential for all people with HIVinfection, as even short lapses in HIV care may have significant consequences for viral suppression, drug resistance, and HIV transmissibility. ${ }^{18}$ As PHIV children mature, they may be less likely to adhere to HIV appointment schedules and ART regimens, compared to younger children and HIV-infected adults. While retaining HIV-infected patients in medical care at regular intervals results in better health outcomes,${ }^{19}$ studies reported prolonged poor engagement in adult HIV care extending from adolescence through young adulthood. ${ }^{20}$ Viral suppression can be achieved with adherence levels of 54\% $100 \%$ to newer, more potent non-nucleoside reverse transcriptase and boosted protease inhibitor containing cART regimens. ${ }^{21}$ Nevertheless, perfect adherence remains an important goal; self-reported adherence among HIV-infected youth was reported between $40 \%-84 \%$, and tends to be lower than in adults. ${ }^{12}$

Long-term survival of youth also comes with unanticipated needs in reproductive health, higher education, and employment. ${ }^{13}$ Growing autonomy and independence, formation of intimate relationships, and management of education and employment may be difficult for all adolescents. These issues may be particularly challenging for PHIV adolescents as they have to be managed in the context of HIV disease and care, HIV/AIDS stigma, and economic and social stress. ${ }^{22}$ 


\section{Transition from Pediatric to Adult Care}

Long-term survival is also accompanied by the need for a "seamless" health care transition from pediatric or adolescent services to adult HIV care settings to ensure continuous HIV care. Most US pediatric or adolescent clinics follow their patients up to age 24-25 years, after which patient care has to be transferred to adult HIV providers. With the 'coming of age' of the largest cohort of PHIV children (infected between early 1980's and late 1990's), more patients than ever before will transfer from pediatric or adolescent services to adult care in the next decade. ${ }^{23}$ Transition from pediatric and adolescent clinical services to adult care is widely regarded to be challenging, largely because of fundamental differences between pediatric and adult HIV care models. ${ }^{22,24}$ Most pediatric and adolescent clinics have long-established relationships with their patients, and offer comprehensive 'one-stop' services in a familiar and nurturing environment. In contrast, adult clinical services tend to be less accommodating and more impersonal, and require patients to self-manage their HIV disease and independently navigate fragmented adult health care systems. PHIV young adults may not have the functional autonomy presumed in adult HIV care. ${ }^{25}$ As PHIV children in the US disproportionally belong to poor racial or ethnic minority communities, psychosocial issues, including living in impoverished neighborhoods, poverty, and HIV/AIDS stigma, may further complicate successful transition. ${ }^{11}$ These issues may be exacerbated by the complexity of the US healthcare system, and the under-resourced and stressed system of HIV care for patients who depend on public health insurance. ${ }^{26,27}$

Recognizing the risks associated with poor health care transition, with transitioned PHIV young adults becoming sub optimally engaged in adult HIV care or 
being lost to care, successful transition has become a key aspect in maintaining the health of PHIV adolescents and young adults. ${ }^{8,28}$ Consequently, transition programs and services to prepare patients for a 'smooth' transition have become a key component of pediatric or adolescent care.

\section{Literature Review: Transition from Pediatric/Adolescent to Adult HIV Care}

Transition of medical care is not simply an administrative procedure. It refers to the purposeful, planned preparation of adolescents and young adults with chronic physical and medical conditions, their families, and their caregivers to successfully transfer from comprehensive, child-centered, care to adult-oriented care. ${ }^{29}$ Successful transition requires autonomy in all realms of life, including taking personal control over health issues, coming to terms with sexual orientation, and planning of future educational and vocational goals. ${ }^{23}$

Health care transition first evolved as a concept of care several decades ago, when prognosis improved for children diagnosed with other pediatric conditions than HIV, including cancer, cystic fibrosis and type 1 diabetes. ${ }^{30}$ In 1984, US Surgeon C. Everett Koop hosted the first national conference "Youth with Disability: The Transition Years," to describe emerging needs and transition challenges. ${ }^{31}$ Five years later, the Surgeon General's conference entitled "Growing Up and Getting Medical Care: Youth with Special Health Care Needs," developed the first national agenda to develop specific strategies and action steps to establish a seamless health care transition from childcentered to adult-centered medical services. ${ }^{31}$ In the following years, the Society of Adolescent Medicine, ${ }^{29}$ US Department of Health and Human Services, ${ }^{28}$ Academy of Pediatrics, ${ }^{8}$ and others professional organizations published transition recommendations 
and guidelines. Despite these efforts, modest progress has been made. There still is an urgent need for coordinated, integrated and evidence-based transition services and programs for adolescents and young adults with chronic diseases. ${ }^{22,32}$

PHIV young adults, due to their more recent improvement in survival, have been relatively understudied. To date, the transition literature has focused on understanding issues young people with HIV face as they "age out" of pediatric or adolescent care. 'State-of-the-Art' review articles concluded that most studies utilized qualitative research methods to explore anticipated transition barriers from the perspectives of youth who still had to transition, their caregivers and providers. ${ }^{24,33,34}$ Across various studies, transition is considered to be challenging because of the loss of longstanding, familiar relationships with pediatric providers, anxieties about increased responsibility for disease management and presumed medical independence in adult HIV care. ${ }^{35-40}$ Logistical challenges, including medical insurance and access to medical and social services, may further complicate transition.

Similar barriers were first discussed at the first national conferences on needs of children with chronic diseases in the 1980s, and were commonly described in following studies of young adults with chronic diseases. ${ }^{30,31,41,42}$ Transitioning adolescents and young adults with chronic diseases share the burden of lifetime disease management and, therefore, may face comparable transition barriers. However, unique challenges including HIV/AIDS stigma and discrimination, disclosure-related issues, and the risk of secondary transmission, may further complicate transition of young adults with $\mathrm{HIV}^{2}{ }^{44}$ HIV/AIDS

\footnotetext{
${ }^{2}$ Young adults with HIV includes youth with perinatally and behaviorally acquired HIV-infection. Although the course of infection differs, transition challenges and outcomes may be similar.8,43
} 
is also different from some other chronic diseases as it disproportionally impacts socially and economically marginalized populations. ${ }^{11}$ Racial and ethnic disparities in transition success are relatively unexamined. Some evidence from studies of youth with chronic diseases indicated that youth from racial and ethnic minorities received less adequate transition preparation, while low-income youth were found to be at higher risk of experiencing gaps in access to care as they aged into adulthood compared to their counterparts with higher incomes. ${ }^{27}$ Qualitative studies of young adults with HIV suggested that adverse social conditions may be barriers to successful transition, including lack of transportation and stable housing, unemployment, food insecurity, and problems obtaining and accessing health insurance. ${ }^{11,25,37}$

The paucity of transition outcome data and the lack of evidence-based transition programs are widely recognized as the most important gaps in the transition literature. ${ }^{33}$ Concerns about poor transition outcomes of PHIV young adults were primarily based on anecdotal information of pediatric providers, and on findings of studies of youth with chronic diseases other than HIV disease. These studies showed poorer outpatient clinic attendance, poorer adherence to medications, and increased morbidity and mortality after transition to adult clinical care. ${ }^{38}$ However, little is known about clinical outcomes of transitioned PHIV young adults, as few pediatric or adolescent clinics track their patients after they leave their care. ${ }^{13,37}$ Post-transition mortality has been assessed in England and Ireland. This retrospective study reported a relatively - compared to adults with HIVhigh mortality rate (4\%) in a cohort of transitioned PHIV adolescents and young adults. ${ }^{45}$ A study conducted in the US reported a non-significant downward trend in immune status (self-reported CD4+ T-lymphocyte [CD4] count) in a cohort of US transitioned PHIV 
young adults. ${ }^{38}$ A recent retrospective study of transitioned patients with behavioral and perinatally-acquired HIV concluded that the health care transition process needs to be optimized as only $50 \%$ of patients were retained in adult HIV care one year posttransition, and had completed at least two clinical visits ${ }^{43}$ Additionally, cross-sectional studies suggested that health may decline after transition to adult HIV care. Poorer clinical outcomes were documented in patients seen in adult HIV care compared to their peers in pediatric care, ${ }^{46,47}$ and HIV-infected adult patients. ${ }^{48}$ Recent studies reported prolonged poor engagement in adult HIV care extending from adolescence through young adulthood (25-34 years old). ${ }^{20}$ Loss-to-follow-up was found to be associated with receiving care at adult clinical settings. ${ }^{49}$

Acknowledging the risk of poor transition outcomes, transition services and programs became a key component of pediatric or adolescent care. ${ }^{8,28}$ Many US pediatric or adolescent HIV clinics have developed and implemented transition programs and services for HIV-infected youth. ${ }^{37}$ In the tradition of chronic diseases, selfmanagement became the central focus of transition programs for adolescents and young adults with HIV. For example, in the policy statement "Transitioning HIV-infected youth into adult health care" of the American Academy of Pediatrics (2013), it was stated that "Seamless and successful transition from pediatric to adult-oriented care is dependent on these youth acquiring skills to allow them to be responsible for their management of their own health care. A well-planned transition enables youth to optimize their ability to assume adult roles and responsibilities. ", 8(p193)

Although the importance of transition preparations and programs for transition success of PHIV young adults is widely supported, there is no high quality evidence 
available to inform policies and programs. Strategies and clinical recommendations for successful transitioning, including development of formal transition plans, assurance of transition readiness, optimizing communication between adolescent and adult clinics, educational, employment and life-skills training, were proposed, but it's not clear how effective these interventions are in improving health outcomes. ${ }^{8,28}$ Likewise, workbooks by the National Resource Centers of the AIDS Education and Training Centers to assist providers to prepare their patients for transition were developed, but - to our knowledge not evaluated. ${ }^{24}$ In addition, of the few published protocols or models for HIV specific health care transition, only one (pilot) evaluation of the "Movin' Out" for behaviorally HIV-infected young adults was published..$^{50}$

Evidence-based transition models may be unavailable because transition of HIVinfected young adults is a relatively new phenomenon. ${ }^{37}$ However, despite the fact that the concept of health care transition was developed decades ago, little high quality evaluation of transition programs for youth with chronic diseases has been published. ${ }^{30,51,52}$ Methodological issues, including lack of well-defined outcome indicators, poorly described interventions, problems in including comparisons groups and measuring separate effects of comprehensive interventions, and a lack of dedicated funding for program development, implementation and evaluation are considered to be major barriers to the development of evidence-based transition programs. ${ }^{51}$

\section{Statement of the Problem}

As the prognosis for HIV disease has improved, an increasing number of PHIV children are living well into adulthood. ${ }^{53}$ With the "coming of age" of the largest cohort of PHIV children, more young adults than ever before will transition from pediatric or 
adolescent services to adult clinical care in the next decade. ${ }^{23}$ Management of HIV disease in medically and socially vulnerable PHIV adolescents and young adults is challenging, and requires lifelong treatment and excellent medication adherence to achieve viral suppression, and prevent deterioration of immunologic status and secondary transmission. ${ }^{12}$

Largely because of system differences between pediatric and adult HIV care settings, transition may be associated with poor health outcomes with potentially negative consequences for both personal and public health. ${ }^{8}$ Because of the risk of poor transition outcomes, with PHIV young adults becoming sub optimally engaged in adult HIV care or being lost to follow-up, transition programs to prepare adolescents and young adults for a smooth, successful, transition became a key component of pediatric or adolescent care.

However, transitioning of PHIV young adults is a new phenomenon who remain understudied. Studies examining outcomes of transition and effects of HIV-specific transition programs are needed to establish theory- and evidence-based programs to support transitioning young adults. This study addresses gaps in the transition literature by assessing health outcomes and the effect of a transition program for PHIV young adults who transitioned from a pediatric outpatient HIV clinic in South Florida. Clinic staff wanted to know: (1) How their transitioned patients were doing post-transition; (2) If the transition program had helped their patients to transition, and (3) What improvements to the transition program were needed.

\section{Study Context: Pediatric Clinic in South Florida}

This study was initiated on request of the Infectious Diseases \& Immunology pediatric clinic, University of Miami, located in Miami, Florida. Florida is among the 
states with the highest HIV/AIDS prevalence and HIV incidence in the nation, with the highest HIV/AIDS burden in South Florida. ${ }^{54}$ Through 2013, Florida ranked second (only to New York State) in the number of pediatric AIDS cases. ${ }^{55}$

The pediatric clinic is a partner of the Miami Family Care Program, which was one of the 13 original Pediatric AIDS Health Care Demonstration Projects in 1988, and has been funded through the Health Resources and Services Administration's (HRSA) Ryan White Part D program since incorporation in the Ryan White Care Act in 1994. The clinic provides out-patient, multi-disciplinary, and family-based healthcare services to low-income and underserved children, adolescents, and young adults up to 25 years in age who acquired HIV early in life, nearly all through vertical transmission. Currently, most of the approximately 160 patients are adolescents or young adults. Funding for supportive or ancillary services is largely unavailable in the adjacent adult public hospital, with about 2,700 adult HIV-infected patients, to where most pediatric patients have transitioned. Consequently, transitioned young adults do not receive the support and assistance to which they were accustomed in comprehensive pediatric HIV care, including but not limited to: follow-up in case of missed appointments, counseling and home delivery services to support medication adherence, and assistance with housing, transportation and completion of insurance paper work.

\section{Study Context: Comprehensive Transition Program}

Since 2008, the pediatric clinic has received funding to implement a comprehensive transition program to address concerns about high attrition rates and nonadherence to medical appointments and medication regimens after patients transitioned to adult HIV care. The transition program aimed to facilitate a smooth transition (Figure 1). 
It was assumed that, in order to maintain health post-transition, patients should be able to independently navigate adult HIV care and attend regularly scheduled HIV appointments, adhere to medication regimens, and access case management and supportive services.

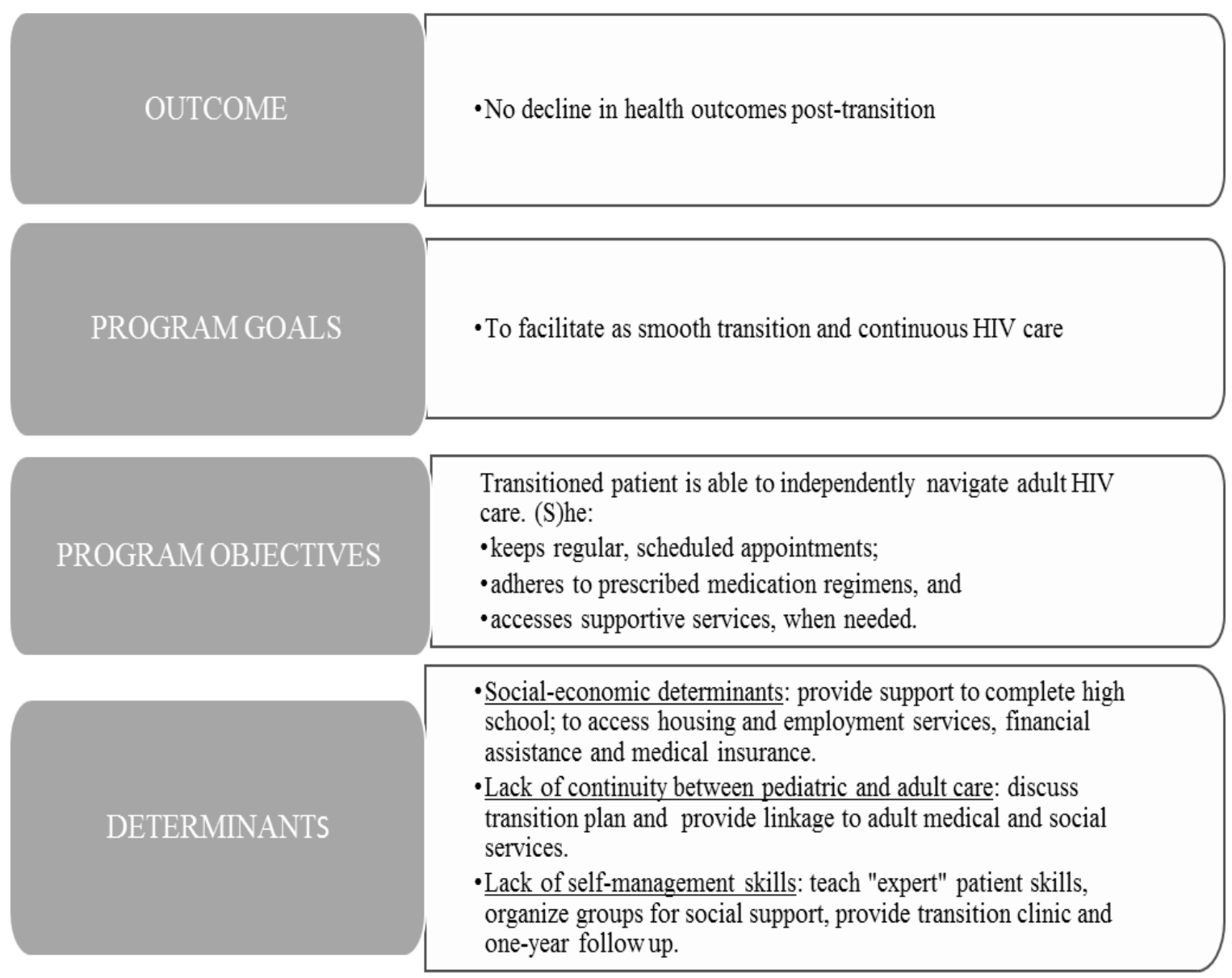

Figure 1. Conceptual model of the transition program

The causal chain from determinants to program methods and interventions was not included in a program plan, in itself a major weakness. Discussions with program planners a posteriori, and subsequent literature review to describe theoretical underpinnings, provided the following information on how the program was expected to cause changes and impact transition outcomes. Health care transition is considered to be a vocational needs of patients as they move from pediatric to adult care settings. ${ }^{29}$ 
Ad 1. Social Determinants. In theories of social production of disease (or social determinants), distribution and access to key health-promoting factors (including: education, income, a safe environment, influence and power) are regarded as more critical to attainment of health than individual knowledge, attitudes and behaviors. ${ }^{56}$ According to these theories, patients who completed high school, were employed and stably housed would have better prospects for transition. As described in Figure 1, transition program interventions included neurocognitive testing to advise educational strategies, vocational support, help to access housing and financial aid, in acknowledgement of the impact of social and economic conditions on the risk on illness, and on the actions people take to prevent or treat their illness. Examples in Box 1 illustrate postulated links between social determinants and health. These examples not only clarify possible associations between social determinants and patient's health and transition success, but also identify potential program limitations. As interventions are restricted to individual-level interventions, the social context (including the quality of education, social services and other neighborhood characteristics, as well as education, labor and social policies), which may impact patients' health is largely beyond the transition program focus and not modifiable through the program's interventions.

Ad 2: Lack of Continuity between Pediatric and Adult HIV Care. Pediatric and adult HIV care have been described as "two different worlds." 44 To support patients to overcome logistic transition barriers, pediatric staff discussed an individual transition plan with patients, provided referrals to adult HIV physicians and social service organizations, and transferred patient medical records to the referred physician. If needed, 
pediatric staff would accompany patients to their first appointment. A pediatric social worker was available to provide support to access services in the first post-transition year.

\section{Box 1. Examples of links between social determinants and health}

Education. Low education attainment was to be associated with increased mortality, especially for US African American s. ${ }^{57}$ Education is highly correlated with better economic and material conditions, greater psychosocial resources, beneficial social ties, and healthier lifestyles, which all promote physical and emotional heal th. 18.59

Employment. Effects of employment, a structural link between education and income, are well-documented in the general population, but few studies examined effects on people with HIV ${ }^{60,61}$ Employment may impact health through multiple pathrays. Besides provision of income and benefits, employment imposes a daily structure and activity, connects with a larger social network and future goals, and defines social sta tus. ${ }^{61}$ However, protective health effects of employment may only benefit those with a stable, and not temporary, employment status. ${ }^{62}$ Working in lower-level jobs with disadvantaged labor conditions (including low control over working conditions, scheduling and work pace, low employment security and high physical demands) may have harmful effects on chronic disease management, and make it difficult to maintain employment while managing a chronic disease..$^{63}$

Ad 3. Lack of Self-management Skills. The change from HIV as an acute condition rapidly progressing to mortality to a chronic condition has brought emphasis to the importance of self-management, with patients assuming an active and informed role in managing physical, psychological, and social aspects of health. ${ }^{64}$ Because pediatric providers may treat their patients protectively and expect a lower level of autonomy of their patients compared to adult providers, interventions to improve self-management of HIV disease are assumed to be essential to prepare pediatric patients for the requirements of adult HIV care. ${ }^{8,35}$ This vision corresponds with the developmental transition model that recognizes the changing needs of patients for autonomy and the lessened role of family members or guardian when patients mature. ${ }^{32}$ Mechanisms to which positive effects of selfmanagement could be attributed is most likely self-efficacy, rather than acquisition of 
knowledge or specific skills. ${ }^{65}$ Self-efficacy, or the context specific self-confidence that one can perform required behavior, is the central concept of the self-management theory and stems from the social-cognitive theory developed by Albert Bandura. ${ }^{66}$ Common elements of self-management programs include tasks in the domain of physical health (including treatment adherence and accessing appropriate treatment and services), psychological functioning (including: empowerment and reducing negative emotions), and social relationships (including: collaborative relationships with providers, social support, and disclosure) ${ }^{64}$

Self-management programs are systematically planned and goal-oriented. Although the pediatric clinic's transition program did not include a systematic plan, interventions including life skills and support groups, and the transition clinic are based on the self-management model. Thematic "life-skills" groups were held periodically to prepare patients for independence. Topics ranged from household skills to medication adherence, seeking employment, and completion of insurance paperwork. Regular support groups were offered to help patients deal with social and emotional aspects of HIV disease. The transition clinic was developed to 'bridge the gap' between pediatric and adult medical HIV care. ${ }^{67}$ In the year before they transitioned, patients were seen for routine appointments by an adult provider at the pediatric clinic (pre-transition clinic) to establish rapport and alleviate anxieties. Subsequently, patients were seen by the same adult provider at the transition clinic (post-transition clinic) located at the adult clinic site, for up to one year. A pediatric social worker provided support services during the first post-transition year. In the second year post-transition, the patient was assumed to be well-established in adult care and able to navigate services independently. The transition 
clinic and follow-up services temporarily facilitated required behavior and were sources of self-efficacy to teach patients to solve their problems, including performance mastering (overcoming obstacles through experience); modelling of expected adult provider-patient interaction, and social persuasion (including: appraisals from the pediatric social worker during follow-up). ${ }^{65}$

Interventions to enable patients to establish a relationship with their future adult provider pre-transition are based on communication theories. A trusting and respectful physician-patient relationship is considered to be critical to health management, although systemic and social barriers may interfere. ${ }^{68}$ Physician-patient communication characterized by effective exchange of information and positive affect may lead to greater patient trust (proximate outcome) and to greater adherence to treatment recommendations (intermediate outcome), which may lead to positive health outcomes. ${ }^{69}$ Patients were invited to meet the adult provider pre-transition to build a trusting relationship and alleviate their anxieties to break ties with familiar and trusted pediatric providers, but specific interventions to achieve affective and effective physician-patient communication were not developed.

\section{Study Aims and Hypotheses}

This study was conducted to answer four major questions:

1. What were the health outcomes and experiences of transitioned PHIV young adults?

2. Were clinical, socioeconomic, and psychosocial vulnerabilities pre-transition associated with adverse health outcomes post-transition?

3. Did the transition program affect transition outcomes? 
4. How can the transition program be improved?

To answer these questions, three study aims were formulated and accompanying hypotheses were tested. In this dissertation, each study aim corresponds to a chapter.

Aim 1 To assess post-transition mortality and associated clinical and sociodemographic factors, including exposure to the transition program.

1.1 $\quad \mathrm{H}_{0} \quad$ Survival does not differ by pre-transition clinical and sociodemographic patient characteristics.

$\mathrm{H}_{\text {alt }} \quad$ Poor health status (low CD4 count and/or high quantitative HIV RNA plasma levels), socioeconomic vulnerability (including: poverty, low educational attainment, unemployment, and reliance on public medical insurance), or psychosocial vulnerability (including: maternal vital status, and patient relationship status) at time of transition are associated with post-transition death.

1.2 $\mathrm{H}_{0} \quad$ There are no differences in survival by transition program exposure.

$\mathrm{H}_{\text {alt }} \quad$ Transition program exposure decreases mortality risk.

Aim 2 To assess post-transition engagement in adult HIV care and associated clinical and socio-demographic factors, including exposure to the transition program.

2.1 $\mathrm{H}_{0} \quad$ No change in engagement in HIV care post-transition.

$\mathrm{H}_{\text {alt }} \quad$ Engagement in HIV care decreases post-transition.

2.2 $\mathrm{H}_{0} \quad$ Engagement in adult HIV care is not associated with clinical, sociodemographic, or psychosocial patient characteristics.

$\mathrm{H}_{\text {alt }} \quad$ Adverse factors at time of transition, including poor health status (low CD4 count and/or high quantitative HIV RNA plasma levels), poor 
medical appointment keeping, socioeconomic vulnerability (including: poverty, low educational attainment, unemployment, and reliance on public medical insurance), or psychosocial vulnerability (including: maternal vital status and patients' relationship status) are associated with poor engagement in adult HIV care post-transition.

2.3 $\quad \mathrm{H}_{0} \quad$ Exposure to transition program activities is not associated with engagement in HIV care post-transition.

$\mathrm{H}_{\text {alt }} \quad$ Patients who were exposed to the transition program are more likely to be engaged in adult HIV care compared to unexposed patients.

Aim 3 To describe participants' satisfaction with the transition program, and assess their pre-and post-transition experiences in order to develop program recommendations and contribute to the development of effective, theory- and evidence-based transition programs.

3.1 Did participants successfully transition? Are they currently regularly engaged in adult HIV care and able to access needed services? How is their health?

3.2 How did participants experience transitioning to adult HIV care? What has helped them to transition?

3.3 What were their post-transition experiences? What were their experiences in adult HIV care? Did they have difficulties with accessing medical and social services, obtaining medical insurance or experience adherence or health-related problems?

3.4 Based on their experiences, what are their recommendations for improvement of the transition program? 


\section{REFERENCES}

1. Kapogiannis BG, Soe MM, Nesheim SR, et al. Mortality trends in the US perinatal AIDS collaborative transmission study (1986-2004). Clin Infect Dis. 2011;53(10):10241034. doi:10.1093/cid/cir641.

2. Brady MT, Oleske JM, Williams PL, et al. Declines in mortality rates and changes in causes of death in HIV-1-infected children during the HAART era. $J$ Acquir Immune Defic Syndr. 2010;53(1):86-94. doi:10.1097/qai.0b013e3181b9869f.

3. Mofenson LM, Watts DH. Safety of pediatric HIV elimination: The growing population of HIV - and antiretroviral-exposed but uninfected infants. PLoS Med. 2014;11(4):e1001636. doi:10.1371/journal.pmed.1001636.

4. Connor EM, Sperling RS, Gelber R, et al. Reduction of maternal-infant transmission of human immunodeficiency virus type 1 with zidovudine treatment. Pediatric AIDS clinical trials group protocol 076 study group. N Engl J Med. 1994;331(18):1173-1180. doi:10.1086/514228.

5. Nesheim S, Taylor A, Lampe MA, et al. A framework for elimination of perinatal transmission of HIV in the United States. Pediatrics. 2012;130(4):738-744. doi: 10.1542/peds.2012-0194.

6. Centers for Disease Control and Prevention. HIV surveillance report. Diagnoses of HIV infection in the United States and dependent areas. http://www.cdc.gov/hiv/pdf/statistics_2012_HIV_Surveillance_Report_vol_24.pdf. Updated November, 2014. Accessed April 9, 2015.

7. Hazra R, Siberry GK, Mofenson LM. Growing up with HIV: Children, adolescents, and young adults with perinatally acquired HIV infection. Annu Rev Med. 2010;61:169185. doi: 10.1146/annurev.med.050108.151127.

8. Committee on Pediatric AIDS. Transitioning HIV-infected youth into adult health care. Pediatrics. 2013;132(1):192-197. doi:10.1542/peds.2013-1073.

9. Florida Department of Health. Epidemiology of HIV among pediatric cases in Florida through 2012. http://www.floridahealth.gov/diseases-andconditions/aids/surveillance/_documents/HIV-AIDS-slide\%20sets/PEDS_2012.pdf. Updated 2013. Accessed March 2, 2016.

10. Denning P, Di Nenno E. Communities in crisis: Is there a generalized HIV epidemic in impoverished urban areas of the United States? https://npin.cdc.gov/publication/communities-crisis-there-generalized-hiv-epidemicimpoverished-urban-areas-united-states. Updated 2013. Accessed September 07, 2016. 
11. Koenig LJ, Nesheim S, Abramowitz S. Adolescents with perinatally acquired HIV: Emerging behavioral and health needs for long-term survivors. Curr Opin Obstet Gynecol. 2011;23(5):321-327. doi:10.1097/gco.0b013e32834a581b.

12. Agwu AL, Fairlie L. Antiretroviral treatment, management challenges and outcomes in perinatally HIV-infected adolescents. J Int AIDS Soc. 2013;16:18579. doi:10.7448/ias.16.1.18579.

13. Sohn AH, Hazra R. The changing epidemiology of the global paediatric HIV epidemic: Keeping track of perinatally HIV-infected adolescents. J Int AIDS Soc. 2013;16:18555. doi:10.7448/ias.16.1.18555.

14. Van Dyke RB, Patel K, Siberry GK, et al. Antiretroviral treatment of US children with perinatally acquired HIV infection: Temporal changes in therapy between 1991 and 2009 and predictors of immunologic and virologic outcomes. J Acquir Immune Defic Syndr. 2011;57(2):165-173. doi:10.1097/qai.0b013e318215c7b1.

15. Mofenson LM, Cotton MF. The challenges of success: Adolescents with perinatal HIV infection. J Int AIDS Soc. 2013;16:18650. doi:10.7448/ias.16.1.18650.

16. Van Rie A, Harrington PR, Dow A, Robertson K. Neurologic and neurodevelopmental manifestations of pediatric HIV/AIDS: A global perspective. Eur J Paediatr Neurol. 2007;11(1):1-9. doi:10.1016/j.ejpn.2006.10.006.

17. Mellins CA, Malee KM. Understanding the mental health of youth living with perinatal HIV infection: Lessons learned and current challenges. J Int AIDS Soc. 2013;16:18593. doi.org/10.7448/ias.16.1.18593.

18. Mayer KH. Introduction: Linkage, engagement, and retention in HIV care: Essential for optimal individual- and community-level outcomes in the era of highly active antiretroviral therapy. Clin Infect Dis. 2011;52 Suppl 2:S205-7. doi: 10.1093/cid/ciq043.

19. Horstmann E, Brown J, Islam F, Buck J, Agins BD. Retaining HIV-infected patients in care: Where are we? Where do we go from here? Clin Infect Dis. 2010;50(5):752-761. doi:10.1086/649933.

20. Doshi RK, Milberg J, Isenberg D, et al. High rates of retention and viral suppression in the US HIV safety net system: HIV care continuum in the Ryan White HIV/AIDS program, 2011. Clin Infect Dis. 2015;60(1):117-125. Doi:10.1093/cid/ciu722.

21. Bangsberg DR. Less than $95 \%$ adherence to nonnucleoside reverse-transcriptase inhibitor therapy can lead to viral suppression. Clin Infect Dis. 2006;43(7):939-941. doi: $10.1086 / 507526$. 
22. Lee S, Hazra R. Achieving 90-90-90 in paediatric HIV: Adolescence as the touchstone for transition success. J Int AIDS Soc. 2015;18(7 Suppl 6):20257. doi:10.7448/ias.18.7.20257.

23. Andiman WA. Transition from pediatric to adult healthcare services for young adults with chronic illnesses: The special case of human immunodeficiency virus infection. $J$ Pediatr. 2011;159(5):714-719. doi:10.1016/j.jpeds.2011.06.040.

24. Dowshen N, D'Angelo L. Health care transition for youth living with HIV/AIDS. Pediatrics. 2011;128(4):762-771. doi:10.1542/peds.2011-0068.

25. Fair CD, Sullivan K, Gatto A. Best practices in transitioning youth with HIV: Perspectives of pediatric and adult infectious disease care providers. Psychol Health Med. 2010;15(5):515-527. doi:10.1080/13548506.2010.493944.

26. Tsuyuki K, Surratt HL, Levi-Minzi MA, O'Grady CL, Kurtz SP. The demand for antiretroviral drugs in the illicit marketplace: Implications for HIV disease management among vulnerable populations. AIDS Behav. 2014. doi:10.1007/s10461-014-0856-2.

27. Lotstein DS, Kuo AA, Strickland B, Tait F. The transition to adult health care for youth with special health care needs: Do racial and ethnic disparities exist? Pediatrics. 2010;126 Suppl 3:S129-36. doi:10.1542/peds.2010-1466f.

28. Panel on Antiretroviral Guidelines for Adults and Adolescents. Department of Health and Human Services. Guidelines for the use of antiretroviral agents in HIV-1-infected adults and adolescents. http://aidsinfo.nih.gov/guidelines. Updated May 1, 2014. Accessed August 26, 2014.

29. Rosen DS, Blum RW, Britto M, Sawyer SM, Siegel DM, Society for Adolescent Medicine. Transition to adult health care for adolescents and young adults with chronic conditions: Position paper of the Society for Adolescent Medicine. J Adolesc Health. 2003;33(4):309-311. doi:10.1016/s1054-139x(03)00208-8.

30. Betz CL, Lobo ML, Nehring WM, Bui K. Voices not heard: A systematic review of adolescents' and emerging adults' perspectives of health care transition. Nurs Outlook. 2013;61(5):311-336. doi:10.1016/j.outlook.2013.01.008.

31. Margrab P, Millar HEC. Surgeon general's conference. Growing up and getting medical care: Youth with special health care needs. A summary of conference proceedings. March 13-15, 1989. https://profiles.nlm.nih.gov/ps/access/NNbczs.pdf. Accessed April 15, 2015. 
32. Wiener LS, Zobel M, Battles H, Ryder C. Transition from a pediatric HIV intramural clinical research program to adolescent and adult community-based care services: Assessing transition readiness. Soc Work Health Care. 2007;46(1):1-19. doi:10.1300/j010v46n01_01.

33. Hussen SA, Chahroudi A, Boylan A, Camacho-Gonzalez AF, Hackett S, Chakraborty R. Transition of youth living with HIV from pediatric to adult-oriented healthcare: A review of the literature. Future Virol. 2015;9(10):921-929. doi:10.2217/fvl.14.73.

34. Persson A, Newman C. When HIV-positive children grow up: A critical analysis of the transition literature in developed countries. Qual Health Res. 2012;22(5):656-667. doi:10.1177/1049732311431445.

35. Sharma N, Willen E, Garcia A, Sharma TS. Attitudes toward transitioning in youth with perinatally acquired HIV and their family caregivers. $J$ Assoc Nurses AIDS Care. 2014;25(2):168-175. doi:10.1016/j.jana.2013.01.007.

36. Fair CD, Sullivan K, Dizney R, Stackpole A. "It's like losing a part of my family": Transition expectations of adolescents living with perinatally acquired HIV and their guardians. AIDS Patient Care STDS. 2012;26(7):423-429. doi:10.1089/apc.2012.0041.

37. Gilliam PP, Ellen JM, Leonard L, Kinsman S, Jevitt CM, Straub DM. Transition of adolescents with HIV to adult care: Characteristics and current practices of the adolescent trials network for HIV/AIDS interventions. J Assoc Nurses AIDS Care. 2011;22(4):283294. doi:10.1016/j.jana.2010.04.003.

38. Wiener LS, Kohrt BA, Battles HB, Pao M. The HIV experience: Youth identified barriers for transitioning from pediatric to adult care. J Pediatr Psychol. 2011;36(2):141154. doi:10.1093/jpepsy/jsp129.

39. Wilcox RD. Transitioning adolescents to adult care can be challenging. HIV Clin. 2012;24(2):22-23.

40. Vijayan T, Benin AL, Wagner K, Romano S, Andiman WA. We never thought this would happen: Transitioning care of adolescents with perinatally acquired HIV infection from pediatrics to internal medicine. AIDS Care. 2009;21(10):1222-1229. doi:1080/09540120902730054.

41. Fegran L, Hall EOC, Uhrenfeldt L, Aagaard H, Ludvigsen MS. Adolescents' and young adults' transition experiences when transferring from paediatric to adult care: A qualitative metasynthesis. Int J Nurs Stud. 2014;51(1):123-135.

doi:10.1016/j.ijnurstu.2013.02.001. 
42. Bloom SR, Kuhlthau K, Van Cleave J, Knapp AA, Newacheck P, Perrin JM. Health care transition for youth with special health care needs. J Adolesc Health.

2012;51(3):213-219. doi: 10.1016/j.jadohealth.2012.01.007.

43. Ryscavage P, Macharia T, Patel D, Palmeiro R, Tepper V. Linkage to and retention in care following healthcare transition from pediatric to adult HIV care. AIDS Care. 2016;28(5):561-565. doi:10.1080/09540121.2015.1131967.

44. Newman C, Persson A, Miller A, Cama E. Bridging worlds, breaking rules: Clinician perspectives on transitioning young people with perinatally acquired HIV into adult care in a low prevalence setting. AIDS Patient Care STDS. 2014. doi:10.1089/apc.2013.0346.

45. Fish R, Judd A, Jungmann E, O'Leary C, Foster C, HIV Young Persons Network (HYPNet). Mortality in perinatally HIV-infected young people in England following transition to adult care: An HIV young persons network (HYPNet) audit. HIV Med. 2014;15(4):239-244. doi:10.1111/hiv.12091.

46. Agwu AL, Siberry GK, Ellen J, et al. Predictors of highly active antiretroviral therapy utilization for behaviorally HIV-1-infected youth: Impact of adult versus pediatric clinical care site. J Adolesc Health. 2012;50(5):471-477.

doi:10.1016/j.jadohealth.2011.09.001.

47. de Mulder M, Yebra G, Navas A, et al. High drug resistance prevalence among vertically HIV-infected patients transferred from pediatric care to adult units in Spain. PLoS One. 2012;7(12):10/1/2014-e52155. doi:10.1371/journal.pone.0052155.

48. Ryscavage P, Anderson EJ, Sutton SH, Reddy S, Taiwo B. Clinical outcomes of adolescents and young adults in adult HIV care. J Acquir Immune Defic Syndr. 2011;58(2):193-197. doi:10.1097/qai.0b013e31822d7564.

49. Agwu AL, Lee L, Fleishman JA, et al. Aging and loss to follow-up among youth living with human immunodeficiency virus in the HIV research network. J Adolesc Health. 2015;56(3):345-351. doi:10.1016/j.jadohealth.2014.11.009.

50. Maturo D, Powell A, Major-Wilson H, Sanchez K, De Santis JP, Friedman LB. Transitioning adolescents and young adults with HIV infection to adult care: Pilot testing the "Movin' Out" transitioning protocol. J Pediatr Nurs. 2015;30(5):e29-35. doi:10.1016/j.pedn.2015.06.013.

51. Davis A, M., Brown R, F., Lounds Taylor J, Epstein R, A., McPheeters M, L. Transition care for children with special health care needs. Pediatrics. 2014;134(5):900908. doi:10.1542/peds.2014-1909d. 
52. Crowley R, Wolfe I, Lock K, McKee M. Improving the transition between paediatric and adult healthcare: A systematic review. Arch Dis Child. 2011;96(6):548-553.

doi:10.1136/adc.2010.202473.

53. Gortmaker SL, Hughes M, Cervia J, et al. Effect of combination therapy including protease inhibitors on mortality among children and adolescents infected with HIV-1. $N$ Engl J Med. 2001;345(21):1522-1528. doi:10.1056/nejmoa011157.

54. Florida Department of Health. Factsheet HIV disease: United States vs. Florida. Florida Department of Health AIDS surveillance web site. http://www.floridahealth.gov/diseases-and-conditions/aids/surveillance/_documents/factsheet/2014/2014-us-vs-fl-fact-sheet1.pdf. Accessed April 15, 2016.

55. Florida Department of Health. Pediatric HIV in Florida. Florida Department of Health Surveillance Web site. http://www.floridahealth.gov/diseases-andconditions/aids/surveillance/_documents/fact-sheet/2013-pediatric.pdf. Updated 2014. Accessed October 10, 2015.

56. Marmot M, Commission on Social Determinants of Health. Achieving health equity: From root causes to fair outcomes. Lancet. 2007;370(9593):1153-1163. doi:10.1016/s0140-6736(07)61385-3.

57. Montez J, Hummer R, Hayward M. Educational attainment and adult mortality in the United States: A systematic analysis of functional form. Demography. 2012;49(1):315. doi:10.1007/s13524-011-0082-8.

58. Montez JK. Cumulative childhood adversity, educational attainment, and active life expectancy among U.S. adults. Demography. 2014;51(2):413; 413-435; 435. doi:10.1007/s13524-013-0261-x.

59. Ruglis J, Freudenberg N. Toward a healthy high schools movement: Strategies for mobilizing public health for educational reform. Am J Public Health. 2010;100(9):15651571. doi:10.2105/ajph.2009.186619.

60. Rueda S, Raboud J, Rourke, SB, et al. Influence of employment and job security on physical and mental health in adults living with HIV: Cross-sectional analysis. Open Medicine. 2012;6(4):November 25, 2014-e118-e126.

61. Rueda S, Raboud J, Mustard C, Bayoumi A, Lavis JN, Rourke SB. Employment status is associated with both physical and mental health quality of life in people living with HIV. AIDS Care. 2011;23(4):435-443. doi:10.1080/09540121.2010.507952. 
62. Dray-Spira R, Gueguen A, Persoz A, et al. Temporary employment, absence of stable partnership, and risk of hospitalization or death during the course of HIV infection. $J$ Acquir Immune Defic Syndr. 2005;40(2):190-197. doi:10.1097/01.qai.0000165908.12333.4e.

63. Dray-Spira R, Gueguen A, Ravaud JF, Lert F. Socioeconomic differences in the impact of HIV infection on workforce participation in France in the era of highly active antiretroviral therapy. Am J Public Health. 2007;97(3):552-558.

doi:10.2105/ajph.2005.081083.

64. Swendeman D, Ingram BL, Rotheram-Borus MJ. Common elements in selfmanagement of HIV and other chronic illnesses: An integrative framework. AIDS Care. 2009;21(10):1321-1334. doi:10.1080/09540120902803158.

65. Taylor D, Bury M. Chronic illness, expert patients and care transition. Sociol Health Illn. 2007;29(1):27-45. doi:10.1111/j.1467-9566.2007.00516.x.

66. Bandura A. Self-efficacy: Toward a unifying theory of behaviorial change. Psychological Review. 2007;84(2):191-215. doi:10.1037/0033-295x.84.2.191.

67. Maturo D, Powell A, Major-Wilson H, Sanchez K, De Santis JP, Friedman LB. Development of a protocol for transitioning adolescents with HIV infection to adult care. J Pediatr Health Care. 2011;25(1):16-23. doi:10.1016/j.pedhc.2009.12.005.

68. IOM (Institute of Medicine). Transforming health care scheduling and access: Getting to now. https://www.nap.edu/download.php?record_id=20220. Updated 2015. Accessed August 31, 2015.

69. Street RL, Epstein R, A. Key interpersonal functions and health outcomes. Lessons from theory and research on clinician-patient communication. In: Glantz K, Rimer BK, Viswanath K, eds. Health Behavior and Health Education: Theory, Research, and Practice. 4th ed. San Francisco, CA: Jossey-Bass; 2008:237-269. 


\section{CHAPTER II \\ STUDY DESIGN AND METHODOLOGY}

\section{Applied Research}

This research was conducted on request of the staff of a pediatric clinic to provide follow up information on their transitioned patients to inform future program activities (Attachment 1). Pediatric clinic staff was involved in all study phases. Participation is not only a fundamental characteristic of health promotion, but also allows the inclusion of views of informed stakeholders; increases understanding and acceptance of the findings, and promotes commitment to act on study findings. ${ }^{1}$

\section{Study Design}

A single-center, retrospective cohort study was conducted to assess the health outcomes mortality (Aim 1) and engagement in HIV care (Aim 2), and associated sociodemographic and clinical factors, including exposure to transition program activities. Information was obtained from participants' medical and social records. To assist in the interpretation of these quantitative findings and formulation of transition program recommendations, transition experiences and experiences in adult HIV care were explored in a mixed-methods explanatory concurrent research design. ${ }^{2}$ Quantitative and qualitative data were obtained from a computer-assisted survey and short debriefing interview (Aim 3).

\section{Study Population and Procedures}

Study approval was obtained from the Institutional Review Boards of Florida International University (IRB-14-0298, most recently on October 19, 2015), and University of Miami (IRB- 20120433, closure on March 30, 2015) [Attachments 2-3]. 
Patients were eligible for study participation if they had transitioned from the Infectious Diseases \& Immunology pediatric clinic, University of Miami, to adult medical HIV care settings between January 2003 and September 2012. Living patients were excluded from study participation if they were unable to provide valid informed consent in person because of severe cognitive disability (as determined by staff psychologists during routine testing while in pediatric HIV care), incarceration, or relocation. Patients received care at the pediatric clinic up to age 25; all transitioned patients eligible for study participation were adults.

Patients who had died post-transition were included. Different recruitment methods were used to enroll living eligible patients, because transition experiences and outcomes of patients who successfully transitioned may differ from those who did not. ${ }^{3}$ Many patients had stayed in contact with the pediatric clinic or with their peers after they transitioned. They were contacted in person or by phone by the pediatric program coordinator to introduce the study. The study lead author followed up to provide additional study information to patients who were interested to participate and set up an appointment. If up-to-date contact information was unavailable, we asked study participants to inform their peers about the study. In addition, pediatric clinic staff was asked to tell former patients about the study, if they contacted the clinic or stopped by. Per protocol, eligible participants were marked as "refused" if they did not respond to three attempts to contact them, or if they did respond and declined participation. "Loss to follow-up" was assigned when current contact information could not be obtained.

Patients willing to participate provided written informed consent (Attachment 4), and signed HIPAA (Authorization to Use and Disclose Health Information) and 
Authorization of Health Information for $3^{\text {rd }}$ Party Disclosures forms at the pediatric clinic site. To further protect the privacy of research participants, a confidentiality certificate from the Department of Health \& Human Services was requested and received (Attachment 5). To enable the patient to make a voluntary and informed decision, consent was obtained by a researcher who had not been involved in previous care. The consent form was written in as simple terms as possible, and all patients were able to read and understand English (per information of the pediatric clinic Ryan White Part D coordinator). Even so, the researcher read and discussed the consent form with participants to ensure comprehension.

Study recruitment began in September 2013 and was completed in February 2014. Review of medical and social records was completed on April 30, 2014. Study participants received $\$ 20$ in cash and reimbursement or validation for parking and travel costs. Participants were offered support from pediatric staff to access adult medical or social services, if needed and desired.

\section{Data Collection}

Data to examine post-transition mortality (Aim 1) and engagement in HIV care (Aim 2) and associated factors were abstracted from participant's medical and social records. Data were recorded on a standardized, de-identified, chart abstraction form (Attachment 6). To asses if measures were clear and unambiguous and to be collected information was available in existing data sources, the data collection instrument was pre-tested using medical records of two deceased patients. Information was abstracted from medical and social paper records (before 2010) and electronic records (UChart for medical and CAREWare for sociodemographic information) thereafter. Specified post- 
transition clinical information of participants who transitioned outside of the University Medical Center was requested by fax, accompanied by signed HIPAA (Authorization to Use and Disclose Health Information) and Authorization of Health Information for $3^{\text {rd }}$ Party Disclosures forms.

Data to assess participants' (post)-transition experiences (Aim 3) were collected with a computer-assisted survey (Qualtrics), administered at the pediatric clinic. The survey was followed by a de-briefing to allow participants to clarify or elaborate on their answers. To improve quality, the survey instrument was pre-tested among six clinic patients with PHIV who had transitioned less than one year ago, and, therefore, were not eligible for study participation. Pre-test was conducted to examine if: (1) questions were clear and understood as intended (validity), (2) participant burden was acceptable, and (3) participants' were at ease with the mode of survey administration. In general, participants felt the survey was easy to understand and complete, asked the right questions, and was not too long. A review of pre-test data showed participants needed on average 24 minutes to complete the survey; all participants completed all questions, and no inconsistent answers were observed. Nevertheless, in de-briefing to retrieve participants' reasoning processes using cognitive probes (e.g. "In your own words, what do you think we wanted to know", and "How did you decide to choose this answer"), it became apparent that some questions needed to be revised. ${ }^{4}$ In addition, while the initial survey had few open-ended questions to minimize participant burden, pre-test participants requested to add more open-ended questions, to - as one participant worded"Have our voices heard." The revised questionnaire was administered to participants. 


\section{Measures}

Measures to test study hypotheses of Aim 1 (Mortality) and Aim 2 (Engagement in HIV care) are presented in Figure 2. Outcome variables differ; co-variates are the same.

Subsequently, quantitative and qualitative measures to assess transition experiences and program recommendations (Aim 3) will be described.

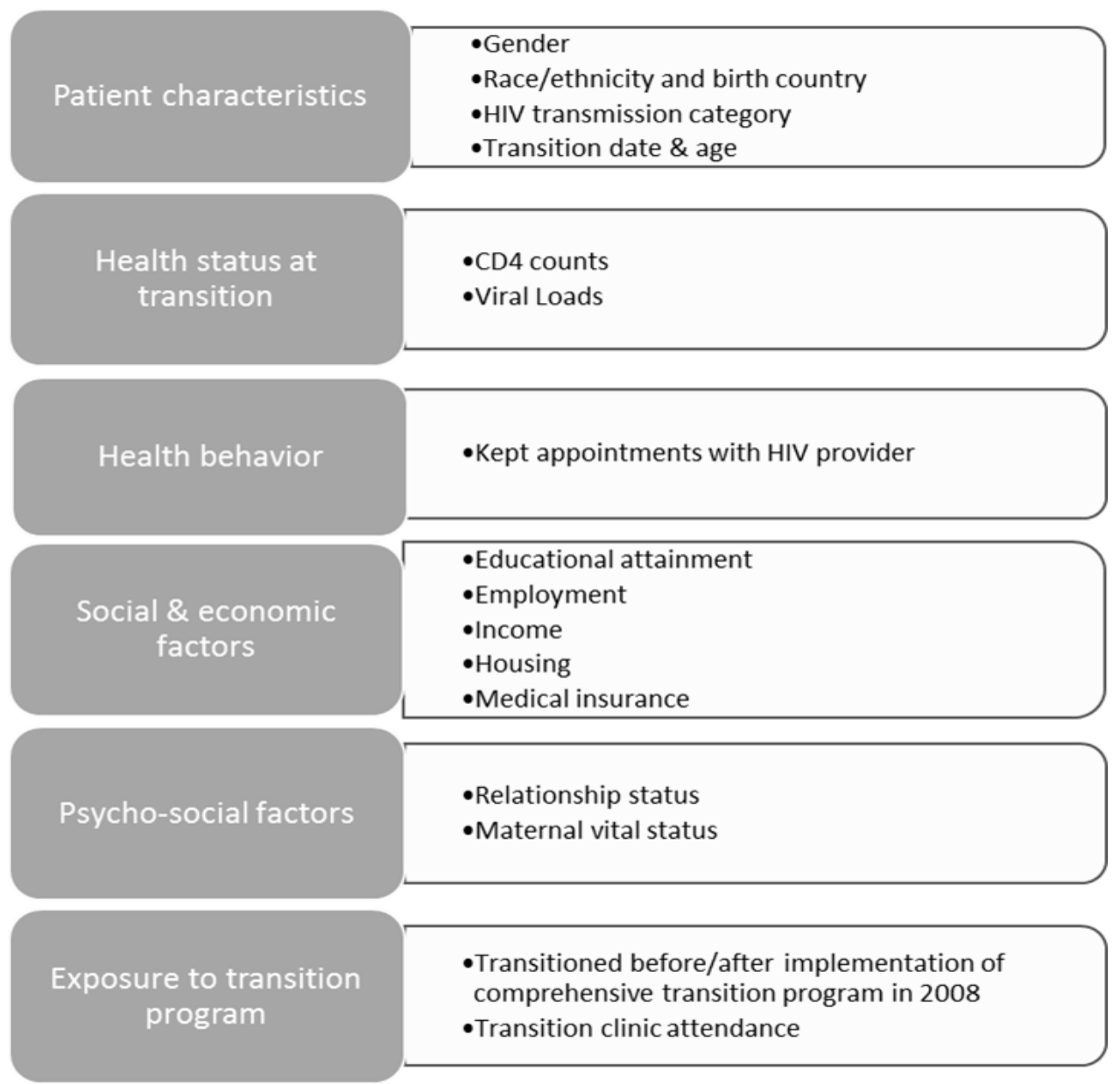

Figure 2. Co-variates study aims 1 (assess post-transition mortality) \& 2 (engagement in HIV care)

Outcome Variables Study Aims $1 \& 2$

Aim 1: To assess post-transition mortality. Primary outcome: death after transition.

Patient status was marked on a transition log, which was kept and updated by pediatric 
staff. Participant status was marked as deceased if patients had died before April 30, 2014, when data collection was completed.

Aim 2: To assess engagement in pediatric and adult HIV care. Primary outcome: engagement in HIV care, defined as kept appointments with an HIV provider. Engagement in HIV primary care is increasingly recognized as a crucial step in maximizing patient outcomes. ${ }^{5}$ Participants' last medical visit at the pediatric clinic was recorded as the transition date. For patients who had dropped out of pediatric care, the administrative transition date was their $24^{\text {th }}$ birthday. For all participants, the number and dates $(\mathrm{m} / \mathrm{y})$ of kept visits were abstracted for at least two observation periods: 12 months before the patient's transition date, and 12 months post-transition. Depending on patient status and transition duration, we also captured the number of medical visits in the second year post-transition.

A recent study comparing six different retention measures concluded that there is no clear "gold standard" and advised to use multiple retention measurements. ${ }^{6} \mathrm{We}$ measured engagement in HIV care as: (1) the number of kept visits during a 12-month observation period, and (2) visit constancy: proportions of participants attending at least one primary care visit at 3-month [quarterly] intervals in a 12-month [four quarters] observation period. We measured visit constancy, because retaining HIV-infected patients in care at regular intervals results in better health outcomes. ${ }^{7}$ The 3 -month interval is based on pediatric clinic practices where patients were scheduled to see their HIV provider quarterly for a routine appointment, consistent with national recommendations. 


\section{$\underline{\text { Co-variates }}$}

Patient characteristics. Information regarding patient characteristics, including patient gender, race ethnicity, transmission category, transition date, and transition age was abstracted from participants' pediatric medical and social records. Racial, ethnic (Black or African American, White, non-Hispanic or Hispanic) and birth country data (US born or not) were collected because disparities were documented in risk of mortality in HIV-infected persons in Florida ${ }^{8,9}$ and engagement in HIV care. ${ }^{10}$ Participants' gender was recorded because of reported gender disparities in health care utilization and medication adherence. ${ }^{10,11}$ Standardized information about patients' mental health status, substance abuse, and medication adherence was not available. Patient records did include physician's observations regarding these factors for some patients, which were reported for deceased patients only.

Primary care history included markers of progression of HIV disease (CD4+ Tlymphocyte [CD4] count and quantitative HIV RNA plasma levels [“viral loads"]). For all participants, CD4 count and viral load were abstracted for 2 periods: pre-transition (most recent test results when participants transitioned and left pediatric care), and oneyear post transition. For participants who had transitioned two years or more ago, we also abstracted two-year post transition information, as well as their most current information e.g. most recent available test results). Frequency of hospital admissions in the year before participants' transition date were also recorded.

Social and economic factors. Social and economic factors included educational attainment, household income, housing, employment status, and type of health insurance. The most recent information at participant's transition date was recorded. Educational 
attainment measured the highest level of education completed at time of transition, and included the following categories: did not complete high school; high school or equivalent; vocational/tech program after high school; college or university (some) or unknown. The equivalent of obtaining a high school diploma was successfully passing the General Education Development (GED) test; a terminal degree for those with interrupted academic trajectories because of health or other problems. ${ }^{12}$ Employment at transition assessed whether participants were (un)employed and/or enrolled in school; more detailed information regarding type of employment, job security, if participants worked full or part-time and other work-related characteristics that may impact health were unavailable. Household income was abstracted using the following categories: equal or below federal poverty level (FPL); 101-200\% of FPL; 201-300\% of FPL; 301$400 \%$ of FPL; $\geq 401$ of FPL, and unknown. Participants with a recorded household income equal to or below the federal poverty level $(\$ 23,850$ for a four-person US household in 2014) were considered to live in poverty. ${ }^{13}$ Housing - in the last 12 months pre-transition, most of the time- was measured using six categories, including homeless (in the street, outdoors or shelter), moved around, lived in own or shared placed, with (extended family), other (please explain), and unknown. Finally, enrollment in health insurance (yes/no) when participants transitioned to adult HIV care was assessed in different categories, measuring whether participants had obtained private or public (Medicaid or Medicare) medical insurance or relied on Ryan White funding to cover their healthcare costs.

Psychosocial factors. Psycho-social factors which may impact participants' health status included participant relationship status at time of transition (including: married, in 
relationship, but not married, single or unknown) and maternal vital status. Information was obtained from the Ryan White Part D coordinator.

Exposure to the comprehensive transition program. To measure exposure to transition program activities, the following information was abstracted: (1) participants' transition date before 2008 or thereafter, when the comprehensive transition program was funded and implemented, and (2) attendance of the transition clinic (including: preand/or post-transition clinic). Information about exposure of individual participants to specific components of the transition program was incomplete. Therefore, with exception of transition clinic attendance, the potential value of single program components could not be assessed.

Transition Experiences and Program Recommendations (Aim 3)

Social-demographic and clinical measures. Social-demographic information, including age, gender, race/ethnicity, educational level, household income below or above poverty level [ $\$ 24,250$ for a four-person household in 2015$],{ }^{14}$ and transition date were abstracted from participant's pediatric records. To assess current circumstances, we asked participants to answer questions about housing, family, and (any) employment status, as well as gaps in medical insurance in the past 12 months. A measure of food insecurity, "In the past year, were you ever worried whether food would run out before you got money to buy more?" was used as a proxy measurement of current poverty. ${ }^{15}$ Data to describe engagement in adult HIV care were abstracted from the patient adult medical records. Based on current HIV/AIDS performance measures, the expectation for medical HIV care was at least one medical visit in a 6-month period in the past 12 months. ${ }^{16}$ 
Participant experiences and program recommendations. This study incorporated questions of a semi-structured transition telephone survey by Wiener and colleagues, developed to describe transition barriers, as identified in earlier studies. ${ }^{17}$ Because this study administered a computer-assisted survey to collect study data, we were able to ask additional, more detailed (close- and open ended) questions. Figure 3 presents the questions to assess participant's exposure to and satisfaction with the transition program, their experiences with transitioning and post-transition experiences, and their suggestions for improvement of the transition program. After survey completion, the lead researcher invited participants to clarify or elaborate on their survey answers in a short de-briefing interview. Participant quotes were written down verbatim; observational notes were completed directly after the interview.

\section{Statistical Analysis}

Analysis of quantitative data was performed using Epi Info 3.5.4 (Atlanta, GA, 2012). Univariate statistics (means, standard deviation [SD], medians, interquartile range [IQR], and mode) were used to describe characteristics of the study population. Continuous data (e.g. CD4+ T-lymphocyte [CD4] count and quantitative HIV RNA plasma levels ["viral loads"]) were analyzed using the Kruskal-Wallis test for two groups (alpha $=0.05$ ), which has no assumption of normal data distribution. Outcome variables (e.g. mortality [Aim 1] and engagement in HIV care [Aim2]) and covariates were dichotomized for inferential statistical analysis. The Fisher exact two-tail test (alpha $=0.05$ ) was used to assess whether differences in categorical variables were statistically significant. Risk ratios (RRs), as measures of relative risk, were calculated to assess the strength of associations between potential predictors and primary outcome 
variables; 95\% confidence intervals (CIs) were calculated to assess precision of RRs.

Stratified analyses were conducted to control for confounding and assess effect

modification, using Mantel-Haenszel (MH) RRs and 95\% CIs and Fisher exact tests to

compare differences across strata for statistical significance.

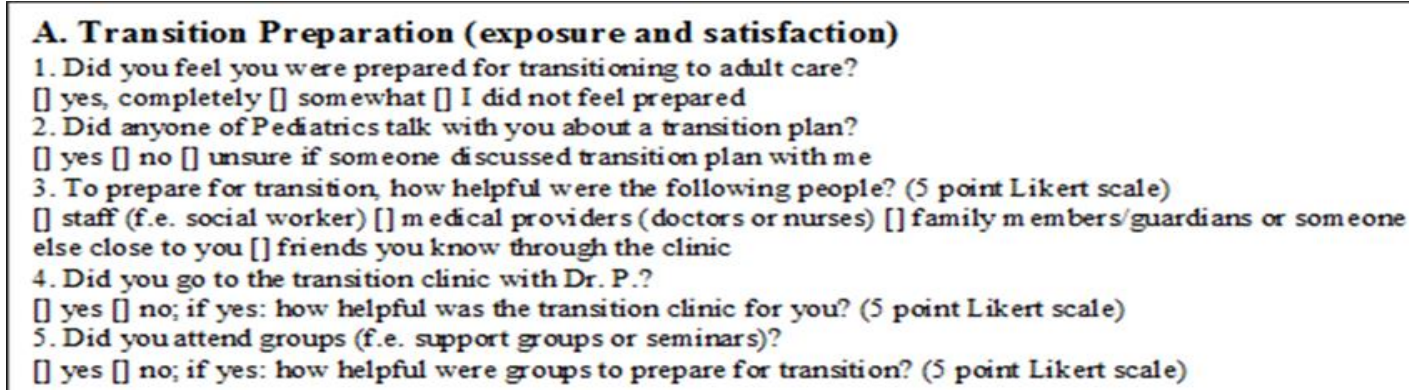

B. Transition experiences: "How was transitioning for you?"

1. How easy or hard was it for you to transition away from Pediatrics?

[] very difficult [] difficult [ ] neutral [] easy [] very easy. Could you tell us why?

2. Was transition to adult care; [] as expected [] better than ex pected [] more difficult than expected

\section{Post-transition experiences}

1. Since you transitioned, have you had (5 point Likert scale; definitely yes -definitely not)

[] more difficulties to take your meds as prescribed [ $]$ more medical needs or complications [] problems to find a HIV provider [] problem s to find services to support you [] problems with m edical insurance [] I had other/more problems than these. Follow-up question: What other problems did you have after transition? Could you please describe them?

2. How easy or difficult was it for you to do well in adult HIV care after you transitioned? Would you say it was: [] very difficult [] difficult [] neutral [] easy [] very easy

3. What is most important to you in your HIV care?

4. After you transitioned, did you ever get help from someone of Pediatrics?

[] yes [ No, but I could have used help [] No, and I did not need them to help me

What did you need help with after you transitioned?

5. In the past 12 months did you see ([] yes [] no, but I would like to [ ] no, because I do not need to)

[] Ryan White case m anager [] a nutritionist [] a dentist [] a GYN [] someone to talk to when you are sad or anx ious [] someone to help you with financial problems [] someone to help you with housing [] someone to help you to get a job or schooling [] someone to help with problems with your kids.

D. What are your suggestions for improvem ent of the transition program?

1. What could make the transition program better and help others who still have to transition to do well in adult care? These are my best ideas for improving the transition program:

Figure 3. Survey questions to assess transition experiences and suggestions for transition program improvements

Qualitative information (Aim 3) included participant's responses to open-ended

questions of the computer-assisted survey and participant's verbatim quotes from a short

de-briefing interview. This information was systematically analyzed using the thematic

analysis method. ${ }^{18}$ Thematic analysis is an iterative process followed to remain true to 
participant's description while developing more abstract concepts in various stages of data analysis. Analysis was conducted manually, and included the following steps: familiarization with data and repeatedly reading texts, generating initial codes, grouping codes in different themes, and refinement and consideration of the meaning within and across themes. In the final, exploratory phase, the analysis was discussed with a third researcher to explore associations between core concepts and themes, established literature, and theoretical perspectives related to transition experiences of PHIV young adults. To minimize pre-conceived notions and potentially expand (alternative) explanations, we conducted multiple coding by two different researchers. Both researchers had HIV-related research experience, but not with PHIV adolescents or young adults. To further minimize the risk of researcher bias and furnish alternate interpretations, a third researcher, who had former clinical and research experience with PHIV adolescents and young adults but had not been involved in the study design or data collection, reviewed the analytic framework and data interpretation.

\section{REFERENCES}

1. Rootman I, Goodstadt M, Potvin L, Springett J. A framework for health promotion evaluation. In: Rootman I, Goodstadt M, Hyndman B, et al, eds. Evaluation in health promotion. Principles and perspectives. WHO Regional Publications. European Series; No.92; 2001:7-41.

http://www.euro.who.int/_data/assets/pdf_file/0007/108934/E73455.pdf. Accessed March 11, 2016.

2. Curry LA, Nembhard IM, Bradley EH. Qualitative and mixed methods provide unique contributions to outcomes research. Circulation. 2009;119(10):1442-1452.

doi:10.1161/circulationaha.107.742775.

3. Valenzuela JM, Buchanan CL, Radcliffe J, et al. Transition to adult services among behaviorally infected adolescents with HIV--a qualitative study. J Pediatr Psychol. 2011;36(2):134-140. doi:10.1093/jpepsy/jsp051. 
4. Collins D. Pretesting survey instruments: An overview of cognitive methods. Qual Life Res. 2003;12(3):229-238.

5. Mugavero MJ, Davila JA, Nevin CR, Giordano TP. From access to engagement: Measuring retention in outpatient HIV clinical care. AIDS Patient Care STDS. 2010;24(10):607-613.doi:10.1089/apc.2010.0086.

6. Mugavero MJ, Westfall AO, Zinski A, et al. Measuring retention in HIV care: The elusive gold standard. J Acquir Immune Defic Syndr. 2012;61(5):574-580. doi:10.1097/qai.0b013e318273762f.

7. Horstmann E, Brown J, Islam F, Buck J, Agins BD. Retaining HIV-infected patients in care: Where are we? Where do we go from here? Clin Infect Dis. 2010;50(5):752-761. doi:10.1086/649933

8. Trepka MJ, Niyonsenga T, Fennie KP, McKelvey K, Lieb S, Maddox LM. Sex and racial/ethnic differences in premature mortality due to HIV: Florida, 2000-2009. Public Health Rep. 2015;130(5):505-513.

9. Sheehan DM, Trepka MJ, Fennie KP, Dillon FR, Madhivanan P, Maddox LM. Neighborhood Latino ethnic density and mortality among HIV-positive Latinos by birth country/region, Florida, 2005-2008. Ethn Health. 2015:1-16. doi:10.1080/13557858.2015.1061104.

10. Doshi RK, Milberg J, Isenberg D, et al. High rates of retention and viral suppression in the US HIV safety net system: HIV care continuum in the Ryan White HIV/AIDS program, 2011. Clin Infect Dis. 2015;60(1):117-125. doi:10.1093/cid/ciu722.

11. Bell DL, Breland DJ, Ott MA. Adolescent and young adult male health: A review. Pediatrics. 2013;132(3):535-546. doi:10.1542/peds.2012-3414.

12. Montez J, Hummer R, Hayward M. Educational attainment and adult mortality in the United States: A systematic analysis of functional form. Demography. 2012;49(1):315. doi:10.1007/s13524-011-0082-8.

13. U.S. Department of Health \& Human Services. Office of the Assistant Secretary for Planning and Evaluation. 2014 poverty guidelines. http://aspe.hhs.gov/poverty/14povertycfm. Updated 2014. Accessed October 25, 2014.

14. U.S Department of Health \& Human Services. Office of the Assistant Secretary for Planning and Evaluation. Prior HHS poverty guidelines and federal register references. http://aspe.hhs.gov/prior-hhs-poverty-guidelines-and-federal-register-references. Updated 2015. Accessed November 9, 2015. 
15. Economic Research Service U. U.S. household food security survey module: Threestage design with screeners. http://www.ers.usda.gov/topics/food-nutritionassistance/food-security-in-the-us/measurement.aspx. Updated 2012. Accessed November 28, 2012.

16. US Department of Health and Human Services. Health Resources and Services Administration. HIV/AIDS bureau performance measures.

http://hab.hrsa.gov/deliverhivaidscare/coremeasures.pdf. Updated 2013. Accessed November 12, 2014.

17. Wiener LS, Kohrt BA, Battles HB, Pao M. The HIV experience: Youth identified barriers for transitioning from pediatric to adult care. J Pediatr Psychol. 2011;36(2):141154. doi:10.1093/jpepsy/jsp129.

18. Braun V, Clarke V. Using thematic analysis in psychology. Qualitative Research in Psychology. 2006;3(2):77-101. doi:10.1191/1478088706qp063oa. 


\section{CHAPTER III. FIRST MANUSCRIPT}

\section{Factors associated with death in perinatally HIV-infected adults after transition to}

\section{adult care in Miami, Florida.}

Susan Biersteker, PhDc, ${ }^{a}$ Consuelo M. Beck-Sagué, MD, FAAP, ${ }^{a}$ Barbara J. Messick, ${ }^{b}$ MPH, Ana Garcia, PhD, LCSW,

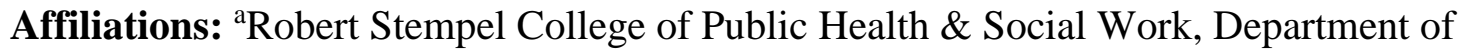
Health Promotion and Disease Prevention, Florida International University, Miami, Fl.;

${ }^{b}$ University of Miami Miller School of Medicine, Department of Obstetrics and Gynecology, Division of Research and Special Projects, Miami, Fl.; ' University of Miami Miller School of Medicine Department of Pediatrics, Division of Infectious Diseases \& Immunology, Miami, Fl.

Address correspondence to: Susan Biersteker, Robert Stempel College of Public Health \& Social Work, Department of Health Prevention and Disease Prevention, Florida International University, 11200 SW 8th Street, AHC5 505, Miami, Fl. 33199, sbier002@fiu.edu,305-494-8415.

Short title: Death in Perinatally HIV-infected Transitioned Adults.

Abbreviations: cART- Combination Antiretroviral Therapy; GED - General Educational Development Test; PHIV - Perinatally HIV-infected

Key Words: perinatally HIV-infected, young adults, mortality, transition

Financial Disclosure: The authors have no financial relationships relevant to this article to disclose.

Conflict of Interest: The authors have no conflicts of interest to disclose. 


\title{
What's Known on This Subject
}

Transition from pediatric to adult care of perinatally HIV-infected young adults may impact health, but post-transition mortality and associated factors have not been assessed in North America.

\section{What This Study Adds}

When stratified by other factors, severe immunodeficiency, high school non-completion and unemployment at time of transition were independently associated with mortality; transition clinic attendance did not affect mortality.

\begin{abstract}
Objective: To describe mortality in perinatally HIV-infected young adults after transition to adult care and identify associated factors.

Methods: Patients who had transitioned from a pediatric outpatient clinic to adult HIV care between January 2003 and September 2012 were recruited for a retrospective cohort study, completed on April 30, 2014. The main study outcome was post-transition death. The most recent clinical and social-demographic data before transition were abstracted from medical and social records.

Results: Of 51 transitioned patients, nine (18\%) had died, all of HIV-related causes, most (5 [56\%]) in the first year post-transition. Of 42 survivors, 33 were eligible; 27 (82\%) provided consent. Immunosuppression (CD4+ T-lymphocyte [CD4] count $<100$ cells per $\mu \mathrm{L})$ at transition was associated with a six-fold higher risk of mortality $(67 \%$ vs. $11 \%$ in patients with $\mathrm{CD} 4$ count $\geq 100$ cells per $\mu \mathrm{L}$; relative risk $[\mathrm{RR}]=6.0,95 \% \mathrm{CI}=1.88$ $19.19[P=.005])$. When controlled for CD4 count, employment at time of transition was associated with an almost $80 \%$ reduction in mortality risk $(\mathrm{MH}$ adjusted $\mathrm{RR}=0.19 ; 95 \%$
\end{abstract}


$\mathrm{CI}=0.04-0.88[P=.02])$, and GED/high school non-completion with three times higher risk of death $(\mathrm{MH}$ adjusted $\mathrm{RR}=2.97 ; 95 \% \mathrm{CI}=1.37-6.40[P=.07])$. All patients who died (9) had a viral load > 1000 copies/ml; all deaths occurred in patients who had CD4 count $<100$ cells per $\mu \mathrm{L}$ (6) or lived in poverty (3). When controlled for CD4 count and poverty, mortality was identical among transition clinic attenders and non-attenders.

Conclusions: Transition was associated with high mortality, particularly in patients who were severely immunosuppressed, unemployed or less educated at time of transition. Comprehensive programs should focus on improvements in clinical care and include academic and employment services.

\section{INTRODUCTION}

Mortality in perinatally HIV-infected (PHIV) children has declined considerably since the introduction of combination antiretroviral therapy (cART) during the late 1990 's. ${ }^{1,2}$ In the United States (US), the pediatric HIV population consists of a relatively stable group ${ }^{3}$ of approximately 10,000 infected children, adolescents, and young adults, with the addition of $<100$ newly infected infants born annually. ${ }^{4}$ Most children who have access to cART now survive into adulthood, "age out" of pediatric care, and transition to adult medical care. ${ }^{5}$

A successful transition is regarded as a key aspect in maintaining health in this population. ${ }^{6,7}$ Recent State-of -the-Art articles describe a shared concern that transition may have adverse health effects, because vulnerable young PHIV adults will need to navigate the adult care system independently after leaving behind the familiar surroundings and comprehensive services available in most pediatric care settings. ${ }^{89}$ To date, however, little is known about clinical outcomes of PHIV young adults as few 
pediatric or adolescent clinics track their patients after transition. ${ }^{10-12}$ As far as we know, post-transition mortality has been assessed in England and Ireland, but not yet in the United States. $^{13}$

There is a critical need to follow-up on transitioned PHIV adults to ensure that therapeutic successes of earlier decades continue to benefit them and to contribute to evidence-based transition practices, which may support young adults who will soon transition. ${ }^{14}$ The purpose of our study was to describe post-transition mortality and identify clinical and socio-demographic factors, including attendance at a transition clinic to facilitate adjustment to adult care, which may affect the risk of death after transition to adult HIV care, in a US cohort of PHIV young adults.

\section{METHODS}

\section{Study Design}

We conducted a single-center, retrospective cohort study consisting of analysis of data of patients who transitioned to adult medical care from a university-based pediatric clinic in Florida in the Southeastern US. The clinic provides comprehensive HIV services to children, adolescents, and young adults up to age 24 who acquired HIV early in life, nearly all through vertical transmission. The clinic's family-centered, comprehensive HIV services include case management, nursing, nutrition, neurodevelopmental assessment, mental health, and peer education and support, and is largely funded by the US Health Resources and Services Administration Ryan White Part D grant programs. Study approval was obtained from the authors' 'parent institutions' institutional review boards. 


\section{Selection and Recruitment of Participants}

Patients were eligible for study participation if they had transitioned from the pediatric clinic to adult care between January 2003 and September 2012. Records of known deceased patients were reviewed. Living patients were excluded from study participation if they were unable to provide valid informed consent for clinical record review due to: (a) severe cognitive disability, as was previously determined by staff psychologists in pediatric HIV care, (b) incarceration, or (c) relocation. Most transitioned patients had stayed in contact with pediatric clinic staff or with each other and were recruited by telephone or in person. Informed consent was obtained by a research staff member who had not been involved in previous care. All living participants were able to read and understand English, were older than 18 years of age, and had signed informed consent and Health Insurance Portability and Accountability Act (HIPAA) patient forms at the clinic site before collection of de-identified data. Participants who were not receiving medical care or other needed services were offered support by pediatric clinic staff to access services. Study participants received $\$ 20$ and were reimbursed for travel and parking costs. Participant enrollment started in September 2013 and was completed in March 2014. Data collection was completed on April 30, 2014.

\section{Data Collection and Measures}

The main outcome was death after transition, confirmed by medical record review or information recorded by the pediatric clinic coordinator. Clinical, laboratory, and sociodemographic information included the most recent information available before transition to adult medical care. Researchers reviewed decedent and living study participants' pediatric clinic medical and psychosocial services records to abstract the 
following information on a de-identified standardized form: primary care history (transition date, age at transition); demographic characteristics (birth year, gender, age at transition, HIV transmission category, race/ethnicity, foreign birth, educational attainment, housing status, household income, employment status, and type of health insurance), and psychosocial resources (relationship and family status). Racial, ethnic and birthplace data were collected because striking disparities by these factors have been documented in risk of mortality in HIV-infected persons in Florida. ${ }^{15,16}$ Abstracted sociodemographic information was reviewed and validated by the pediatric clinic coordinator. Clinical information included markers of progression of HIV disease and response to ART (CD4+ T-lymphocyte [CD4] counts and quantitative HIV RNA plasma

levels ["viral loads"]. Primary care history data included exposure to the comprehensive transition program (transitioned before 2008 or later when a formal transition program was implemented), and attendance of the pre- or post-transition clinic (see below). Objective, standardized, measures of ART adherence and substance use were unavailable; comments in progress notes were selected to describe clinician's impressions.

\section{Transition Program}

In 2008, a formal comprehensive transition program was funded and implemented to address high attrition rates and to prepare patients for successful transition to adult HIV care. Program components included services to prepare patients for independent living (including educational and vocational support), increase self-management skills (including "life skills" and support groups), and "bridge" pediatric and adult HIV care (including discussion of transition plans, provision of linkages to adult services, and 
availability of a transition clinic). Pediatric patients, primarily those who may have needed additional transition support, were referred to the transition clinic by pediatric staff. In the last year pre-transition, patients were seen by an adult physician for at least one routine appointment at the pediatric clinic (pre-transition clinic) ${ }^{17}$ In the first year post-transition, patients were seen by the same adult physician, with whom they had started to build a relationship and who had more time allotted for a routine visit, in the adult HIV clinic of the nearby public hospital (post-transition clinic). For one year posttransition, support was also provided by the pediatric transition social worker.

\section{Statistical Analysis}

Analysis was performed using Epi Info 3.5.4 (Atlanta, GA, 2012). Univariate statistics (means, standard deviation [SD], medians, interquartile ranges and proportions) were used to describe characteristics of the study population. Continuous data were analyzed using the Kruskal-Wallis test for two groups (alpha $=0.05$ ), which has no assumption of normal data distribution. Covariates were dichotomized for inferential statistical analysis. The Fisher exact two-tail test $(\mathrm{alpha}=0.05)$ was used to determine whether differences in categorical variables were statistically significant. Risk ratios (RRs), as measures of relative risk, were calculated to assess the strength of associations between potential predictors and mortality, and 95\% confidence intervals (CIs) were calculated to assess precision of RRs. Stratified analyses were conducted to control for confounding and assess effect modification, using Mantel-Haenszel (MH) RRs and 95\% CIs and Fisher exact tests to compare differences across strata for statistical significance. 


\section{RESULTS}

A total of 51 patients transitioned from the pediatric clinic to adult medical care between January 2003 and September 2012. Nine (18\%) had died by April 30, 2014, when data collection was completed. All had died of HIV-related causes. Five (56\%) patients died within a year of their last pediatric clinic visit. Median survival time among decedents was 195 days (range 13-2142 days). None of the nine decedents were virally suppressed at time of transition and all had adherence issues (Table 3.1). Of the surviving 42 patients, nine were excluded from recruitment for consenting because of severe cognitive impairment (3), incarceration (1), or residence outside of the county and inability to come to the clinic to provide informed consent (5). Of the 33 eligible to consent to medical record review, one was lost to follow-up, five declined participation, and $27(82 \%)$ consented. The total study population for this analysis consisted of 36 transitioned patients of whom nine had died since their transition to adult care.

Study participants were African-American/Haitian (83\%) or Hispanic (17\%) (Table 3.2). Only $17 \%$ were foreign-born. Almost half (47\%) lived in poverty with household incomes equal to or below the federal poverty level ( $\$ 23,850$ for a four-person US household in 2014). ${ }^{18}$ Most were known to have been infected by vertical transmission (94\%); one participant was infected by transfusion in the perinatal period and one by sexual abuse. Most participants transitioned to adult HIV care at age 24; in 2008 or later when a formal comprehensive transition program was funded and implemented. Pre-transition CD4 count were less than 200 cells/ $\mu \mathrm{L}$ in almost half (47\%) of the study population; median CD4 count was 381 cells/ $/ \mathrm{L}$, and was lower for males (144; range 7-722 cells/ $\mu \mathrm{L})$ than females (386; range $12-831$ cells $/ \mu \mathrm{L} ; P=.06)$. Similarly, 
median viral load in males (16,708; range 40-4,870,720 copies/ml) was higher than in females (318; range 28-500,000 copies/ml; $P=.09)$.

Risk of post-transition mortality did not differ significantly by gender, race, ethnicity or foreign birth (Table 3.3). Household income, type of health insurance, whether s/he was in a relationship and if his/her mother was deceased were also not associated with a significantly different risk of mortality. Mortality risk was somewhat lower among participants who transitioned before 2008 (when no formal transition support program was available), and was almost twice as high among those who ever had attended the transition clinic, although neither of these differences achieved statistical significance. Those who had severe immunosuppression (CD4 count $<100$ cells $/ \mu \mathrm{L}$, viral loads $>1000$ copies/ml) pre-transition were significantly more likely to have died. Pretransition viral loads were higher in decedents (median=83,800 copies/ml; IQR=15,416238,581 copies/ml) than in survivors (median=328 copies/ml; IQR=127-18,000 copies $/ \mathrm{ml} ; P<.001)$. Conversely, employment was associated with a significant reduction in mortality. Completion of high school/General Educational Development test (GED) requirements was also associated with a reduction of mortality risk.

Stratified analysis controlling for CD4 count affected the strength of associations between non-completion of high school/GED and mortality and employment and mortality (Supplemental Table 3.4). Low CD4 counts ( $<100$ cells/ $\mu \mathrm{L})$ confounded the association between employment and mortality, weakening somewhat the protective effect of employment. When controlled for CD4 count, employment at time of transition was associated with almost $80 \%$ reduction in mortality risk $(\mathrm{MH}$ adjusted $\mathrm{RR}=0.19 ; 95 \%$ $\mathrm{CI}=0.0-0.9, P=.02)$; GED/high school non-completion was associated with three times 
higher risk of death ( $\mathrm{MH}$ adjusted $\mathrm{RR}=2.97 ; 95 \% \mathrm{CI}=1.4-6.4, P=.07)$. Patients living in poverty (income below FPL) or who had CD4 counts $<100$ cells per $\mu \mathrm{L}$ were more likely to die than others; all decedents had either a CD4 count $<100 / \mu 1$ (6) or household income below poverty level (3). All nine deaths occurred in the 21 (43\%) who had CD4 counts $<100$ cells or lived in severe poverty (vs. 0 of 15 patients neither living in poverty nor severely immunosuppressed [0\%]; $P=.006$ ). Participants with these characteristics were also more likely to have attended the transition clinic (14/21 [67\%] vs. 5/15 [33\%]; $\mathrm{RR}=2.0 ; 95 \% \mathrm{CI}=.92-4.4, P=.10)$. When the analysis was confined to participants who had a CD4 count $<100$ cells $/ \mu \mathrm{L}$ and who lived in poverty, risk of death was identical in transition clinic attenders and non-attenders [42.9\%].

\section{DISCUSSION}

These data suggest a very high post-transition risk of mortality; of 51 patients who transitioned between January 2003 and September 2012, nine (18\%) patients died after transition, most within one year, all of HIV-related causes. In the study population (36 participants of whom nine decedents and 27 who were eligible and consenting), factors significantly associated with mortality were advanced immunosuppression, poor viral suppression, unemployment, and high school/GED non-completion at time of transition. Most participants were US-born African-Americans or Haitians, reflecting the striking health disparities in perinatal HIV transmission in the United States. ${ }^{19}$ Social disadvantages were evidenced by the high proportion of patients living in poverty and who relied on Medicaid or Ryan White insurance for their health care costs. Transition clinic participation seemed to have been preferentially recommended to patients living in extreme poverty or with severe immunosuppression; when controlled for these factors, 
mortality risk was identical among transition clinic attenders and non-attenders, suggesting that this intervention did not impact mortality.

At transition, 25 out of $36(69 \%)$ participants had CD4 counts $<500$ cells/ $\mu \mathrm{L}$, which was not unexpected as the young adults in our study acquired HIV before the development of their immune system, and before highly effective treatment became available in the late1990s; many PHIV patients have complex clinical histories and possibly HIV antiretroviral drug-resistant virus, complicating their care and limiting the choice of therapy. ${ }^{1,5,14}$ Treatment may have been further complicated by cognitive, developmental, and psychosocial challenges exacerbating difficulties adhering to lifelong therapies. $^{20}$

Several studies have documented poor health outcomes among HIV-infected adolescents and young adults in adult HIV care. ${ }^{12,21,22}$ As far as we know, only one study conducted in England and Ireland (United Kingdom [UK]) assessed mortality after transition to adult care. ${ }^{13}$ That audit of 14 adult clinics caring for 248 transitioned PHIV reported 11 deaths (4\%) between September 2003 and March 2011, with seven deaths directly related to HIV-progression. Compared to our study in a similar time period, UK patients transitioned at an earlier age (median 17 versus 23 years in our cohort), were less likely to die (11/248 [4\%] versus 9/51[18\%]), and had a longer post-transition survival time. The increased post-transition survival in UK PHIV adolescents and young adults may suggest a bias towards earlier death among our participants due to the longer duration of life with HIV infection at time of transition. Differences between health systems and social policies suggest additional explanations: the UK reports far superior retention in HIV care and viral suppression, ${ }^{23}$ while outcomes are particularly poor in 
Florida for African-Americans and Hispanics. ${ }^{15,16}$ US patients on public insurance may be vulnerable to gaps in health insurance, ${ }^{24}$ whereas the UK National Health Service covers all citizens and is comparatively easier to navigate. ${ }^{25}$ Differences in social services expenditures also may be of importance in explaining differential health outcomes. Expenditures on social services, including housing, employment training, unemployment benefits and family support which have been found to be associated with improved outcomes, are proportionally higher in the UK, whereas the US allocates most health resources to health care. ${ }^{26}$

The impact of social determinants on health is well documented. ${ }^{27,28}$ In our study, GED/high school non-completion and unemployment were associated with posttransition mortality, particularly in patients who were not severely immunosuppressed. Lower educational attainment has been found to be associated with increased mortality, with substantial benefits of high school completion, especially for US AfricanAmericans. ${ }^{29}$ Several studies have shown associations between employment status and health among HIV-infected people. ${ }^{30,31}$ In our study, however, employment may also have been partially a marker for health, despite its independence of immune status. With few exceptions, studies show that "the lower an individual's socioeconomic position the worse their health." 27 p.1153 Study findings suggested that poverty impacted mortality, although the small sample size precluded definite conclusions.

Our study is a preliminary exploration of mortality and associated factors among transitioned PHIV. One of the strengths of this study is the long duration of follow-up. Limitations include the small sample size and reduced power to detect statistically significant differences despite large effect sizes, ineligibility or non-participation of 15 
living patients, and the retrospective nature of our study. We could not entirely discard the possibility that employment and education were markers of levels of health or social disorganization. Because of the poor health status of deceased patients at transition, it is unclear whether transition itself had negatively impacted the disease course. Because our study was conducted at a single site, generalizability of study findings may be limited.

Despite these limitations, our study supports American Academy of Pediatrics guidelines suggesting that transition planning start early in adolescence and should ensure comprehensive care addressing physical health, and social, psychological, educational, and vocational needs. ${ }^{6}$ As PHIV youth mature, they encounter daunting challenges in managing their HIV disease while obtaining education and employment. Comprehensive services should support youth to complete high school, obtain employment, and escape poverty. Clearly, transition of young adults who are severely immunosuppressed requires extreme caution; it may be prudent to provide ample resources to enable pediatric clinics to provide intensive support to improve patients' immune status and viral responses to antiretroviral therapy before transition. Finally, in Florida, where mortality among adult African-American and Hispanic HIV patients is considerably higher than in White counterparts and mortality elsewhere in the United States, supportive, comprehensive, family-centered coordinated care typical of pediatric clinics should be considered even for adults instead of prioritizing preparation of pediatric patients to adjust to the less supportive services of adult care. ${ }^{32}$

\section{REFERENCES}

1. Agwu AL, Fairlie L. Antiretroviral treatment, management challenges and outcomes in perinatally HIV-infected adolescents. J Int AIDS Soc. 2013;16:18579. doi:10.7448/ias.16.1.18579. 
2. Kapogiannis BG, Soe MM, Nesheim SR, et al. Mortality trends in the US perinatal AIDS collaborative transmission study (1986-2004). Clin Infect Dis. 2011;53(10):10241034. doi:10.1093/cid/cir641.

3. Hazra R, Siberry GK, Mofenson LM. Growing up with HIV: Children, adolescents, and young adults with perinatally acquired HIV infection. Annи Rev Med. 2010;61:169. doi:10.1146/annurev.med.050108.151127.

4. Centers for Disease Control and Prevention. HIV surveillance report. Diagnoses of HIV infection in the United States and dependent areas. http://www.cdc.gov/hiv/pdf/statistics_2012_HIV_Surveillance_Report_vol_24.pdf. Updated November, 2014. Accessed September 4, 2015.

5. Panel on Antiretroviral Guidelines for Adults and Adolescents. Department of Health and Human Services. Guidelines for the use of antiretroviral agents in HIV-1-infected adults and adolescents. http://aidsinfo.nih.gov/guidelines. Updated May 1, 2014.

Accessed August 26, 2014.

6. Committee on Pediatric AIDS. Transitioning HIV-infected youth into adult health care. Pediatrics. 2013;132(1):192-197. doi:10.1542/peds.2013-1073.

7. New York State Department of Health. Transitioning HIV-infected adolescents into adult health care. http://www.hivguidelines.org/wp.content/uploads/2012/2011/transitioning-hiv-infectedadolescents-into-adult-care-11-06-2012.pdf. Updated 2012. Accessed October 8, 2014.

8. Persson A, Newman C. When HIV-positive children grow up: A critical analysis of the transition literature in developed countries. Qual Health Res. 2012;22(5):656-667. doi:10.1177/1049732311431445.

9. Dowshen N, D'Angelo L. Health care transition for youth living with HIV/AIDS. Pediatrics. 2011;128(4):762-771. doi:10.1542/peds.2011-0068.

10. Hussen SA, Chahroudi A, Boylan A, Camacho-Gonzalez AF, Hackett S, Chakraborty R. Transition of youth living with HIV from pediatric to adult-oriented healthcare: A review of the literature. Future Virol. 2015;9(10):921-929. doi:10.2217/fvl.14.73.

11. Gilliam PP, Ellen JM, Leonard L, Kinsman S, Jevitt CM, Straub DM. Transition of adolescents with HIV to adult care: Characteristics and current practices of the adolescent trials network for HIV/AIDS interventions. J Assoc Nurses AIDS Care. 2011;22(4):283294. doi:10.1016/j.jana.2010.04.003.

12. Wiener LS, Kohrt BA, Battles HB, Pao M. The HIV experience: Youth identified barriers for transitioning from pediatric to adult care. J Pediatr Psychol. 2011;36(2):141154. doi:10.1093/jpepsy/jsp129. 
13. Fish R, Judd A, Jungmann E, O'Leary C, Foster C, HIV Young Persons Network (HYPNet). Mortality in perinatally HIV-infected young people in England following transition to adult care: An HIV young persons network (HYPNet) audit. HIV Med. 2014;15(4):239-244. doi:10.1111/hiv.12091.

14. Sohn AH, Hazra R. The changing epidemiology of the global paediatric HIV epidemic: Keeping track of perinatally HIV-infected adolescents. J Int AIDS Soc. 2013;16:18555. doi:10.7448/ias.16.1.18555.

15. Trepka MJ, Niyonsenga T, Fennie KP, McKelvey K, Lieb S, Maddox LM. Sex and racial/ethnic differences in premature mortality due to HIV: Florida, 2000-2009. Public Health Rep. 2015;130(5):505-513.

16. Sheehan DM, Trepka MJ, Fennie KP, Dillon FR, Madhivanan P, Maddox LM. Neighborhood Latino ethnic density and mortality among HIV-positive Latinos by birth country/region, Florida, 2005-2008. Ethn Health. 2015:1-16.

doi:10.1080/13557858.2015.1061104.

17. Maturo D, Powell A, Major-Wilson H, Sanchez K, De Santis JP, Friedman LB. Development of a protocol for transitioning adolescents with HIV infection to adult care. J Pediatr Health Care. 2011;25(1):16-23. doi:10.1016/j.pedhc.2009.12.005.

18. U.S. Department of Health \& Human Services. Office of the Assistant Secretary for Planning and Evaluation. 2014 poverty guidelines.

http://aspe.hhs.gov/poverty/14povertycfm. Updated 2014. Accessed October 25, 2014.

19. Nesheim S, Taylor A, Lampe MA, et al. A framework for elimination of perinatal transmission of HIV in the United States. Pediatrics. 2012;130(4):738-744. doi:10.1542/peds.2012-0194.

20. Mofenson LM, Cotton MF. The challenges of success: Adolescents with perinatal HIV infection. J Int AIDS Soc. 2013;16:18650. doi:10.7448/ias.16.1.18650.

21. de Mulder M, Yebra G, Navas A, et al. High drug resistance prevalence among vertically HIV-infected patients transferred from pediatric care to adult units in Spain. PLoS One. 2012;7(12):10/1/2014-e52155. doi:10.1371/journal.pone.0052155.

22. Ryscavage P, Anderson EJ, Sutton SH, Reddy S, Taiwo B. Clinical outcomes of adolescents and young adults in adult HIV care. J Acquir Immune Defic Syndr. 2011;58(2):193-197. doi:10.1097/qai.0b013e31822d7564.

23. Raymond A, Hill A, Pozniak A. Large disparities in HIV treatment cascades between eight European and high-income countries - analysis of break points. J Int AIDS Soc. 2014;17(4 Suppl 3):19507. doi:10.7448/ias.17.4.19507. 
24. Tsuyuki K, Surratt HL, Levi-Minzi MA, O'Grady CL, Kurtz SP. The demand for antiretroviral drugs in the illicit marketplace: Implications for HIV disease management among vulnerable populations. AIDS Behav. 2014. doi:10.1007/s10461-014-0856-2.

25. Blumenthal D, Dixon J. Health-care reforms in the USA and England: Areas for useful learning. Lancet. 2012;380(9850):1352-1357.

doi:10.1016/s0140-6736(12)60956-8.

26. Bradley EH, Elkins BR, Herrin J, Elbel B. Health and social services expenditures: Associations with health outcomes. BMJ Qual Saf. 2011;20(10):826-831. doi:10.1136/bmjqs.2010.048363.

27. Marmot M, Commission on Social Determinants of Health. Achieving health equity: From root causes to fair outcomes. Lancet. 2007;370(9593):1153-1163. doi:10.1016/s0140-6736(07)61385-3.

28. Lynch J KG. Socioeconomic position. In: Berkman LF, Kawachi I, ed. Social epidemiology. New York: Oxford University Press, Inc; 2000:13-35.

29. Montez JK. Cumulative childhood adversity, educational attainment, and active life expectancy among U.S. adults. Demography. 2014;51(2):413; 413-435; 435.

doi:10.1007/s13524-013-0261-x.

30. Rueda S, Raboud J, Plankey M, et al. Labor force participation and health-related quality of life in HIV-positive men who have sex with men: The multicenter AIDS cohort study. AIDS Behav. 2012;16(8):2350-2360. doi:10.1007/s10461-012-0257-3.

31. Rueda S, Raboud J, Mustard C, Bayoumi A, Lavis JN, Rourke SB. Employment status is associated with both physical and mental health quality of life in people living with HIV. AIDS Care. 2011;23(4):435-443. doi:10.1080/09540121.2010.507952.

32. Attiah MA. A piece of my mind. Treat me like a child. JAMA. 2013;310(7):693-694. doi:10.1001/jama.2013.169412. 
Table 3.1. Characteristics of perinatally HIV-infected young adults at transition who died post-transition.

\begin{tabular}{|c|c|c|c|c|c|c|c|c|c|}
\hline \# & Gender & Race/Ethnicity & $\begin{array}{l}\text { Transition } \\
\text { year }\end{array}$ & $\begin{array}{l}\text { Transition } \\
\text { age } \\
\text { (years) }\end{array}$ & $\begin{array}{l}\text { CD4 } \\
\text { count } \\
(\text { cells/ } \mu \mathrm{l})\end{array}$ & $\begin{array}{l}\text { Viral load } \\
\text { (copies/ml) }\end{array}$ & $\begin{array}{l}\text { Hospital } \\
\text { Admissions } \\
12 \text { months } \\
\text { pre- } \\
\text { transition } \\
\text { (days/times) }\end{array}$ & $\begin{array}{l}\text { Survival } \\
\text { time } \\
\text { (days) }\end{array}$ & $\begin{array}{l}\text { Pediatric clinical } \\
\text { notes }\end{array}$ \\
\hline 1 & female & Haitian & 2004 & 18 & 143 & 83,800 & unavailable & 2,142 & $\begin{array}{l}\text { "Unwilling to take } \\
\text { meds. Does not } \\
\text { want to discuss it." }\end{array}$ \\
\hline 2 & female & Hispanic & 2007 & 19 & 12 & 500,000 & $63(6)$ & 152 & $\begin{array}{l}\text { "Multi-drug use." } \\
\text { "Extremely non- } \\
\text { compliant." }\end{array}$ \\
\hline 3 & male & Haitian & 2008 & 23 & $<20$ & 33,400 & $5(1)$ & 1,167 & $\begin{array}{l}\text { "Does not keep his } \\
\text { appointments." }\end{array}$ \\
\hline 4 & female & African-American & 2010 & 24 & 157 & 1,613 & $12(2)$ & 1,614 & $\begin{array}{l}\text { "Could not } \\
\text { understand viral } \\
\text { loads and explain } \\
\text { it." }\end{array}$ \\
\hline 5 & female & African-American & 2010 & 22 & 157 & 210,812 & $86(13)$ & 83 & $\begin{array}{l}\text { "Multi-drug use." } \\
\text { "Does not keep } \\
\text { appointments." }\end{array}$ \\
\hline 6 & male & African-American & 2011 & 23 & $<20$ & 15,416 & $49(5)$ & 13 & $\begin{array}{l}\text { "Huge compliance } \\
\text { issues." }\end{array}$ \\
\hline 7 & male & African-American & 2012 & 23 & $<20$ & $4,870,720$ & $142(15)$ & 195 & $\begin{array}{l}\text { "Chronic non- } \\
\text { compliance." }\end{array}$ \\
\hline 8 & male & African-American & 2012 & 23 & $<20$ & 11,437 & $15(2)$ & 180 & $\begin{array}{l}\text { "Patient is not } \\
\text { motivated to get any } \\
\text { treatment." }\end{array}$ \\
\hline & male & Haitian & 2012 & 24 & $<20$ & 238,581 & $32(3)$ & 413 & $\begin{array}{l}\text { "Does not believe } \\
\text { he has the virus." } \\
\text { "Huge resentment } \\
\text { toward mother." }\end{array}$ \\
\hline
\end{tabular}


Table 3.2. Sociodemographic and clinical characteristics at time of transition $(\mathrm{N}=36)$

\begin{tabular}{|c|c|}
\hline Characteristic & $\begin{array}{c}\text { Overall } \\
(\mathrm{n} / \%)\end{array}$ \\
\hline Female & $18(50)$ \\
\hline $\begin{array}{l}\text { Race/Ethnicity } \\
\text { African American } \\
\text { Haitian } \\
\text { Hispanic }\end{array}$ & $\begin{array}{r}18(50) \\
12(33) \\
6(17)\end{array}$ \\
\hline Foreign born & $6(17)$ \\
\hline $\begin{array}{l}\text { HIV transmission route } \\
\text { Mother-to-child } \\
\text { Blood products } \\
\text { Sexual (abuse) }\end{array}$ & $\begin{array}{c}34(94) \\
1(3) \\
1(3)\end{array}$ \\
\hline Mother deceased & $30(83)$ \\
\hline Married/in relationship & $15(42)$ \\
\hline Completed high school/GED & $29(81)$ \\
\hline Employment (full or part-time) & $20(56)$ \\
\hline $\begin{array}{l}\text { Housing } \\
\text { Unstable } \\
\text { With (extended) family } \\
\text { Own or shared }\end{array}$ & $\begin{array}{c}2(6) \\
18(50) \\
16(44)\end{array}$ \\
\hline $\begin{array}{l}\text { Household income } \\
\text { Equal or below Federal Poverty Level (FPL) } \\
101-200 \% \text { FPL } \\
201-400 \% \text { FPL }\end{array}$ & $\begin{array}{r}17(47) \\
12(33) \\
7(20)\end{array}$ \\
\hline $\begin{array}{l}\text { Health Insurance } \\
\text { Medicaid } \\
\text { Ryan White } \\
\text { Medicare } \\
\text { Private } \\
\text { No insurance }\end{array}$ & $\begin{aligned} & 25(69) \\
& 7(19) \\
& 1(3) \\
& 2(6) \\
& 1(3)\end{aligned}$ \\
\hline $\begin{array}{l}\text { Age (years) at transition } \\
\text { Mean: } \\
\text { Median } \\
\text { Mode }\end{array}$ & $\begin{array}{l}23 \text { (SD1.7) } \\
23 \text { (18-26) } \\
24\end{array}$ \\
\hline Transitioned in or after 2008 & $26(72)$ \\
\hline Attended Transition Clinic & $19(53)$ \\
\hline $\begin{array}{l}\text { CD4+ T-lymphocyte count }(\text { cells } / \mu \mathrm{L}) \\
\quad<100 \\
100-<200 \\
200-499 \\
\geq 500\end{array}$ & $\begin{array}{cc}9 & (25) \\
8 & (22) \\
8 & (22) \\
11(31) \\
\end{array}$ \\
\hline
\end{tabular}


Table 3.3. Factors associated with death $(n=9)$ after transition to adult care $(N=36)$

\begin{tabular}{|c|c|c|c|c|}
\hline $\begin{array}{l}\text { Characteristics at time of } \\
\text { transition }\end{array}$ & $\begin{array}{l}\text { Died } \\
\#(/ \%)\end{array}$ & Total & $\begin{array}{l}\text { Risk ratio } \\
(95 \% \text { C.I. })\end{array}$ & $P$ value ${ }^{a}$ \\
\hline $\begin{array}{l}\text { Gender } \\
\text { Male } \\
\text { Female }\end{array}$ & $\begin{array}{l}5(28) \\
4(22)\end{array}$ & $\begin{array}{l}18 \\
18\end{array}$ & $1.25(0.40,3.91)$ & $>0.99$ \\
\hline $\begin{array}{l}\text { Race } \\
\text { African-American or Haitian } \\
\text { Hispanic }\end{array}$ & $\begin{array}{l}8(27) \\
1(17)\end{array}$ & $\begin{array}{l}30 \\
6\end{array}$ & $1.6(0.24,10.54)$ & $>0.99$ \\
\hline $\begin{array}{l}\text { Birth Country } \\
\text { Foreign-born } \\
\text { US-born }\end{array}$ & $\begin{array}{l}1(17) \\
8(27)\end{array}$ & $\begin{array}{l}6 \\
30\end{array}$ & $0.63(0.09,4.12)$ & $>0.99$ \\
\hline $\begin{array}{l}\text { Relationship status } \\
\text { Married/in relationship } \\
\text { Single }\end{array}$ & $\begin{array}{l}4(27) \\
5(24)\end{array}$ & $\begin{array}{l}15 \\
21\end{array}$ & $1.12(0.36,3.49)$ & $>0.99$ \\
\hline $\begin{array}{l}\text { Educational attainment } \\
\text { Less than High School/GED } \\
\text { High school/GED }\end{array}$ & $\begin{array}{l}4(57) \\
5(17)\end{array}$ & $\begin{array}{l}7 \\
29\end{array}$ & $3.31(1.19,9.22)$ & 0.10 \\
\hline $\begin{array}{l}\text { Employment status } \\
\text { Employed } \\
\text { Unemployed }\end{array}$ & $\begin{array}{l}1(5) \\
8(50)\end{array}$ & $\begin{array}{l}20 \\
16\end{array}$ & $0.1(0.01,0.72)$ & $.006 * *$ \\
\hline $\begin{array}{l}\text { Household income } \\
\text { Below Federal Poverty Level } \\
\text { At or above Federal Poverty Level }\end{array}$ & $\begin{array}{l}6(35) \\
3(16)\end{array}$ & $\begin{array}{l}17 \\
19\end{array}$ & $2.2(0.66,7.58)$ & 0.34 \\
\hline $\begin{array}{l}\text { Medicaid status } \\
\text { Medicaid insured } \\
\text { Not Medicaid insured }\end{array}$ & $\begin{array}{l}8(32) \\
1(9)\end{array}$ & $\begin{array}{l}25 \\
11\end{array}$ & $3.5(0.50,24.84)$ & 0.30 \\
\hline $\begin{array}{l}\text { Maternal vital status } \\
\text { Mother deceased } \\
\text { Mother alive }\end{array}$ & $\begin{array}{l}6(20) \\
3(50)\end{array}$ & $\begin{array}{l}30 \\
6\end{array}$ & $0.4(0.14,1.17)$ & 0.30 \\
\hline $\begin{array}{l}\text { Transition time period } \\
\text { Before } 2008 \\
\text { In or after } 2008\end{array}$ & $\begin{array}{l}2(20) \\
7(27)\end{array}$ & $\begin{array}{l}10 \\
26\end{array}$ & $0.7(0.18,2.99)$ & $>0.99$ \\
\hline $\begin{array}{l}\text { Transition clinic attendance } \\
\text { Attended transition clinic } \\
\text { Did not attend transition clinic }\end{array}$ & $\begin{array}{l}6(32) \\
3(18)\end{array}$ & $\begin{array}{l}19 \\
17\end{array}$ & $1.8(0.53 .6 .07)$ & 0.56 \\
\hline $\begin{array}{l}\text { Viral load } \\
>1000 \text { copies } / \mathrm{ml} \\
\leq 1000 \text { copies } / \mathrm{ml}\end{array}$ & $\begin{array}{l}9(43) \\
0\end{array}$ & $\begin{array}{l}21 \\
15\end{array}$ & ----- & $.006 * *$ \\
\hline $\begin{array}{l}\text { CD4+ T-lymphocyte count category } \\
<100 \text { cells } / \mu \mathrm{L} \\
\geq 100 \text { cells } / \mu \mathrm{L}\end{array}$ & $\begin{array}{l}6(67) \\
3(11)\end{array}$ & $\begin{array}{l}9 \\
27\end{array}$ & $6.0(1.88,19.19)$ & $.005^{* *}$ \\
\hline
\end{tabular}

${ }^{a}$ Fisher exact two-tailed test 
Supplemental Tables 3.4. Characteristics at transition associated with death posttransition, controlled for: a.) CD4+ T-lymphocyte count $<100$ cells per $\mu \mathrm{L}$ and b.) CD4+ T-lymphocyte count $<100$ cells per $\mu \mathrm{L}$ and living in poverty

a.) CD4+ T-lymphocyte count $<100$ cells per $\mu \mathrm{L}$

\begin{tabular}{|l|c|c|c|}
\hline \multicolumn{1}{|c|}{ Characteristic } & Number who Died (\%) & $\begin{array}{c}\text { Relative Risk } \\
(\mathbf{9 5 \%} \text { CI)* }\end{array}$ & P-value $^{\dagger}$ \\
\hline Employed & $1 / 3(33.3)$ & .40 & .45 \\
\hline Unemployed & $5 / 6(83.3)$ & $(.08-2.06)$ & \\
\hline
\end{tabular}

CD4+ T-lymphocyte count $\geq \mathbf{1 0 0}$ cells per $\mu \mathrm{L}$

\begin{tabular}{|c|c|c|c|}
\hline Characteristic & Number who Died (\%) & $\begin{array}{c}\text { Relative Risk } \\
\text { (95\% CI)* }\end{array}$ & P-value \\
\hline Employed & & 0 & .08 \\
\hline Unemployed & $3 / 10(30)$ & --- & \\
\hline & & $\begin{array}{c}\text { Adjusted } \\
\text { Mantel-Haenszel } \\
\text { Relative Risk } \\
(95 \% \text { CI })^{*}\end{array}$ & P-value ${ }^{\dagger}$ \\
\hline & & .19 & .02 \\
\hline & & $(.04-.88)$ & \\
\hline
\end{tabular}

CD4+ T-lymphocyte count $<100$ cells per $\mu \mathrm{L}$

\begin{tabular}{|l|c|c|c|}
\hline \multicolumn{1}{|c|}{ Characteristic } & Number who Died (\%) & $\begin{array}{c}\text { Relative Risk } \\
\text { (95\% CI)* }\end{array}$ & P-value $^{\dagger}$ \\
\hline $\begin{array}{l}\text { High School non- } \\
\text { completer }\end{array}$ & $2 / 2(0)$ & 1.8 & .83 \\
\hline High School graduate & $4 / 7(57.1)$ & $(.92-3.32)$ & \\
\hline
\end{tabular}

CD4+ T-lymphocyte count $\geq \mathbf{1 0 0}$ cells per $\boldsymbol{\mu L}$

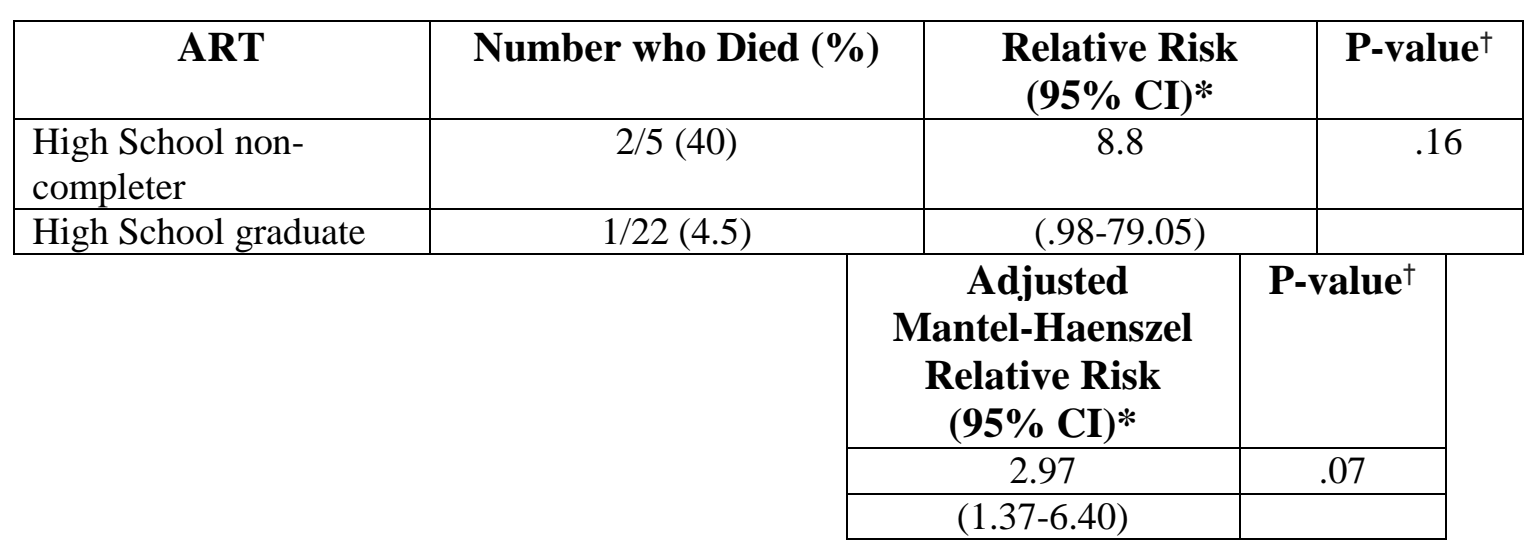


b) CD4+ T-lymphocyte count $<100$ cells per $\mu \mathrm{L}$ and living in poverty

\begin{tabular}{|l|c|c|c|}
\hline \multicolumn{1}{|c|}{ Characteristic } & Number who Died (\%) & $\begin{array}{c}\text { Relative Risk } \\
(\mathbf{9 5 \%} \text { CI)* }\end{array}$ & P-value $^{\dagger}$ \\
\hline $\begin{array}{l}\text { Transition Clinic } \\
\text { Attendance }\end{array}$ & $6 / 14(42.9)$ & 1.0 & $>0.99$ \\
\hline Non-Attender & $3 / 7(42.9)$ & $(.35-2.9)$ & \\
\hline
\end{tabular}

CD4+ T-lymphocyte count $\geq \mathbf{1 0 0}$ cells and not living in poverty

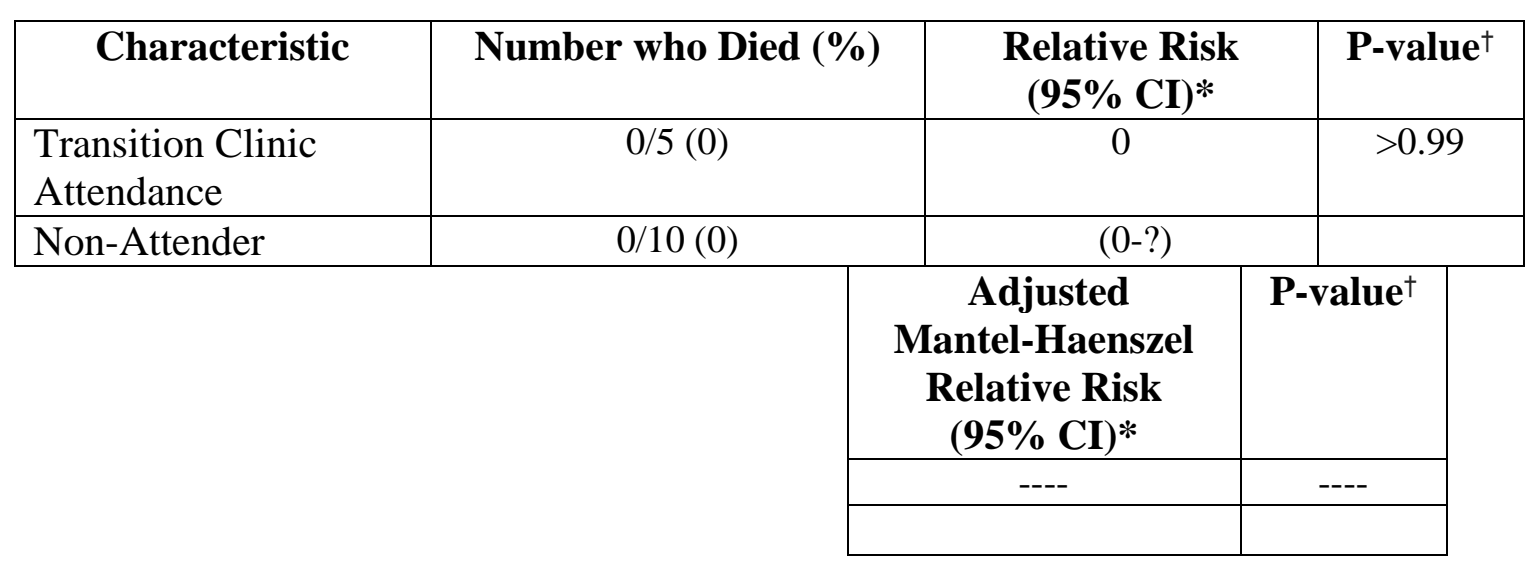




\section{CHAPTER IV. SECOND MANUSCRIPT}

\section{Engagement in HIV care of perinatally HIV-infected young adults after transition}

to adult medical care settings: Effectiveness assessment of a comprehensive

\section{transition program}

Susan Biersteker, Ph.Dc ${ }^{\mathrm{a}}$, Ana Garcia, Ph.D., LCSW ${ }^{\mathrm{b}}$, Barbara J. Messick, M.P.H. ${ }^{\mathrm{c}}$, Consuelo M. Beck-Sagué, M.D., FAAP

Affiliations: ${ }^{a}$ Robert Stempel College of Public Health \& Social Work, Department of Health Promotion and Disease Prevention, Florida International University, Miami, Fl.;

${ }^{b}$ University of Miami Miller School of Medicine Department of Pediatrics, Division of Infectious Diseases \& Immunology, Miami, Fl. ; ${ }^{\mathrm{c}}$ University of Miami Miller School of Medicine, Department of Obstetrics and Gynecology, Division of Research and Special Projects, Miami, Fl.

Address correspondence to: Susan Biersteker, Robert Stempel College of Public Health \& Social Work, Department of Health Prevention and Disease Prevention, Florida International University, 11200 SW 8th Street, AHC5 505, Miami, Fl. 33199, sbier002@fiu.edu

\section{Summary statement:}

Transition to adult HIV care may lead to poorer health outcomes, but few studies have examined the effect of transition and programs to improve post-transition outcomes. This study of transitioned perinatally HIV-infected young adults provides information about post-transition engagement in adult HIV care and assesses the effectiveness of a transition program. 


\begin{abstract}
Purpose: To examine changes in HIV care engagement post-transition and identify associated factors.
\end{abstract}

Methods: We conducted a longitudinal, retrospective cohort study of perinatally HIVinfected patients who transitioned from a pediatric clinic in the Southeastern US to adult HIV care between January 2003 and September 2012. We assessed differences in the number of kept appointments and visit constancy (at least one quarterly visit) in 3 years (one year pre-transition and two years post-transition). We examined associations between clinical and sociodemographic characteristics, including exposure to transition program activities, and frequent care engagement in the first year post-transition.

Stratified analysis controlled for confounding.

Results: Of 31 eligible and consenting participants, we could obtain medical records of 25 participants for both the last pre-transition and first post-transition years. Participants kept over twice as many appointments in the last pre-transition year than the first posttransition year $($ Median = 5, IQR 4-6 versus Median = 2, IQR 1-10; P=.002). In the first year post-transition, the proportion of poorly engaged participants increased from one out of $30(3 \%)$ in pediatric to nine out of $26(35 \%)$ in adult HIV care $(P=.006)$, while the proportion of frequently engaged participants decreased from 24 out of 30 (80\%) in pediatric to eight out of $26(30 \%)$ in adult HIV care $(P<.001)$. No significant changes were observed between the first and second post-transition year. Patients who were African-American or Haitian (19\%) or low-income (8\%) were less likely to have kept frequent appointments than others $(80 \%, P=.04 ; 50 \%, P=.06$, respectively) in the first 
year post-transition. Engagement in adult HIV care was not significantly associated with participation in a clinic transition program.

Conclusions: Care engagement decreased after transition to adult HIV care. Effective interventions to support transition to welcoming, high-quality adult HIV services are urgently needed.

\section{INTRODUCTION}

Advances in HIV care and treatment, specifically the introduction of combined antiretroviral therapy (ART), have greatly increased life-expectancy of children HIVinfected in early life. ${ }^{1}$ As the prognosis has improved, an increasing number of perinatally HIV-infected (PHIV) children will "age out" of pediatric or adolescent care and transition to adult care services. ${ }^{2}$ Concerns have arisen about whether therapeutic successes of earlier decades will continue to benefit PHIV young adults after transition. ${ }^{3}$ Continuous care is essential for all patients on ART as even short lapses in treatment may have significant consequences for viral suppression, drug resistance, and HIV transmission. ${ }^{4}$ Successful transition to adult care services may be more critical for PHIV patients. Many will be in advanced stages of HIV-disease having longer and more complex medical histories than their behaviorally infected counterparts, leading to complicated treatment and limited therapy options. ${ }^{5}$

Transition experiences and outcomes are context-dependent and may vary according to policies and health systems. ${ }^{6}$ In the US, transition may be particularly challenging, in part because of fundamental differences between pediatric and adult medical care settings. ${ }^{7,8}$ In general, most pediatric patients have longstanding relationships with their HIV provider and receive comprehensive "one-stop shopping" 
medical and psychosocial services in a welcoming and familiar environment. In contrast, adult care services tend to be less accommodating and more impersonal, requiring patients to independently navigate health and social services and self-manage their chronic conditions. PHIV young adults may not have the functional autonomy presumed in adult HIV care. ${ }^{9}$ PHIV children in the US are disproportionally members of ethnic minority groups living in underserved urban areas, burdened by psychosocial issues, including poverty and HIV stigma, which may further complicate transition. ${ }^{10}$ These issues may be exacerbated by the complexity of the US healthcare system, ${ }^{11}$ and the under-resourced, stressed system of HIV care for patients who depend on public health insurance. $^{12}$

To date, most transition studies have been qualitative and described barriers to transition from the perspectives of pre-transition youth, their caregivers and providers. ${ }^{13}$ The few studies of young adults post-transition found considerable challenges and barriers to accessing adult HIV care and supportive services. ${ }^{14,15}$ A recent retrospective study of transitioned patients with behavioral and perinatally-acquired HIV concluded that the health care transition process needs to be optimized as only $50 \%$ of patients were retained in adult HIV care one year post-transition, and had completed at least two clinical visits. ${ }^{16}$ Cross-sectional studies documented poorer health outcomes in patients in adult HIV care compared to their peers in pediatric care, ${ }^{17,18}$ and to $\mathrm{HIV}$-infected adult patients. ${ }^{19}$ A recent study reported prolonged poor engagement in adult HIV care extending from adolescence through young adulthood (25-34 years old). ${ }^{20}$ Loss-to-follow-up among HIV-infected youth was found to be associated with receiving care at adult clinical settings. ${ }^{21}$ 
Acknowledging the risk of poor transition outcomes, transition services and programs are increasingly recognized as key components of pediatric or adolescent care..$^{3,22}$ Although many clinics have implemented programs to prepare and support transition in PHIV young adults, few empirical data exist to guide these programs. ${ }^{13,23}$ This study assessed engagement in HIV care one and two years after PHIV patients transitioned from a comprehensive pediatric treatment program in the Southeastern US to adult care, exploring the role of various factors, including exposure to a transition program, in posttransition engagement in care.

\section{METHODS}

We conducted a longitudinal retrospective study of patients who had transitioned to adult medical care from a university-based pediatric HIV clinic in the southeastern United States. The clinic provides outpatient comprehensive services to low-income and underserved children, adolescents and young adults through 24 years in age who acquired HIV early in life, nearly all through vertical transmission. Since 2008, the clinic has implemented a comprehensive transition program, largely supported by Ryan White funding. Available interventions included support from medical and psychosocial staff, educational workshops, support groups, peer and individual counseling, attendance of a transition clinic and follow-up by a transition social worker in the first year posttransition. The transition clinic is a collaborative effort between pediatric and adult services to address post-transition attrition. ${ }^{24}$ To bridge the gap between pediatric and adult care, pediatric patients could be referred to an adult provider for one or more quarterly appointments, which were held at the pediatric clinic site in the last pretransition year. In the first year post-transition, transitioned patients could schedule 
appointments with the now familiar adult provider at the academic center's adult HIV clinic, who allots more than the traditional 15-minutes for a routine medical visit. In the second year post-transition, no transition services were provided.

\section{Participants}

Patients were eligible for study participation if they had transitioned from the pediatric clinic to adult medical HIV care settings between January 2003 and September 2012. Living patients were excluded from study participation if they were unable to provide valid informed consent in person because of severe cognitive disability (as determined by staff psychologists during routine neuropsychological testing while in pediatric HIV care), incarceration, or relocation. Because we collected follow-up information for at least one year after transition, patients who died within one year of their transition date were also excluded.

\section{Procedures}

Approval for the study protocol was granted by the institutional review boards of relevant institutions. Former patients were contacted by phone or in person, as many maintained contact with pediatric clinic staff or their peers. Those interested in participating provided written informed consent at the clinic, and authorized disclosure and use of health information for study purposes. Consent was obtained by a researcher who had not been involved in the participants' previous care. After providing informed consent, participants completed a computer-assisted (Qualtrics) questionnaire about their transition experiences. Sociodemographic and clinical data were abstracted from patients' medical and social records using an abstraction form, without personal 
identifiers. Sociodemographic information was reviewed and validated by the transition coordinator.

Participants were recruited from September 2013 to February 2014. Data collection was completed on April 30, 2014. Study participants received $\$ 20$ and were reimbursed for travel and parking costs. All participants were offered support from pediatric staff to re-engage in adult medical or social services, if needed and desired.

\section{Measures}

The primary outcome variable was engagement in medical HIV care, defined by the number of kept appointments. Participants' last medical visit at the pediatric clinic was recorded as the transition date. For all participants, the number of kept medical visits as recorded in medical records was abstracted for at least two observation periods: 12 months before the patient's transition date, and 12 months post-transition. Depending on transition date and patient status, we also captured the number of medical visits in the second year in adult HIV care. Research suggested using multiple retention measurements. ${ }^{25}$ We measured engagement in HIV care as: (1) the number of kept visits during a 12-month observation period, and (2) "visit constancy" (proportions of participants attending at least one primary care visit at 3-month [quarterly] intervals in a 12-month [four quarters] observation period). Patients were categorized as having had at least one kept visit with an HIV provider in 4,3,2,1 or 0 quarters. We measured visit constancy, because retaining HIV-infected patients in care at regular intervals results in better health outcomes. ${ }^{26}$ The 3-month interval is based on pediatric clinic practices where patients were scheduled to see their HIV provider quarterly for a routine appointment, ${ }^{22}$ which reduces the risk of exhausting the supply of anti-retrovirals (usually 
prescribed for three months) and facilitates early detection of emergence of resistance. To assess factors associated with frequent care engagement in the first year post-transition, we assigned patients to two groups: regularly engaged (kept at least one medical appointment in each of the 3 or 4 quarters) and not regularly engaged (did not keep at least one appointment in each 3 or 4 quarters).

\section{Transition Program Effectiveness}

To assess the effects of the transition program, we examined if exposure to the comprehensive transition program (transitioned in 2008 or thereafter) and attendance of the pre- and/or post-transition clinic (at least one kept appointment) were associated with regular care engagement in the first year post-transition (at least one kept appointment in three or four quarters). Information about transition clinic attendance was derived from data abstracted from medical records. Participants reported their satisfaction with the transition clinic in a computer-based survey. Systematic records of follow-up contacts with the pediatric transition social worker in the first year post-transition were not kept.

\section{Patient Characteristics}

Collected clinical and sociodemographic information included the most recent information before transition to adult medical care. Study participants' pediatric medical and social records were reviewed to abstract the following information: primary care history (including: transition date, age and CD4 count, viral load); demographic data (including: gender, HIV transmission category, race/ethnicity, educational attainment, household income, housing and employment status, type of health insurance), and psychosocial resources (including: relationship and family status). Mental health and substance use information was incomplete and not included. 


\section{Analysis}

Analysis was performed using Epi Info 3.5.4 (Atlanta, GA, 2012). Univariate statistics (medians, interquartile range [IQR], and mode) were used to describe characteristics of the study population. The Kruskal-Wallis test for two groups, which has no assumption of normality, was used to compare numbers of kept HIV appointments and assess significance of differences between the three observation periods (pre-transition, and one-and two-years post-transition). Outcome variables and covariates were dichotomized for inferential statistical analysis. Significance testing for categorical variables was conducted using the Fisher exact two-tailed test (alpha=0.05). Stratified analysis was conducted to control for confounding. Prevalence ratios (crude and MantelHaenszel adjusted RRs) were calculated to assess the strength of associations; the 95\% confidence interval (CIs) interval was calculated to assess precision of estimates.

\section{RESULTS}

Between January 2003, and September 2012, 51 patients transitioned from the pediatric clinic to adult medical HIV care settings. Of these, nine patients (18\%) were not eligible for study participation because of cognitive impairment (3), incarceration (1), or relocation (5). Nine patients (18\%) were deceased when data collection was completed; five died within one year of care transfer and were not included in this study; four were included. Of the 33 eligible patients who were alive at time of data collection, 27 (82\%) agreed to participate. Reasons for refusal were not ascertained. The total study population consisted of 31 patients (including 27 who agreed to participate and four who died after the first post-transition year). 
All study participants were members of racial or ethnic minority populations, including African-Americans/Haitians (84\%) or Hispanics (16\%) [Table 4.1]. Nearly half lived in extreme poverty, with household incomes equal to or below the federal poverty level. At transition, most participants had completed high school or had passed the General Education Development (GED) test, were employed, and housed. All but one had health insurance, and most relied on public insurance or Ryan White to cover their health care costs. The last available CD4 count at the pediatric clinic showed severe immunosuppression (CD4 count $<200$ cells $/ \mathrm{mm}^{3}$ ) in over one-third of the study population. The median CD4 count was 333 cells/ $\mathrm{mm}^{3}$ (range $7-831$ cells/ $\mathrm{mm}^{3}$ ). Median viral load was 1,613 copies/ml (range 28-238,581 copies/ml).

Most participants had transitioned at age 24; 22 out of $31(71 \%)$ participants transitioned in 2008 or thereafter, when the comprehensive transition program was implemented. Sixteen (52\%) study participants had ever attended the transition clinic; most $(63 \%)$ had attended both the pre-and post-transition clinic. Of 13 attendants alive at the time of data collection, less than half $(47 \%)$ reported they felt the transition clinic had been "very" or "quite" helpful to transition successfully.

The median number of kept HIV, specialty-care, appointments decreased significantly in the first year in adult HIV care (Table 4.2). Participants kept more than twice as many appointments in the last year in pediatric care as in the first year posttransition $($ median $=5$, interquartile range $(I Q R)=4-6$ appointments versus median $=2$, $\mathrm{IQR}=1-10$ appointments; $P=.002)$. The median number of appointments increased in the second year post-transition, but this increase was not significant. Trends were similar for visit constancy (Table 4.3). The proportion of poorly engaged participants significantly 
increased from $3 \%$ in pediatric care to $35 \%$ in the first year post-transition $(P=.006)$, while the proportion of regularly engaged participants significantly decreased from $80 \%$ in pediatric care to $30 \%$ in the first year post-transition $(P<.001)$. No significant changes were observed between the first and second year post-transition.

The likelihood of regular engagement in the first year post-transition did not vary significantly by relationship status, educational achievement, employment status, housing arrangements, type of insurance, or health status (Table 4.4). However, non-Hispanic black participants or those who lived in extreme poverty at transition were considerably less likely to be engaged in regular HIV care ( $P=.04, P=.06$, respectively). These associations were also observed in the last pre-transition year at the pediatric clinic, but there, the differences did not approach statistical significance $(\mathrm{P}=.38 ; \mathrm{P}=.65$, respectively). Participants who transitioned in or after 2008 were only slightly more likely to be regularly engaged in adult health care compared to those who transitioned before 2008 (33\% versus $20.0 \%$, respectively; $P=>.99$ ). Overall, participants who attended the transition clinic were less likely to see their HIV provider regularly one year post-transition. However, participants living in extreme poverty were significantly more likely to have attended the transition clinic (10/12 [83\%) versus 5/14 [36\%]; $\mathrm{RR}=2.3$; $95 \%$ C.I. $=1.1-4.9, P=.04)$. When controlled for household income, the association between transition clinic attendance and less likelihood of regular appointment attendance no longer approached statistically significance (Supplemental Table 4.5).

\section{DISCUSSION}

To our knowledge, this is the first report that compared pre-and post-transition engagement in HIV care in a cohort of transitioned PHIV young adults. Both indicators - 
frequency of kept appointments and visit constancy- showed that engagement deteriorated post-transition. Participants saw their HIV provider significantly less frequently and less regularly in the first year post-transition compared to the last year in pediatric care. Of particular concern was the increase in the proportion of study participants, from 1 out of $30(3 \%)$ in pediatric care to 9 out of $26(35 \%)$ one year posttransition, who dropped out of care altogether or only had seen an adult provider in one quarter. We did not observe any significant improvements in the second year posttransition, which might have suggested that patients needed time to adjust but eventually would learn how to successfully navigate adult HIV care. The first year post-transition seemed crucial to establish care-engagement behavior for the transitioned PHIV young adults in our study. Similarly, a recent health care transition study of patients with behavioral-and perinatally- acquired HIV suggested that retention in adult HIV care in the first year post-transition may be a reliable marker of durable transition success. ${ }^{16}$ Retention studies among diverse US populations of HIV-infected adults also have documented high attrition rates in the first year of enrollment in adult HIV care. ${ }^{27}$ Participants who were African-American or Haitian, or who lived in extreme poverty, were less likely to be frequently engaged in adult HIV care in the first year post-transition compared to Hispanic participants and those with higher incomes, consistent with findings of other US studies. ${ }^{20,28,29}$

This study did not provide evidence for the effectiveness of the pediatric clinic's transition program to ensure a continuous transition. There is some evidence that interventions for other chronically ill youth (primarily youth with diabetes), including attendance at a transition clinic, meeting adult providers pre-transition and educational 
activities, increased appointment attendance and satisfaction. ${ }^{30}$ In our study, economically vulnerable participants were significantly more likely to attend the transition clinic. Identification of patients in highest need for enhanced transition support could be a well-founded policy decision when resources are limited, especially when a comprehensive program available to all is implemented on a systemic level. However, both exposure to the comprehensive program and transition clinic attendance were not associated with greater likelihood of consistent appointment attendance, one year posttransition.

Lack of transition program success may be partially explained by a "type III error": failing to detect program effectiveness because of problems in program design and implementation. ${ }^{31}$ Participant satisfaction among transition clinic attendants was relatively low, and over one-third only had visited the pre-or post-transition clinic. A "dose-response" relationship may have been operating; the transition clinic may have been of more help if attended more frequently. The data, however, suggest that transition clinic attendance was not only unassociated with significant improvement in engagement in care, but was actually associated with somewhat lower engagement in adult care. It, therefore, appears that lack of program success was related to failure to address important determinants of care-engagement behavior on different influential levels. ${ }^{32}$ Engagement in adult HIV medical care results from the complex interplay of factors at individual, social, community (including healthcare system) and policy levels. ${ }^{27} \mathrm{~A}$ mixed-methods study of transition experiences of the same study participants concluded that experiences in adult HIV care were characterized by the often times unmet need for patient-centered care, with convenient, accessible services and a personal, caring relationship with adult 
providers. ${ }^{33}$ Study findings suggested that transition programs should include systemlevel interventions to improve access and delivery of adult services to better facilitate transitioned patients, and recommended the use of a multi-level theory (socio-ecological theory) and a systematic planning model to inform program development, implementation, and evaluation. ${ }^{32}$

Study participants were more frequently and regularly engaged in pediatric than adult HIV care, which seems to support the effectiveness of the pediatric clinic's comprehensive care services to retain patients in care. The comprehensive pediatric HIV care model was developed to address the challenges of meeting the complex medical and psychosocial needs of HIV-infected patients. ${ }^{34}$ Possibly, the comprehensive coordinated primary care and psychosocial pediatric clinic services, the long-standing relationship with pediatric providers, and clinic operations, including easy access, may have compensated for some of the effects of social marginalization, poverty and HIVinfection. ${ }^{35-37}$ As PHIV young adults have complex medical and social needs, co-located and integrated adult medical and social adult services more similar to the pediatric model may be needed to prevent barriers or gaps in service delivery. ${ }^{38}$

Our findings are preliminary; limitations include the small sample size and reduced power to detect statistically significant differences. Because this study was conducted at a single-site among PHIV young adults, findings might not be applicable to other settings and to behaviorally HIV-infected young adults. Our (mediator) outcome measurement was restricted to engagement in HIV care, which is a pre-requisite for HIV care, but may not be always translate to desirable health outcomes, specifically viral suppression. Finally, program evaluation was planned and conducted about five years 
after the comprehensive transition program was implemented. Measurable objectives were not established during planning, and opportunities to systematically monitor program implementation were missed.

Despite these limitations, our study assessed key indicators at one- and two-years post-transition, showing that engagement in care declined post-transition. Poor retention and sub-optimal engagement in adult HIV care is a correctable cause of poor posttransition health outcomes and disparities. Sufficiently funded, sustained, and wellplanned strategies are needed to prepare PHIV adolescents and young adults for transition and keep them engaged in care post-transition. Care-engagement behavior seemed to be established in the first year post-transition, suggesting that this is a critical year for establishing engagement patterns. This study suggests that differences in health care delivery systems in pediatric versus adult HIV services impacts post-transition care, indicating the need for much less fragmented, comprehensive adult care. Given the high risk associated with poor post-transition outcomes, it is essential that promising, wellplanned models be developed, fully implemented, and systematically evaluated to try to approximate in adult HIV care the comprehensive approach seen in pediatric care.

\section{REFERENCES}

1. Kapogiannis BG, Soe MM, Nesheim SR, et al. Mortality trends in the US perinatal AIDS collaborative transmission study (1986-2004). Clin Infect Dis. 2011;53(10):10241034. doi:10.1093/cid/cir641.

2. Agwu AL, Fairlie L. Antiretroviral treatment, management challenges and outcomes in perinatally HIV-infected adolescents. J Int AIDS Soc. 2013;16:18579.

doi:10.7448/ias.16.1.18579.

3. Committee on Pediatric AIDS. Transitioning HIV-infected youth into adult health care. Pediatrics. 2013;132(1):192-197. doi:10.1542/peds.2013-1073. 
4. Mayer KH. Introduction: Linkage, engagement, and retention in HIV care: Essential for optimal individual- and community-level outcomes in the era of highly active antiretroviral therapy. Clin Infect Dis. 2011;52 Suppl 2:S205-7. doi:10.1093/cid/ciq043.

5. Mofenson LM, Cotton MF. The challenges of success: Adolescents with perinatal HIV infection. J Int AIDS Soc. 2013;16:18650. doi:10.7448/ias.16.1.18650.

6. Persson A, Newman C. When HIV-positive children grow up: A critical analysis of the transition literature in developed countries. Qual Health Res. 2012;22(5):656-667. doi:10.1177/1049732311431445.

7. Wilcox RD. Transitioning adolescents to adult care can be challenging. HIV Clin. 2012;24(2):22-23.

8. Dowshen N, D'Angelo L. Health care transition for youth living with HIV/AIDS. Pediatrics. 2011;128(4):762-771. doi:10.1542/peds.2011-0068.

9. Fair CD, Sullivan K, Gatto A. Best practices in transitioning youth with HIV: Perspectives of pediatric and adult infectious disease care providers. Psychol Health Med. 2010;15(5):515-527. doi:10.1080/13548506.2010.493944.

10. Koenig LJ, Nesheim S, Abramowitz S. Adolescents with perinatally acquired HIV: Emerging behavioral and health needs for long-term survivors. Curr Opin Obstet Gynecol. 2011;23(5):321-327. doi:10.1097/gco.0b013e32834a581b.

11. Lotstein DS, Kuo AA, Strickland B, Tait F. The transition to adult health care for youth with special health care needs: Do racial and ethnic disparities exist? Pediatrics. 2010;126 Suppl 3:S129-36. doi:10.1542/peds.2010-1466f.

12. Tsuyuki K, Surratt HL, Levi-Minzi MA, O'Grady CL, Kurtz SP. The demand for antiretroviral drugs in the illicit marketplace: Implications for HIV disease management among vulnerable populations. AIDS Behav. 2014. doi:10.1007/s10461-014-0856-2.

13. Hussen SA, Chahroudi A, Boylan A, Camacho-Gonzalez AF, Hackett S, Chakraborty R. Transition of youth living with HIV from pediatric to adult-oriented healthcare: A review of the literature. Future Virol. 2015;9(10):921-929. doi:10.2217/fvl.14.73.

14. Wiener LS, Kohrt BA, Battles HB, Pao M. The HIV experience: Youth identified barriers for transitioning from pediatric to adult care. J Pediatr Psychol. 2011;36(2):141154. doi:10.1093/jpepsy/jsp129.

15. Valenzuela JM, Buchanan CL, Radcliffe J, et al. Transition to adult services among behaviorally infected adolescents with HIV--a qualitative study. J Pediatr Psychol. 2011;36(2):134-140. doi:10.1093/jpepsy/jsp051. 
16. Ryscavage P, Macharia T, Patel D, Palmeiro R, Tepper V. Linkage to and retention in care following healthcare transition from pediatric to adult HIV care. AIDS Care. 2016;28(5):561-565. doi:10.1080/09540121.2015.1131967.

17. de Mulder M, Yebra G, Navas A, et al. High drug resistance prevalence among vertically HIV-infected patients transferred from pediatric care to adult units in Spain. PLoS One. 2012;7(12):10/1/2014-e52155. doi:10.1371/journal.pone.0052155.

18. Agwu AL, Siberry GK, Ellen J, et al. Predictors of highly active antiretroviral therapy utilization for behaviorally HIV-1-infected youth: Impact of adult versus pediatric clinical care site. J Adolesc Health. 2012;50(5):471-477.

doi:10.1016/j.jadohealth.2011.09.001.

19. Ryscavage P, Anderson EJ, Sutton SH, Reddy S, Taiwo B. Clinical outcomes of adolescents and young adults in adult HIV care. J Acquir Immune Defic Syndr. 2011;58(2):193-197. doi:/10.1097/qai.0b013e31822d7564.

20. Doshi RK, Milberg J, Isenberg D, et al. High rates of retention and viral suppression in the US HIV safety net system: HIV care continuum in the Ryan White HIV/AIDS program, 2011. Clin Infect Dis. 2015;60(1):117-125. doi:10.1093/cid/ciu722.

21. Agwu AL, Lee L, Fleishman JA, et al. Aging and loss to follow-up among youth living with human immunodeficiency virus in the HIV research network. J Adolesc Health. 2015;56(3):345-351. doi:10.1016/j.jadohealth.2014.11.009.

22. Panel on Antiretroviral Guidelines for Adults and Adolescents. Department of Health and Human Services. Guidelines for the use of antiretroviral agents in HIV-1-infected adults and adolescents. http://aidsinfo.nih.gov/guidelines. Updated May 1, 2014. Accessed August 26, 2014.

23. Crowley R, Wolfe I, Lock K, McKee M. Improving the transition between paediatric and adult healthcare: A systematic review. Arch Dis Child. 2011;96(6):548-553. doi:10.1136/adc.2010.202473.

24. Maturo D, Powell A, Major-Wilson H, Sanchez K, De Santis JP, Friedman LB. Development of a protocol for transitioning adolescents with HIV infection to adult care. J Pediatr Health Care. 2011;25(1):16-23. doi:10.1016/j.pedhc.2009.12.005.

25. Mugavero MJ, Westfall AO, Zinski A, et al. Measuring retention in HIV care: The elusive gold standard. J Acquir Immune Defic Syndr. 2012;61(5):574-580. doi:10.1097/qai.0b013e318273762f.

26. Horstmann E, Brown J, Islam F, Buck J, Agins BD. Retaining HIV-infected patients in care: Where are we? Where do we go from here? Clin Infect Dis. 2010;50(5):752-761. doi:10.1086/649933. 
27. Mugavero MJ, Norton WE, Saag MS. Health care system and policy factors influencing engagement in HIV medical care: Piecing together the fragments of a fractured health care delivery system. Clin Infect Dis. 2011;52 Suppl 2:S238-46. doi:10.1093/cid/ciq048.

28. Israelski D, Gore-Felton C, Power R, Wood MJ, Koopman C. Sociodemographic characteristics associated with medical appointment adherence among HIV-seropositive patients seeking treatment in a county outpatient facility. Prev Med. 2001;33(5):470-475. doi:10.1006/pmed.2001.0917.

29. Catz SL, McClure JB, Jones GN, Brantley PJ. Predictors of outpatient medical appointment attendance among persons with HIV. AIDS Care. 1999;11(3):361-373. doi:10.1080/09540129947983.

30. Davis A, M., Brown R, F., Lounds Taylor J, Epstein R, A., McPheeters M, L. Transition care for children with special health care needs. Pediatrics. 2014;134(5):900908. doi:10.1542/peds.2014-1909d.

31. Green J. The role of theory in evidence-based health promotion practice. Health Education Research. 2000;15(2):125-129. doi:10.1093/her/15.2.125.

32. Bartholomew LK, Parcel GS, Kok G, Gottleib NH, Fernandez ME. Planning health promotion programs: An intervention mapping approach. 3rd ed. San Francisco, CA: Jossey-Bass; 2011.

33. Biersteker S. Outcomes of transition to adult HIV care in perinatally HIV-infected young adults. [dissertation]. Miami, Florida International University; 2016.

34. Saag MS. Editorial commentary: Fixing a hole in the HIV safety net. Clin Infect Dis. 2015;60(1):126-127. doi:10.1093/cid/ciu729.

35. Richter LM, Sherr L, Adato M, et al. Strengthening families to support children affected by HIV and AIDS. AIDS Care. 2009;21 Suppl 1:3-12. doi:10.1080/09540120902923121.

36. Cheever LW. Engaging HIV-infected patients in care: Their lives depend on it. Clin Infect Dis. 2007;44(11):1500-1502. doi:10.1086/517534.

37. Cervia JS. Transitioning HIV-infected children to adult care. J Pediatr. 2007;150(1):e1. doi:10.1016/j.jpeds.2006.09.025.

38. Gallant JE, Adimora AA, Carmichael JK, et al. Essential components of effective HIV care: A policy paper of the HIV Medicine Association of the Infectious Diseases Society of America and the Ryan White Medical Providers Coalition. Clin Infect Dis. 2011;53(11):1043-1050. doi:10.1093/cid/cir689. 
Table 4.1. Study population: Sociodemographic and clinical characteristics at time of transition to adult HIV care $(N=31)$

\begin{tabular}{|c|c|}
\hline Characteristic & $N(\%)$ \\
\hline Male gender & $15(48)$ \\
\hline $\begin{array}{l}\text { Race/Ethnicity } \\
\text { African American } \\
\text { Haitian } \\
\text { Hispanic }\end{array}$ & $\begin{array}{c}14(45) \\
12(39) \\
5(16)\end{array}$ \\
\hline $\begin{array}{l}\text { HIV-1 acquisition } \\
\text { Mother-to-child } \\
\text { Blood products } \\
\text { Sexual (abuse) }\end{array}$ & $\begin{array}{cl}29 & (94) \\
1 & (3) \\
1 & (3)\end{array}$ \\
\hline Married/in relationship & $14(45)$ \\
\hline Completed high school/General Education Development test (GED) & $27(87)$ \\
\hline Employed (full or part-time) & $20(65)$ \\
\hline $\begin{array}{l}\text { Household income } \\
\text { Equal or below Federal Poverty Level (FPL) } \\
101-200 \% \text { of FPL } \\
201-300 \% \text { of FPL } \\
301-400 \% \text { of FPL }\end{array}$ & $\begin{array}{l}15(48) \\
9(29) \\
5(16) \\
2(7)\end{array}$ \\
\hline $\begin{array}{l}\text { Housing } \\
\text { Unstable, moved around } \\
\text { With (extended) family } \\
\text { Own or shared }\end{array}$ & $\begin{array}{c}1(3) \\
14(45) \\
16(52) \\
\end{array}$ \\
\hline $\begin{array}{l}\text { Health Insurance } \\
\text { Medicaid } \\
\text { Ryan White } \\
\text { Medicare } \\
\text { Private } \\
\text { No insurance }\end{array}$ & $\begin{array}{l}20(65) \\
7(23) \\
1(3) \\
2(7) \\
1(3)\end{array}$ \\
\hline $\begin{array}{l}\text { CD4 T-cell count }\left(\text { cells } / \mathrm{mm}^{3}\right) \\
\quad<200 \\
\quad 200-499 \\
\geq 500\end{array}$ & $\begin{array}{r}12(39) \\
8(26) \\
11(36)\end{array}$ \\
\hline $\begin{array}{l}\text { Viral load (copies per ml) } \\
\quad<40 \\
\quad 40-1000 \\
\geq 1000\end{array}$ & $\begin{array}{l}1 \quad(3) \\
14(45) \\
16(52)\end{array}$ \\
\hline $\begin{array}{l}\text { Age (years) at transition } \\
\text { Mean (SD) } \\
\text { Median } \\
\text { Mode }\end{array}$ & $\begin{array}{l}23 \text { (SD 1.7) } \\
24(18-26) \\
24\end{array}$ \\
\hline $\begin{array}{l}\text { Transitioned after 1/1/08 (exposed to comprehensive transition } \\
\text { program) }\end{array}$ & $22(71)$ \\
\hline Attended transition clinic & $16(52)$ \\
\hline
\end{tabular}


Table 4.2. Number of kept HIV appointments:

pre-transition, one- and two years post-transition

\begin{tabular}{|l|c|c|c|c|}
\hline Period & $\mathbf{N}$ & $\begin{array}{c}\text { Median Number } \\
\text { of Scheduled } \\
\text { Appointments Kept } \\
\text { (Interquartile Range) }\end{array}$ & $\begin{array}{c}\text { Median } \\
\text { Difference } \\
\text { (Interquartile } \\
\text { Range) }\end{array}$ & $\boldsymbol{P}^{\mathbf{3}}$ \\
\hline Pre-transition (Pediatrics) & $25^{1}$ & $5.0(4.0-6.0)$ & 3.0 & .002 \\
One Year Post-Transition & & $2.0(1.0-10.0)$ & $(0-4.0)$ & .78 \\
\hline One Year Post-Transition & $20^{2}$ & $2.0(1.0-4.0)$ & 1.0 & $(-1.0-1.0)$ \\
Two Years Post-Transition & & $3.0(1.0-4.0)$ & & \\
\hline
\end{tabular}

${ }^{1}$ Thirty medical records were obtained from pediatric and 26 from adult clinics with information on visits during the first post-transition year; records from 25 patients were obtained for both pediatric and adult clinics.

${ }^{2}$ Of the 25 adult clinic medical records with information from the first post-transition year, three belonged to patients who transferred less than two years post-transition, and one patient died. Matched records were available for 20 participants.

${ }^{3}$ From Kruskal Wallis test for two groups

\section{Table 4.3. Visit constancy (at least one quarterly kept appointment): pre-transition, one- and two years post-transition}

\begin{tabular}{|l|l|l|l|c|c|}
\hline $\begin{array}{l}\text { Number of } \\
\text { quarters in which } \\
\text { participant kept } \\
\text { at least one } \\
\text { appointment }\end{array}$ & $\begin{array}{l}\text { Last year in } \\
\text { Pediatric } \\
\text { clinic } \\
\mathbf{n = 3 0}\end{array}$ & $\begin{array}{c}\text { First } \\
\text { year } \\
\text { post- } \\
\text { transition } \\
\mathbf{n = 2 6}\end{array}$ & p-value* & $\begin{array}{c}\text { Second year } \\
\text { post-transition } \\
\mathbf{n = 2 1}\end{array}$ & p-value $\dagger$ \\
\hline 0 or 1 quarter & $1(3)$ & $9(35)$ & .006 & $8(38)$ & $>.99$ \\
\hline 2 quarters & $5(17)$ & $9(35)$ & .21 & $5(24)$ & .63 \\
\hline 3 or 4 quarters & $24(80)$ & $8(30)$ & $<.001$ & $8(38)$ & .83 \\
\hline Total & $100 \%$ & $100 \%$ & & $100 \%$ & \\
\hline
\end{tabular}

*Fisher exact two-tailed p-value, comparing last year in pediatrics to first year post-transition

${ }^{\dagger}$ Fisher exact two-tailed p-value, comparing first year post-transition to second year post-transition 


\section{Table 4.4. Factors associated with regular engagement in adult HIV care, $1^{\text {st }}$ year post-transition $(n=26)^{1}$}

\begin{tabular}{|c|c|c|c|}
\hline Characteristic at time of transition & $\mathbf{n}$ & $\begin{array}{l}\text { Regular: } \geq 1 \text { kept } \\
\text { appointment in } 3 \\
\text { or } 4 \text { quarters } \mathrm{n}(\%)\end{array}$ & $P$-value ${ }^{2}$ \\
\hline $\begin{array}{l}\text { Male } \\
\text { yes } \\
\text { no }\end{array}$ & $\begin{array}{l}14 \\
12\end{array}$ & $\begin{array}{l}2(14) \\
6(50)\end{array}$ & .12 \\
\hline $\begin{array}{l}\text { Non-Hispanic black } \\
\text { yes } \\
\text { no }\end{array}$ & $\begin{array}{l}21 \\
5\end{array}$ & $\begin{array}{l}4(19) \\
4(80)\end{array}$ & .04 \\
\hline $\begin{array}{l}\text { Married/in relationship } \\
\text { yes } \\
\text { no }\end{array}$ & $\begin{array}{l}14 \\
12\end{array}$ & $\begin{array}{l}6(43) \\
2(17)\end{array}$ & .31 \\
\hline $\begin{array}{l}\text { Completed high school/GED } \\
\text { yes } \\
\text { no }\end{array}$ & $\begin{array}{l}4 \\
22\end{array}$ & $\begin{array}{l}1(25) \\
7(32)\end{array}$ & $>.99$ \\
\hline $\begin{array}{l}\text { Employed } \\
\text { yes } \\
\text { no }\end{array}$ & $\begin{array}{l}16 \\
10\end{array}$ & $\begin{array}{l}6(38) \\
2(20)\end{array}$ & .62 \\
\hline $\begin{array}{l}\text { Household income below FPL } \\
\text { yes } \\
\text { no }\end{array}$ & $\begin{array}{l}12 \\
14\end{array}$ & $\begin{array}{l}1(8) \\
7(50)\end{array}$ & .06 \\
\hline $\begin{array}{l}\text { Lived with extended family } \\
\text { yes } \\
\text { no }\end{array}$ & $\begin{array}{l}10 \\
16 \\
\end{array}$ & $\begin{array}{l}4(40) \\
4(25)\end{array}$ & .70 \\
\hline $\begin{array}{l}\text { Medicaid insured } \\
\text { yes } \\
\text { no }\end{array}$ & $\begin{array}{l}18 \\
8\end{array}$ & $\begin{array}{l}7(39) \\
1(13)\end{array}$ & .38 \\
\hline $\begin{array}{l}\text { CD4 T-cell count <200 }\left(\text { cells } / \mathrm{mm}^{3}\right) \\
\text { yes } \\
\text { no }\end{array}$ & $\begin{array}{l}9 \\
17\end{array}$ & $\begin{array}{l}2(22) \\
6(35)\end{array}$ & .83 \\
\hline $\begin{array}{l}\text { Viral load } \\
\geq 1000 \text { copies } / \mathrm{ml} \\
<1000 \text { copies } / \mathrm{ml}\end{array}$ & $\begin{array}{l}14 \\
12\end{array}$ & $\begin{array}{l}2(14) \\
6(50)\end{array}$ & .12 \\
\hline $\begin{array}{l}\text { Transitioned after } 1 / 1 / 2008 \\
\text { yes } \\
\text { No }\end{array}$ & $\begin{array}{l}21 \\
5\end{array}$ & $\begin{array}{l}7(33) \\
1(20)\end{array}$ & $>.99$ \\
\hline $\begin{array}{l}\text { Attended transition clinic } \\
\text { yes } \\
\text { no }\end{array}$ & $\begin{array}{l}15 \\
11\end{array}$ & $\begin{array}{l}2(13) \\
6(55)\end{array}$ & .07 \\
\hline
\end{tabular}

${ }^{1}$ Of participants, we were able to locate 26 medical records one-year post-transition

${ }^{2}$ Fishers exact two tailed test $(\mathrm{P}=.05)$ 
Supplemental Table 4.5. Association of transition clinic attendance with regular engagement in care in $1^{\text {st }}$ year post-transition, controlled for poverty.

Living in Poverty (household income $\leq$ Federal Poverty Level)

\begin{tabular}{|l|c|c|c|}
\hline $\begin{array}{l}\text { Characteristic at Time of } \\
\text { Transition }\end{array}$ & $\mathbf{n}$ & $\begin{array}{c}\text { Frequent: } \geq \mathbf{1} \text { kept } \\
\text { appointment in } \mathbf{3} \text { or } \mathbf{4} \\
\text { quarters } \mathbf{~ ( \% )}\end{array}$ & P-value $^{\mathbf{1}}$ \\
\hline $\begin{array}{l}\text { Attended transition clinic } \\
\text { Yes } \\
\text { No }\end{array}$ & $\begin{array}{c}10 \\
2\end{array}$ & $\begin{array}{c}1(10) \\
0\end{array}$ & $>.99$ \\
\hline
\end{tabular}

Not living in Poverty (household income > Federal Poverty Level)

\begin{tabular}{|c|c|c|c|}
\hline $\begin{array}{l}\text { Characteristic at Time of } \\
\text { Transition }\end{array}$ & $\mathbf{n}$ & $\begin{array}{c}\text { Frequent: } \geq 1 \text { kept } \\
\text { appointment in } 3 \text { or } 4 \\
\text { quarters } n(\%)\end{array}$ & P-value ${ }^{1}$ \\
\hline $\begin{array}{l}\text { Attended transition clinic } \\
\text { Yes } \\
\text { No }\end{array}$ & $\begin{array}{l}5 \\
9\end{array}$ & $\begin{array}{ll}1 & (20) \\
6 & (67)\end{array}$ & .27 \\
\hline $\begin{array}{l}\text { Crude Prevalence Ratio } \\
\text { Adjusted Prevalence Ratio }\end{array}$ & & $\begin{array}{l}95 \% \text { C.I. }) \\
(.06-.99) \\
(.07-2.1)\end{array}$ & $\begin{array}{l}\mathrm{P} \\
.07 \\
.39\end{array}$ \\
\hline
\end{tabular}

${ }^{1}$ Fisher exact two tailed test $(\mathrm{p}=.05)$ 


\section{CHAPTER V. THIRD MANUSCRIPT}

"Now we are adults they do not care anymore:" Mixed-methods study of experiences of transitioned young adults with perinatally acquired HIV infection in adult care

Susan Biersteker ${ }^{1}$, Joseph P. De Santis $^{2}$, Ana Garcia ${ }^{3}$, Barbara Messick ${ }^{4}$,

${ }^{1}$ Department of Health Promotion and Disease Prevention, Robert Stempel College of Public Health \& Social Work, Florida International University, Miami, Florida, USA.

${ }^{2}$ School of Nursing \& Health Studies, University of Miami, Coral Gables, Florida, USA.

${ }^{3}$ Department of Pediatrics, Division of Infectious Diseases \& Immunology, University of Miami Miller School of Medicine Miami, Florida, USA.

${ }^{4}$ Department of Obstetrics and Gynecology, Division of Research and Special Projects, University of Miami Miller School of Medicine, Miami, Florida, USA.

Corresponding author: Susan Biersteker, Robert Stempel College of Public Health \& Social Work, Department of Health Prevention and Disease Prevention, Florida International University, 11200 SW 8th Street, AHC5 505, Miami, Fl. 33199, telephone: 305-494-8415, fax: 305-348-4901, email: sbier002@fiu.edu

Running head: Post-transition experiences of young adults with perinatally acquired HIV-infection Acknowledgments: This study was supported with a one-time supplemental grant from the US Health Resources and Services Administration HIV/AIDS Bureau to evaluate an adolescent transition model of care. The content of this article is solely the responsibility of the authors. 


\begin{abstract}
We conducted a mixed-methods study of perinatally HIV-infected young adults 25-34 years of age, who had transitioned from a pediatric clinic in Florida to adult settings. Participants completed a computer-assisted survey about pre- and post-transition experiences, satisfaction with transition program activities, demographics, and health status. Information was supplemented with debriefing notes and medical record abstraction. Data of 27 participants were analyzed using quantitative and qualitative (thematic analysis) methods. While most of 27 study participants had received transition services, $16(59 \%)$ had trouble "doing well” in adult HIV care, nine (33\%) had not seen an HIV provider in the past six months, eight (30\%) felt they were currently in poor health, and $13(48 \%)$ reported numerous unmet service needs in the past year. Transition was experienced as a loss of emotional and practical support. Needs for convenient, accessible adult HIV services and a personal, caring, relationships with adult providers characterized post-transition experiences. Programs should transcend individual-level interventions to prepare patients for transition, and include interpersonal (expand social networks and mutual support) and system-level interventions (improve access to and delivery of quality adult services) to facilitate transitioned patients.
\end{abstract}

Key words: health care transition, HIV, perinatally HIV-infected, transition programs

\title{
INTRODUCTION
}

Combination antiretroviral therapies transformed HIV infection from a progressive, fatal disease to a manageable chronic condition. ${ }^{1}$ As the prognosis for HIV infection greatly improved, most perinatally HIV-infected (PHIV) children who were not expected to survive, are now adolescents or young adults. ${ }^{2}$ These long-term survivors 
continue to be pioneers as they "age out" of pediatric or adolescent services and transition to adult HIV-care settings.

A smooth transition between these fundamentally different systems of care delivery is critical to achieving continued beneficial health outcomes, and purposeful transition is considered to be a key component in continuing care. ${ }^{3}$ However, as is the case with other chronic diseases, the development of theory-based transition programs has not kept up with medical advances which have increased survival. ${ }^{4}$ The growing body of transition literature for youth with chronic diseases has only just begun to describe youth with HIV-infection. ${ }^{5}$ Despite strong agreement for the importance of a purposeful, planned transition, limited data and little consensus exists as to which transition services are needed and which strategies are most effective. ${ }^{6,7}$

Successful transition programs should be based on the young adult's needs. ${ }^{4}$ Transition expectations and concerns of HIV-infected adolescents and young adults, their caregivers, and providers have been the subject of several prospective qualitative studies. ${ }^{8-10}$ Although these studies provide critical insights, a full understanding of the issues and program implications must include the experiences of transitioned young adults, as patients who still receive pediatric care may have a limited understanding of upcoming challenges and expectations. ${ }^{4}$

Earlier, Wiener and colleagues ${ }^{11}$ reported on the experiences of youth with HIV infection, most perinatally acquired, who transitioned from a large pediatric treatment and research facility to adult HIV care in 23 different states and the District of Columbia. This first study to report transition experiences and outcomes of PHIV young adults elucidated concerns about the complexity of transition and potentially adverse health 
consequences of unsuccessful transition and interrupted HIV care, and reiterated the need for adequate transition preparation. Because transition experiences and outcomes are impacted by the health system and social context, ${ }^{12}$ we conducted a study of PHIV young adults who transitioned from a pediatric HIV clinic and then, for the most part, continued to obtain adult care in the same community. This study is a part of a larger research project to assess post-transition mortality and engagement in adult HIV care in PHIV young adults, and was conducted to assist in the interpretation of the quantitative findings of these studies and to formulate program recommendations based on transitioned participants experiences and needs. ${ }^{13}$ Our purpose was to describe exposure to and satisfaction with the transition program, pre- and post-transition experiences, and program recommendations in order to contribute to the development of effective, theorybased transition programs.

\section{Context}

This study was conducted in Florida, a southern US state with a very high HIV/AIDS burden. ${ }^{14}$ Access to adult HIV care and services may pose difficulties as many of our patients are covered under public health insurance programs (e.g. Medicaid) which exposes them to gaps in insurance coverage. ${ }^{15}$ Patients are eligible for Medicaid insurance until age 18, after which they may no longer qualify or may experience lapses in coverage. Due to the Florida gubernatorial decision not to implement Medicaid expansion, many low-income adults continue to have limited options for health coverage, even after the implementation of the 2010 Affordable Care Act. ${ }^{16}$ Medicaid enrollment and reimbursement in Florida is lower than the national average ${ }^{17}$ and falls short in supporting comprehensive HIV care. ${ }^{18}$ Ryan White programs for uninsured or 
underinsured patients are inadequately funded to address the needs of the increasing number of patients with HIV-infection who have complex medical and social needs. ${ }^{19}$ Consequently, the safety net of clinics and hospitals that serves the underinsured population in Florida has been stretched in recent years.

All study participants had transitioned from a university-based pediatric HIV clinic in Miami-Dade County, Florida; a county with the highest poverty rates in Florida and with the highest HIV prevalence in the US. ${ }^{14,20}$ The pediatric clinic provides multidisciplinary, family-centered healthcare services to low-income and underserved children, adolescents and young adults up to age 24 who acquired HIV early in life, nearly all through vertical transmission. Comprehensive transition services were funded and implemented in 2008. The transition programs aims to prepare and support patients to independently navigate adult HIV services. Available services include program components to: (1) prepare patients for independent living (including: educational and psycho-social support, assistance to access housing and employment services, financial assistance and medical insurance); (2) address the lack of continuity between pediatric and adult HIV care (including: discussion of a transition plan, provision of linkage to adult services, and a transition clinic to temporarily bridge pediatric and adult care), and (3) increase patients' self-management skills (including "life skills" training, support groups, and one year post-transition follow-up by a transition social worker to teach patients to solve problems encountered in adult HIV care). In the "transition clinic" 21,22 patients could be seen by an adult provider in the pediatric clinic one year pre-transition. In the first year post-transition, transitioned patients could schedule appointments with the now familiar adult provider at the academic center's adult HIV clinic, who allots 
more than the traditional 15-minutes for a routine medical visit. In the second year posttransition, no transition services were provided.

In a small study previously conducted at the pediatric clinic, patients and their families expressed concerns about transitioning to the nearby adult immunology clinic, because of its size, higher caseloads of adult physicians, and fewer available services. ${ }^{8}$ The university-based adult HIV clinic is located at the county's public hospital through a contract with the medical school. The clinic serves approximately 2,800 HIV-infected patients, and funding for supportive or ancillary services is limited. Consequently, young adults who transitioned may not receive the education and support they were accustomed to in the pediatric clinic, including: follow-up in case of missed appointments; counseling and home delivery services to support medication adherence; mental health services; assistance with housing, transportation and completion of insurance paper work, and other supportive services.

\section{METHODS}

\section{Participants and Recruitment}

Permission for this study was granted by the Human Subjects Committee of the Institutional Review Board of appropriate institutions. Former patients were eligible for participation if they had transitioned from the pediatric HIV clinic to adult care settings between January 2003 and September 2012. Exclusion criteria were: (1) substantial cognitive disability, as formerly established by staff psychologists at the pediatric clinic; (2) incarceration, or (3) relocation.

Because experiences of patients who successfully transitioned may differ from those who did not, ${ }^{5}$ we used several recruitment methods to maximize enrollment. 
Eligible patients were contacted by the pediatric program coordinator to introduce the study. If up-to-date contact information was unavailable, we asked study participants to inform their peers about the study. If interested, the study lead author, who did not have any prior involvement with potential study participants, followed up to provide additional study information and set up an appointment to review and obtain informed consent and participants' permission to abstract de-identified information from medical and social records. Study recruitment began in September 2013 and was completed in February 2014. Study participants received $\$ 20$ in cash and reimbursement for travel and parking costs, and were offered support from pediatric staff to access adult medical or social services, if needed and desired.

\section{Study Design and Data Collection}

This study used both quantitative and qualitative research methods to capitalize on the strengths of a mixed methods approach. ${ }^{23}$ Study participants completed a computer-assisted survey (Qualtrics), with open-ended and close-ended questions, supplemented with demographic and clinical information, obtained from patient's medical records using a standardized abstraction form. The survey was conducted on-site at the pediatric clinic.

Demographic information, including age, gender, race/ethnicity, educational level, household income below or above poverty level [ $\$ 24,250$ for a four-person household in 2015], ${ }^{24}$ and transition date were abstracted from participant's pediatric records. To assess current circumstances, we asked participants to answer questions about housing, family, and (any) employment, as well as gaps in medical insurance in the past 12 months. A measure of food insecurity, "In the past year, were you ever worried whether 
food would run out before you got money to buy more?" was used as a proxy measure of current poverty. ${ }^{25}$ Data to assess engagement in adult HIV care were abstracted from the adult medical record. Based on current HIV/AIDS performance measures, the expectation for medical HIV care was at least one kept medical visit in the past 6 months. ${ }^{26}$

Questions to describe transition experiences and recommendations for future programs were based on a semi-structured telephone transition questionnaire, developed by Wiener and colleagues. ${ }^{11}$ Because this study used a computer-assisted survey to collect study data, we could ask additional, detailed, questions about transition preparation, experiences in adult HIV care, and unmet service needs. We asked both quantitative (Likert scale) and qualitative questions (e.g. "could you please explain why") to examine how well participants felt prepared for transition, and to assess exposure to and satisfaction with the pediatrics clinics transition program activities. This included discussion of their transition plan, attendance at support groups and transition clinic, and personal and clinical support received. We also asked participants to rate and explain how easy or difficult it was for them "to doing well" in adult HIV care. Additionally, we assessed usage and unmet needs of supportive and additional medical services in the past 12 months, including use of a Ryan White case manager, help with emotional and financial problems, housing, employment or education, child care services, as well as usage and needs for specialty services, including gynecology, dental and nutrition. Debriefing after survey completion was offered to allow participants to further elaborate on their answers. Participant quotes were written down verbatim and debriefing notes were recorded in writing immediately after debriefing. 


\section{Analysis}

Quantitative analysis, conducted with SPSS 21, included univariate analysis to present descriptive information, followed by bivariate analyses. Covariates were dichotomized for inferential statistical analysis. Fisher's exact two-tail test (alpha< 0.10$)$ was used to determine whether differences in categorical variables with few observations were statistically significant.

Qualitative information was systematically analyzed using the thematic analysis method; an iterative process followed to remain true to participant's description while developing more abstract concepts in various stages of data analysis. ${ }^{27}$ Analysis was conducted manually, and included the following steps: familiarization with data and repeatedly reading texts, generating of initial codes, grouping of codes by various themes, and refinement and consideration of the meaning within and across themes. Initial coding was conducted by two researchers; in the final, exploratory phase, the analysis was discussed with a third researcher to explore associations between core concepts and themes, established literature, and theoretical perspectives related to transition experiences of PHIV young adults.

\section{Data Validation Strategies}

Pre-testing, informal respondent validation, and peer review were used to ensure adequacy and plausibility of the qualitative data. First, the survey instrument was pretested with six clinic patients who would transition within one year. Based on their recommendations, we revised questions which were unclear and added open-ended questions to provide participants more opportunities to "tell their stories." Second, after survey completion, we asked participants if any questions were unclear and if they 
wished to clarify or elaborate, in order to enable them to correct potential misunderstandings and add information they believed was important. Hand- recorded verbatim quotes were validated with the participant. Third, to minimize pre-conceived notions and potentially expand alternative explanations, we conducted multiple coding by two different researchers. Both researchers had HIV-related research experience, but not with PHIV adolescents or young adults. To further minimize researcher bias, a third researcher, who had former clinical and research experience with PHIV adolescents and young adults but had not been involved in the study design or data collection, reviewed the analytic framework and data interpretation.

\section{RESULTS}

Between January 2003 and September 2012, 51 patients transferred from the pediatric clinic to an adult medical HIV-care setting. Of these, nine patients (18\%) had died when data collection was completed, and nine more (18\%) were ineligible for study participation because of cognitive impairments $(n=3)$; incarceration $(n=1)$, or relocation $(n=5)$. Of the 33 eligible patients, one patient was lost to follow-up; five patients refused or did not return phone calls, and 27 (82\%) agreed to participate. Reasons for nonparticipation were not ascertained.

\section{Quantitative data}

At time of study enrollment, participants were between 25-34 years of age (Mean=27 years); most had transitioned from the pediatric clinic to adult HIV care at 24 years of age (Table 5.1). All participants were members of a racial or ethnic minority group, primarily African-American, most had completed high school or GED requirements, were currently housed, and had some type of employment. Fourteen out of 
$27(52 \%)$ currently lived independently from their families or caregivers, were in a steady relationship, and had dependent children. At the time of study participation, $12(44 \%)$ had experienced food insecurity in the past 12 months. About one-third of participants recounted a gap in their medical insurance coverage, had not kept an appointment with their adult HIV provider in the past 6 months, and felt they currently were in poor health. Participants who had not seen an HIV provider in the last 6 months, were more likely to assess their health as "poor" (5/8 [63\%] versus 4/19 [21\%] in "good" or "excellent" health; $P=.07)$, and to report gaps in health insurance coverage in the past 12 months $(5 / 8$ [63\%] versus $4 / 18[22 \%]$ no gaps in health insurance coverage; $P=.08)$.

Participants' transition experiences were mixed. Fifteen out of 27 (56\%) participants remembered that transition was "easy" or "very easy," although $11(41 \%)$ reported that transition had been more difficult than expected. Most participants (23 out of 27) recalled that someone had discussed a transition plan with them. Participants reported that medical providers and pediatric clinic staff were most helpful in preparing them for transition, compared to family members and peers (Table 5.2). Appreciation of transition clinic attendance was rated relatively low compared to participation in support groups: $8 / 17$ [47\%] versus $6 / 8$ [75\%] of participants rated the intervention as "helpful," respectively.

Overall, 6 out of 10 participants reported it had been difficult for them to do well in adult HIV care, and many had problems post-transition (Table 5.3). Almost half of participants (14 out of 27) experienced a multitude (three to seven) of unmet needs for supportive and ancillary medical services in the past 12 months. Most frequently mentioned unmet needs were: support with finances, employment and education, and 
dental and nutritional services. Participants who reported a multitude of unmet needs were more likely to have not completed high school/GED requirements $(3 / 3[100 \%]$ noncompletion versus 10/24 [42\%] completion; $\mathrm{P}=.10$ ), and to report a gap in health insurance coverage in the past 12 months (6/8 [75\%] versus 6/18 [33\%] no gap in health insurance; $\mathrm{P}=.09)$.

After transition, 19 participants had stayed in contact with the pediatric clinic. Of the eight participants who did not, six thought they should have remained in contact. Only two participants reported they had not needed any help from pediatric staff posttransition.

\section{Qualitative data}

We identified themes in the following major categories: (1) transition experiences, (2) experiences in adult HIV care, and (3) recommendations for transition programs.

\section{Transition experiences}

The overarching theme was "loss;" as represented in three sub-themes: (1) loss of long-term, close relationships with pediatric staff; (2) loss of "quality" services, and (3) loss of familiar, known, care. As previously noted, transition experiences were mixed. However, none of the participants described benefits associated with transition to adult HIV care.

Loss of close relationships with the pediatric team

When participants were asked to explain why transition was difficult or easy for them, many referred to the long-term, close relationships they had with their pediatric team, which transcended professional, patient-physician relationships. As one participant 
described, "You [are] practically raised here. They have become like family to you" (Hispanic male, transitioned 8 years ago). Similarly, another participant replied : "I was very comfortable in the pediatrics because the doctor basically raised me from when I was a little girl and they was the only doctor I know that was there every step of the way" (African-American female, transitioned 2 years ago). Several participants referred to strong emotional bonds with pediatric staff. One participant wrote: "I was very attached to everyone, like the other patients, the doctors, the social workers and everyone else who was part of the team" (African-American female, transitioned 10 years ago), while another simply stated "I love it there" (African-American male, transitioned 1 year ago). Transition had been difficult not only because it was "difficult to let go of family" (Hispanic male, transitioned 8 years ago), but also because it would be difficult "finding people that care the way peds [pediatric clinic] treats you. I do not have any family except for him [his son]. I found some type of family here" (African-American male, transitioned 3 years ago). Another participant wrote: "Now I'm basically alone but I guess I am getting older" (Haitian male, transitioned 1 year ago). The importance of personal support was also expressed by a participant who felt transition was easy, "Because of the support system I had with my family" (Hispanic female, transitioned 1 year ago).

Loss of "quality" services

In addition, participants referred to the loss of easy accessible services and tangible support of the pediatric team to explain difficulties with transitioning. One participant briefly stated: "Pediatrics provided the best service" (African-American female, transitioned 3 years ago), while another remarked: "I was used to getting VIP 
treatment and everything was handed to me, but now things have changed a lot" (Haitian male, transitioned 1 year ago). Differences in required autonomy between pediatric and adult HIV care were also recognized by others. For example, one participant explained difficulties with transition as follows: "They (Pediatric staff) are here for you. They help us a lot more" (African American male, transitioned 1 year ago), while another participant wrote: "Everything was much more simple and easier for me" (AfricanAmerican female, transitioned 10 years ago).

Loss of familiar care.

While a few participants reported that transition had been easy because they already had met the adult HIV provider or were receiving adult (specialty) care services, others reported that transition was difficult because they were unsure of what to expect. For example, one participant wrote: "It was difficult to imagine what it would be like somewhere else and how their services would be compared the one received since pediatric care" (Hispanic female, transitioned 1 year ago). More specific concerns were expressed by others. While one participant was worried about the adult clinic environment "I was not ready for that world and how other people got the disease" (Haitian female, transitioned 8 years ago), others recalled concerns regarding the quality of the relationship with their adult provider. For example, one participant wrote: "Will the doctor listen to me was a major concern as well" (African-American female, transitioned 3 years ago). Another said: "I had to get used to someone which is very hard to me because I have to trust someone with my information" (African-American female, transitioned 4 years ago). 
In contrast, some participants may have engaged in avoidance coping and reported they had not believed that adult HIV care would be different. As one participant explained in the de-briefing: "They [pediatric staff] tell you that you will be on your own but you do not really listen" (African-American male, transitioned 2 years ago).

Similarly, another participant said: "I did not take it too seriously. I really did not think it would be so different. I figured it would be much easier than they told me. Until it hits you... I was not coping too much. It's like going from high school to college" (AfricanAmerican male, transitioned 3 years ago).

\section{Experiences in adult HIV care}

As noted previously, six out of 10 participants felt it was difficult for them to do well in adult HIV care. Two primary themes became apparent: (1) access to adult HIV care, and (2) the relationship with the adult HIV provider. In both, the perception of "being cared for" seemed to be important.

Access to HIV care: Need for accessible and convenient services

All participants reported they had experienced problems accessing adult HIV care. Most were "straightforward" access problems, including problems making appointments, getting urgent care questions answered, and difficulties with obtaining and keeping health insurance coverage. For example, participants reported they did not know "How to follow up on future appointments," (Hispanic male, transitioned 2 years ago); or wrote: "I need help to remind me of when my appointment with the doctor is cause I tend to forget" (Haitian male, transitioned 2 years ago). Two participants, both currently not engaged in HIV care, described how inter-personal and system-related issues may be related. One participant wrote: “Amazing doctor, took amazing care of me. Problem was 
to get into her office to see her. They did not pick up the phone" (Hispanic male, transitioned 2 years ago). Another reported similar experiences: "She [adult physician] is a nice lady, it's not her. It's the system. It was the waiting and the trouble of making an appointment. Did not feel right over there" (African-American male, transitioned 2 years ago).

Several participants reported that staff of the adult clinic had accommodated them. For example, one participant said: "I did not know how to do it. Now they make them [appointments] for me" (African-American female, transitioned 4 years ago). Another participant wrote: "I can call him [physician] whenever, he calls me back, puts me on the list when I need to see him. He is personal" (African-American female, transitioned 10 years ago). The importance of easy access was also noted by participants who described problems with urgent care or walk-in appointments. As one participant worded it: "You leave a message with the nurse and when it is really urgent they call you back. I like my doctor, but I do not like the system" (Hispanic female, transitioned 4 years ago). Another participant commented: "In the adult clinic you were just a number. You cannot just show up". After changing providers, he said: "You can just walk in and speak to someone who is there" (African-American male, transitioned 4 years ago).

Finally, as noted previously, many participants had experienced difficulties with health insurance. In particular, public insurance was perceived to be complicated to navigate. For example, one participant wrote: “They [Medicaid insurance] made it very difficult for me to enroll again" (African-American male, transitioned 4 years ago), while another stated: "Ryan White is a nightmare over here. It's much easier in Broward [adjacent county], I tell everyone to move" (Haitian female, transitioned 3 years ago). 
Remarking on the advantages of private health insurance, another participant wrote: "It wasn't too bad for me because I had private health insurance through my job and was able to choose a really good doctor. I have heard some of the experiences other people had and they were not good experiences so I am glad I was able to avoid that" (Haitian female, transitioned 3 years ago).

Physician-patient relationship: Need for a personal, caring relationship

Many participants described their perception of the relationship with a HIV provider and indicated the importance of a personal and caring relationship. For example, one participant stated, "Adult care is not personal" (African-American male, transitioned 1 year ago), while another wrote: "Most doctors I went to were very generic and cold. They lacked the connection and care I received since birth" (African-American female, transitioned 8 years ago). The strong feeling of "not being cared for" after transition was frequently mentioned. For example, one participant concluded: "Now we are adults, they do not care anymore" (African-American female, transitioned 3 years ago).

Several participants explained why they believed a personal and caring relationship with the adult physician was important. One participant changed doctors a couple of times, until she found, "Someone who takes the time for me. AIDS is not just a disease, but it influences my whole life, everything. My doctor now understands that. He takes a lot of time for me and really wants to know how I am doing. He is interested in me" (Haitian female, transitioned 8 years ago). Others described how the physicianpatient relationship may impact how well patients take care of themselves. For example, one participant wrote "They stop caring. I think that's why so many die. If you do not have the support of your family you get lost" (African-American male, transitioned 3 
years ago). Several participants concurred. For instance, one participant stated: "They do not care for you in adult care. You just lose interest in that part of your life" (AfricanAmerican male, transitioned 3 years ago), while another said: “They just went through the motions. If they care, you will take better care of yourself also" (African-American female, transitioned 10 years ago).

\section{Recommendations for transition programs}

All participants offered recommendations for improving of the transition program. The following subcategories were developed (1) "Make it real," (2) Match patient with HIV care that is responsive to their needs, and (3) Increase continuity between pediatric and adult care.

As noted before, possibly with the exception of participants who had previous experience in adult (specialty) care, many observed they were aware that adult HIV care was "another world," but had limited understanding of future expectations. Some participants seemed to manage uncertainty with avoidance coping, which may have led them to advise: "To listen and be focused on what they say. I did not want to believe it until it's in front of me" (African-American male, transitioned 2 years ago), while others recommended "To make [patients] clear that things are going to change" (AfricanAmerican male, transitioned 3 years ago), and to "Keep reminding them" (Haitian female, transitioned 8 years ago). Limited understanding of future expectations in adult care settings may have led participants to recommend to: "Giving the patients the reality of the outcome" (African-American female, transitioned 10 years ago), or "Get them more prepared, like months ahead so they know exactly what's going to happen when they actually get there" (African-American female, transitioned 4 years ago). 
Participants suggested that interventions include peer education or modeling or: "Having someone who has gotten through transition and be somewhat of a guide to others to let them know that it is possible to come out on the other side" (Hispanic female, transitioned 1 year ago). Others recommended that staff "Walk you through everything until one foot is inside the door" (Haitian male, transitioned 1 year ago). Another recommendation was to match transitioning patients with accommodating clinics, physicians and other providers. For example, as one participant recalled: "I should have gone to another clinic.... I would have done better. If you do not show up at [clinic name] they do not call you. At [clinic name] they call” (African-American male, transitioned 2 years ago). Others advised to provide choices of adult providers to "Make sure the patient is with the best doctor that suits their needs" (African-American female, transitioned 10 years ago), or "Give a list of providers who can relate to young/working adults or college students." (African-American female, transitioned 8 years ago).

Participants suggested that more continuity between pediatric and adult care would be beneficial. As stated by one participant: "It's very different especially coming from somewhere that does everything for you [and] all you have to do is show up" (Haitian female, transitioned 8 years ago), while someone else wrote :"They [insurance] send me papers but I never looked at them because they [Pediatric staff] were taking care of it. Now I have trouble and do not know how to do it" (African-American female, transitioned 2 years ago). Increasing self-management of pediatric patients was, therefore, recommended. For example, one participant advised to: "Make sure they are willing to take their meds because $\mathrm{u}$ have no one to push or encourage you to take your medicine. It's all up to u" (African-American male, transitioned 1 year ago). Meeting an 
adult provider a couple of times before transition was suggested. As one participant explained: "The patient will feel comfortable and build a relationship with them before leaving" (Hispanic female, transitioned 4 years ago).

Continued support of the pediatric team and follow-up after transition to adult HIV care was proposed. As one participant stated: "Once you are out there you know how it is" (African-American male, transitioned 2 years ago). Recommendations included: follow-up by a pediatric social worker "To show them how to do things on their own" (African-American female, transitioned 10 years ago); support groups (AfricanAmerican male, transitioned 3 years ago), and " $\mathrm{A}$ few check- up calls throughout the year to see how the patient is doing" (Haitian female, transitioned 3 years ago). Many also recommended continued assistance with medical insurance and provision of access to services post-transition.

\section{DISCUSSION}

Both quantitative and qualitative methods were used to describe the experiences of 27 PHIV young adults between 25-34 years of age, who transitioned from a pediatric clinic to adult HIV care in Miami-Dade County, Florida. HIV/AIDS disproportionally impacts already vulnerable populations; ${ }^{28}$ all study participants were members of a racial or ethnic minority group, primarily African-American, and most were low-income. Participants had transitioned from a pediatric clinic with comprehensive HIV services to adult HIV care settings with less or no "wrap around" services, in a community with a high HIV/AIDS burden and limited resources. In the few available studies of transitioned young adults, all participants were currently engaged in HIV care. ${ }^{5,11}$ In our study, nine 
out of 27 participants (33\%) did not have an appointment with an HIV provider in the past 6 months.

Transition experiences, including loss of longstanding relationships with the pediatric team and loss of supportive services, were similar to those described in transition studies of youth with chronic diseases, including youth with HIV..$^{8,11,29,30}$ In contrast, none of our participants described benefits of transitioning to adult HIV care, such as increased control and autonomy, suggested by others. ${ }^{5,9}$ Most participants recalled preparation for transition, had discussed a transition plan, and had received support from the pediatric clinic team for the transition process. Nevertheless, 11 out of $27(41 \%)$ participants reported that transition was more difficult than expected; findings which were comparable with results reported previously. ${ }^{11}$ Transition preparation may have been hampered by avoidance coping, which was found to be a widely used strategy to cope with HIV infection in a study of HIV-infected adolescents. ${ }^{31}$ In addition, participants without prior adult care experience recalled that they had a limited understanding of future expectations in adult HIV care, as was observed in other studies of PHIV adolescents. ${ }^{9,32}$

HIV-infected adolescents and young adults have been characterized as a 'hidden population,' due to their experiences with and fears of HIV/AIDS stigma. ${ }^{33}$ De Santis and colleagues $^{31}$ described how social isolation starts at disclosure when PHIV adolescents are told to keep their HIV diagnosis secret, and is further reinforced by community stigma. Although concealment of HIV status may be appropriate in an unsupportive environment, concealment also acts as barrier to social support, which includes emotional (empathy, caring), instrumental (provision of services), informational (advice or 
suggestions), and appraisal (feedback for self-evaluation and affirmation) help through social interactions. ${ }^{34}$ The extent and nature of social support has been associated with health status and may influence the ability to remain in care. ${ }^{35,36}$ Explanatory mechanisms include modeling and reinforcement of desired behaviors, buffering of stress, and provision of access to resources. ${ }^{34}$ Previous studies of PHIV youth and health-care providers also suggested that HIV/AIDS stigma impacted both treatment and care transition, and reported disclosure concerns and anxieties about the adult clinic's more diverse patient population. ${ }^{5,710,11}$ Our study suggests that the impact of HIV/AIDS may be more extensive. In particular, we were struck by feelings of loneliness and social isolation. After participants transitioned to adult HIV care, they lost the extensive social support of the pediatric team and their peers. As one participant expressed: "Now I am an adult, I am basically alone."

In a concurrent retrospective, longitudinal study, we observed that participants were less frequent and less regular engaged in adult HIV care in the first post-transition year, compared to the last year in pediatric care. ${ }^{13}$ No significant changes were observed between the first and second post-transition year. Results of this study expand upon these findings. Overall, 16 out of 27 (59\%) participants reported it had been difficult for them to do well in adult HIV care, and many had experienced problems post-transition, including more difficulties taking meds as prescribed and more medical needs and complications. These results may not be surprising, as several studies have documented suboptimal clinical and retention outcomes among HIV-infected youth and young adults, but they are concerning. ${ }^{37-39}$ Successful transition is particularly important for PHIV young adults, as many may be in advanced stages of HIV-disease and have complex 
medical histories, which complicates treatment and limits therapy options. ${ }^{40}$ Patients must keep frequent appointments and adhere to strict medication regimens, as poorly managed HIV infection will have adverse consequences for both personal and public health. ${ }^{41,42}$ Unmet needs for food, income or other essentials may have made it difficult for participants to prioritize their health care. ${ }^{43}$ Although supportive services are available in the community, many participants reported problems accessing these services posttransition, and 14 out of $27(52 \%)$ participants experienced a multitude of unmet needs for supportive and ancillary medical services in the past 12 months. Despite resource allocation for supportive services for low-income people with HIV-infection, barriers that prevent access and service utilization, including poor publicizing of available services, and systemic problems such as confusing systems, long wait lists and financial barriers, were documented among other HIV-infected patient populations. ${ }^{44}$

Clearly, medical advances in HIV treatment will have little benefit without an understanding and improvement of systems responsible for attracting people to their services and retaining them in care. ${ }^{45}$ In our study, many participants reported it was difficult for them to do well in adult HIV care. In general, research indicates that positive patient-care experiences are associated with greater adherence to recommended care, better clinical-care quality outcomes, and less health care utilization. ${ }^{46}$ In summary, many of our participants felt that the adult health care system fell short in meeting their needs. Participants reported having problems to access adult HIV care and perceived their relationship with an adult provider to be "impersonal." Access problems included problems making, changing and remembering appointments, getting urgent care questions answered, and long wait times. Similarly, a study of patient experiences in 
England found straightforward initial access elements (including the ability to get through on the telephone and problems to make appointments) to be most strongly related with quality of care. ${ }^{47}$ In addition, previous studies have documented difficulties with medical insurance as important transition barriers. ${ }^{5,710,11}$ Likewise, 11 out of 27 (41\%) study participants reported problems with medical insurance after transition, while eight out of $27(30 \%)$ reported a gap in medical coverage in the past 12 months. In our study, we observed an association between poor engagement in adult HIV care and gaps in medical insurance; other studies of HIV-infected adults reported an association between gaps in medical coverage and viral rebound and clinically significant resistance. ${ }^{48}$ Financial barriers to regular HIV care are worrisome as they may impact both personal and public health. Participants' problems with obtaining and keeping health insurance coverage post-transition warrant a further exploration of the accessibility of public insurance in our community.

Different physician-patient relationships in adult care compared to pediatric care, with providers being more impersonal and disease-focused, seems to be a common, shared, experience among transitioned youth with chronic diseases, including HIVinfection. ${ }^{5,11,29}$ Although some participants were very complimentary about the 'personal' relationship with their physician, others experienced a mismatch between their own and providers' expectations. In essence, participants expressed the need to be treated as a person and wanted their physician to care for them, while they felt their physician treated their symptoms and took care of them. Patients' needs for patient-centered care and an affective, supportive relationship with their medical provider should be sufficient justification to transform the patient-provider relationship. However, as also was 
suggested by our study participants, the quality of the patient-provider relationship has been found to be associated with disease management and health outcomes. ${ }^{18}$

Traditionally, transition programming has been the responsibility of pediatric and adolescent providers and little has been done by adult providers to ensure that the needs of transitioned patients are being met. ${ }^{49}$ Because of concerns that the adult clinic would require an autonomy level that pediatric patients may not possess, increasing selfmanagement skills to prepare young adults to independently navigate the health system became an important goal of transition programs for youth with chronic diseases. ${ }^{4}$ Or, as stated in the position paper "Transitioning HIV-infected youth into adult health care" of the Academy of Pediatrics (2013):

Seamless and successful transition from pediatric to adult-oriented care is dependent on these youth acquiring skills to allow them to be responsible for their management of their own health care. A well-planned transition enables youth to optimize their ability to assume adult roles and responsibilities. ${ }^{3(\mathrm{p} 193)}$

Although enabling and empowering youth with HIV infection to self-manage their HIV disease is important for daily disease management, the emphasis on individual behavior also leads to a narrow-focus on changing the behavior of individuals, with limited attention for other factors that may inhibit or facilitate required behaviors. Consistent with the socio- ecological theory, ${ }^{50}$ participants experienced multi-level barriers in adult HIV care, including lack of social support (inter-personal), problems to access adult HIV care and supportive services, and impersonal relationships with adult providers. These barriers are influenced by community and macro-level (policy) influences, including HIV/AIDS stigma and the availability and allocation of resources 
for HIV care for the poor. Consequently, multiple retention strategies appear to be necessary to effectively address barriers to adult HIV care. $^{51}$

Participant recommendations for improving transition programs reiterated suggestions in previous studies and position papers, including but not limited to: timely preparations, meeting adult providers pre-transition, and post-transition follow-up to provide assistance with medical insurance and access to services. ${ }^{3,52}$ Because transition from pediatric to adult care is guided by individual transition readiness and preparation, transition models and strategies focus on preparations at the individual-level. Given the social isolation of many PHIV young adults and the importance of social support for disease management, we suggest to transition patients in cohorts, instead of individually, and to develop (on site or and/or on-line) group-level interventions. Recently, a hospital in northern Thailand reported their experiences with preparing and transitioning patients in groups, which facilitated positive peer interactions and mutual support. ${ }^{53}$ In addition, with limited available resources, cost-effective group-level interventions allow clinic staff to address collective needs and establish networks for mutual assistance and on-going support. We recommend that these groups be continued post-transition, as patients may encounter problems in adult HIV care they did not anticipate and were not prepared for. These group-level interventions should be co-managed by members of both pediatric and adult teams. Planning models should be used to guide program development, implementation, and evaluation to contribute to the development of evidence-based transition programs. ${ }^{54}$

There are limitations to the present study. First, this study was conducted among patients of a single pediatric clinic. Therefore, experiences of these patients may not be 
reflective of those young adults with PHIV elsewhere. To allow readers to determine if study results have relevance for other clinical settings and patient populations, we provided detailed descriptions of our study population, study context, and findings. ${ }^{23}$ In addition, recall bias is possible because participants were asked to reflect on experiences that have occurred in the past. Finally, qualitative studies are inherently concept and hypothesis generating and not confirming.

Despite these limitations, this mixed-methods study of transitioned young adults with PHIV has important implications. First, future programs to prepare youth for transitioning should expand beyond programs to increase individual transition preparation to group-based interventions that build capacity of groups of PHIV young adults to cope collectively with transition to allow for mutual learning, empowerment, and on-going support. Ample resources should be made available for program planning, implementation, and timely evaluation to contribute to the development of evidencebased transition programs. Second, a successful transition will not only depend on effective transition preparation, but also on the capacity of the adult health system to retain patients in optimal care. Our results highlight the need for continuing improvement in the delivery of HIV care and supportive services in south Florida, which will require dedicated resources and attention. In essence, our participants expressed the need for patient-centered care, which addresses patients' needs for a personal relationship with their physician and convenient and accessible services. ${ }^{55}$ Because of the social, economic, and medical vulnerability of many PHIV young adults, we recommend to explore strategies to increase the continuity between pediatric and adult HIV care, including models to offer pediatric and adult HIV care at the same clinic site with shared 
comprehensive services, or the creation of a network of adult HIV providers and social service organizations that are willing and able to "go that extra mile" to meet the needs of transitioned patients. Finally, resources should be mobilized to counter HIV/AIDS stigma, which continues to adversely affect the lives of people with HIV-infection. ${ }^{56}$

\section{REFERENCES}

1. Agwu AL, Fairlie L. Antiretroviral treatment, management challenges and outcomes in perinatally HIV-infected adolescents. J Int AIDS Soc. 2013;16:18579.

doi:10.7448/ias.16.1.18579.

2. Kapogiannis BG, Soe MM, Nesheim SR, et al. Mortality trends in the US perinatal AIDS collaborative transmission study (1986-2004). Clin Infect Dis. 2011;53(10):10241034. doi:10.1093/cid/cir641.

3. Committee on Pediatric AIDS. Transitioning HIV-infected youth into adult health care. Pediatrics. 2013;132(1):192-197. doi:10.1542/peds.2013-1073.

4. Betz CL, Lobo ML, Nehring WM, Bui K. Voices not heard: A systematic review of adolescents' and emerging adults' perspectives of health care transition. Nurs Outlook. 2013;61(5):311-336. doi:10.1016/j.outlook.2013.01.008.

5. Valenzuela JM, Buchanan CL, Radcliffe J, et al. Transition to adult services among behaviorally infected adolescents with HIV--a qualitative study. J Pediatr Psychol. 2011;36(2):134-140. doi:10.1093/jpepsy/jsp051.

6. Dowshen N, D'Angelo L. Health care transition for youth living with HIV/AIDS. Pediatrics. 2011;128(4):762-771. doi:10.1542/peds.2011-0068.

7. Gilliam PP, Ellen JM, Leonard L, Kinsman S, Jevitt CM, Straub DM. Transition of adolescents with HIV to adult care: Characteristics and current practices of the adolescent trials network for HIV/AIDS interventions. J Assoc Nurses AIDS Care. 2011;22(4):283294. doi:10.1016/j.jana.2010.04.003.

8. Sharma N, Willen E, Garcia A, Sharma TS. Attitudes toward transitioning in youth with perinatally acquired HIV and their family caregivers. J Assoc Nurses AIDS Care. 2014;25(2):168-175. doi:10.1016/j.jana.2013.01.007.

9. Fair CD, Sullivan K, Dizney R, Stackpole A. "It's like losing a part of my family": Transition expectations of adolescents living with perinatally acquired HIV and their guardians. AIDS Patient Care STDS. 2012;26(7):423-429. doi:10.1089/apc.2012.0041. 
10. Vijayan T, Benin AL, Wagner K, Romano S, Andiman WA. We never thought this would happen: Transitioning care of adolescents with perinatally acquired HIV infection from pediatrics to internal medicine. AIDS Care. 2009;21(10):1222-1229.

doi:10.1080/09540120902730054.

11. Wiener LS, Kohrt BA, Battles HB, Pao M. The HIV experience: Youth identified barriers for transitioning from pediatric to adult care. J Pediatr Psychol. 2011;36(2):141154. doi:10.1093/jpepsy/jsp129.

12. Chu PY, Maslow GR, von Isenburg M, Chung RJ. Systematic review of the impact of transition interventions for adolescents with chronic illness on transfer from pediatric to adult healthcare. J Pediatr Nurs. 2015;30(5):e19-27. doi:10.1016/j.pedn.2015.05.022.

13. Biersteker S. Outcomes of transition to adult HIV care in perinatally HIV-infected young adults. [dissertation]. Miami, Florida International University; 2016.

14. Florida Department of Health. Factsheet HIV disease: United States vs. Florida. Florida Department of Health AIDS Surveillance Web site. http://www.floridahealth.gov/diseases-and-conditions/aids/surveillance/_documents/factsheet/2014/2014-us-vs-fl-fact-sheet1.pdf. Accessed April 25, 2016.

15. Tsuyuki K, Surratt HL, Levi-Minzi MA, O'Grady CL, Kurtz SP. The demand for antiretroviral drugs in the illicit marketplace: Implications for HIV disease management among vulnerable populations. AIDS Behav. 2014. doi:10.1007/s10461-014-0856-2.

16. Garfield R, Damico A, Stephens J, Rouhani S. The coverage gap: Uninsured poor adults in states that do not expand Medicaid - an update. http://kff.org/healthreform/issue-brief/the-coverage-gap-uninsured-poor-adults-in-states-that-do-not-expandmedicaid-an-update/. Updated April 17, 2015. Accessed June 25, 2015.

17. Reif, S., Whetten, K. Duke Center for Health Policy and Inequalities Research. SASI update: The continuing HIV crisis in the US South.

http://www.hivlawandpolicy.org/sites/www.hivlawandpolicy.org/files/The\%20Continuin g\%20HIV\%20Crisis\%20in\%20the\%20U.S.\%20South\%20\%28Southern\%20HIV\%20AI DS\%20Strategy\%20Initiative\%29.pdf. Updated December 2012. Accessed September $10,2015$.

18. Gallant JE, Adimora AA, Carmichael JK, et al. Essential components of effective HIV care: A policy paper of the HIV medicine association of the infectious diseases society of America and the Ryan White medical providers coalition. Clin Infect Dis. 2011;53(11):1043-1050. doi:10.1093/cid/cir689.

19. Mugavero MJ, Norton WE, Saag MS. Health care system and policy factors influencing engagement in HIV medical care: Piecing together the fragments of a 
fractured health care delivery system. Clin Infect Dis. 2011;52 Suppl 2:S238-46. doi:10.1093/cid/ciq048.

20. Miami-Dade County Department of Regulatory and Economic Resources. Poverty in Miami-Dade. Miami-Dade County At-A-Glance Web site.

http://www.miamidade.gov/planning/library/reports/at-a-glance/2012-poverty.pdf.

Updated 2013. Accessed November 9, 2015.

21. Maturo D, Powell A, Major-Wilson H, Sanchez K, De Santis JP, Friedman LB. Development of a protocol for transitioning adolescents with HIV infection to adult care. J Pediatr Health Care. 2011;25(1):16-23. doi:10.1016/j.pedhc.2009.12.005.

22. Maturo D, Powell A, Major-Wilson H, Sanchez K, De Santis JP, Friedman LB. Transitioning adolescents and young adults with HIV infection to adult care: Pilot testing the "Movin' Out" transitioning protocol. J Pediatr Nurs. 2015;30(5):e29-35. doi:10.1016/j.pedn.2015.06.013.

23. Curry LA, Nembhard IM, Bradley EH. Qualitative and mixed methods provide unique contributions to outcomes research. Circulation. 2009;119(10):1442-1452. doi:10.1161/circulationaha.107.742775.

24. U.S Department of Health \& Human Services. Office of the Assistant Secretary for Planning and Evaluation. Prior HHS poverty guidelines and federal register references. http://aspe.hhs.gov/prior-hhs-poverty-guidelines-and-federal-register-references. Updated 2015. Accessed November 9, 2015.

25. Economic Research Service. U.S. household food security survey module: Threestage design with screeners. http://www.ers.usda.gov/topics/food-nutritionassistance/food-security-in-the-us/measurement.aspx. Updated 2012. Accessed November, 28, 2012.

26. US Department of Health and Human Services. Health Resources and Services Administration. HIV/AIDS Bureau Performance Measures. http://hab.hrsa.gov/deliverhivaidscare/coremeasures.pdf. Updated 2013. Accessed December 11, 2014.

27. Braun V, Clarke V. Using thematic analysis in psychology. Qualitative Research in Psychology. 2006;3(2):77-101. doi:10.1191/1478088706qp063oa.

28. Koenig LJ, Nesheim S, Abramowitz S. Adolescents with perinatally acquired HIV: Emerging behavioral and health needs for long-term survivors. Curr Opin Obstet Gynecol. 2011;23(5):321-327. doi:10.1097/gco.0b013e32834a581b. 
29. Fegran L, Hall EOC, Uhrenfeldt L, Aagaard H, Ludvigsen MS. Adolescents' and young adults' transition experiences when transferring from paediatric to adult care: A qualitative metasynthesis. Int J Nurs Stud. 2014;51(1):123-135.

doi:10.1016/j.ijnurstu.2013.02.001.

30. Wilcox RD. Transitioning adolescents to adult care can be challenging. HIV Clin. 2012;24(2):22-23.

31. De Santis JP, Garcia A, Chaparro A, Beltran O. Integration versus disintegration: A grounded theory study of adolescent and young adult development in the context of perinatally-acquired HIV infection. J Pediatr Nurs. 2014;29(5):422-435.

doi:10.1016/j.pedn.2014.01.001.

32. Miles K, Edwards S, Clapson M. Transition from paediatric to adult services: Experiences of HIV-positive adolescents. AIDS Care. 2004;16(3):305-314. doi:10.1080/09540120410001665312.

33. Fielden SJ, Sheckter L, Chapman GE, et al. Growing up: Perspectives of children, families and service providers regarding the needs of older children with perinatallyacquired HIV. AIDS Care. 2006;18(8):1050-1053. doi:10.1080/09540120600581460.

34. Bartholomew LK, Parcel GS, Kok G, Gottleib NH, Fernandez ME. Environmentoriented theories. In: Bartholomew LK, Parcel GS, Kok G, Gottleib NH, Fernandez ME. Planning health promotion programs: An intervention mapping approach. 3rd ed. San Francisco, CA: Jossey-Bass; 2011:113-167.

35. Wolitski RJ, Pals SL, Kidder DP, Courtenay-Quirk C, Holtgrave DR. The effects of HIV stigma on health, disclosure of HIV status, and risk behavior of homeless and unstably housed persons living with HIV. AIDS Behav. 2009;13(6):1222-1232. doi:10.1007/s10461-008-9455-4.

36. Abramowitz S. Characterizing social support: Global and specific social support experiences of HIV-infected youth. AIDS Patient Care and STDs. 2009; 23(5):323; 323330; 330. doi:10.1089/apc.2008.0194.

37. de Mulder M, Yebra G, Navas A, et al. High drug resistance prevalence among vertically HIV-infected patients transferred from pediatric care to adult units in Spain. PLoS One. 2012;7(12):10/1/2014-e52155. doi:10.1371/journal.pone.0052155.

38. Ryscavage P, Anderson EJ, Sutton SH, Reddy S, Taiwo B. Clinical outcomes of adolescents and young adults in adult HIV care. J Acquir Immune Defic Syndr. 2011;58(2):193-197. doi:10.1097/qai.0b013e31822d7564. 
39. Doshi RK, Milberg J, Isenberg D, et al. High rates of retention and viral suppression in the US HIV safety net system: HIV care continuum in the Ryan White HIV/AIDS program, 2011. Clin Infect Dis. 2015;60(1):117-125. doi:10.1093/cid/ciu722.

40. Mofenson LM, Cotton MF. The challenges of success: Adolescents with perinatal HIV infection. J Int AIDS Soc. 2013;16:18650. doi:10.7448/ias.16.1.18650.

41. Cohen RA, Bloom B. Access to and utilization of medical care for young adults ages 20-29 years: United States, 2008. NCHS Data Brief. 2010;(29)(29):1-8.

doi:10.1037/e665352010-001.

42. Giordano TP, Hartman C, Gifford AL, Backus LI, Morgan RO. Predictors of retention in HIV care among a national cohort of US veterans. HIV Clin Trials. 2009;10(5):299-305. doi:10.1310/hct1005-299.

43. Cheever LW. Engaging HIV-infected patients in care: Their lives depend on it. Clin Infect Dis. 2007;44(11):1500-1502. doi:10.1086/517534.

44. Wohl AR, Carlos JA, Tejero J, et al. Barriers and unmet need for supportive services for HIV patients in care in Los Angeles County, California. AIDS Patient Care STDS. 2011;25(9):525-532. doi:10.1089/apc.2011.0149.

45. Coates TJ. An expanded behavioral paradigm for prevention and treatment of HIV-1 infection. J Acquir Immune Defic Syndr. 2013;63 Suppl 2:S179-82. doi:10.1097/qai.0b013e318299effo.

46. Anhang Price R, Elliott MN, Zaslavsky AM, et al. Examining the role of patient experience surveys in measuring health care quality. Med Care Res Rev. 2014;71(5):522554. doi:10.1177/1077558714541480.

47. Llanwarne NR, Abel GA, Elliott MN, et al. Relationship between clinical quality and patient experience: Analysis of data from the English quality and outcomes framework and the national GP patient survey. Ann Fam Med. 2013;11(5):467-472. doi:10.1370/afm.1514.

48. Sethi AK, Celentano DD, Gange SJ, Moore RD, Gallant JE. Association between adherence to antiretroviral therapy and human immunodeficiency virus drug resistance. Clin Infect Dis. 2003;37(8):1112-1118. doi:10.1086/378301.

49. Reiss JG, Gibson RW, Walker LR. Health care transition: Youth, family, and provider perspectives. Pediatrics. 2005;115(1):112-120.

50. McLeroy KR, Bibeau D, Steckler A, Glanz K. An ecological perspective on health promotion programs. Health Educ Q. 1988;15(4):351-377.

doi:10.1177/109019818801500401. 
51. Higa DH, Marks G, Crepaz N, Liau A, Lyles CM. Interventions to improve retention in HIV primary care: A systematic review of U.S. studies. Curr HIV/AIDS Rep. 2012;9(4):313-325. doi:10.1007/s11904-012-0136-6.

52. Newman C, Persson A, Miller A, Cama E. Bridging worlds, breaking rules: Clinician perspectives on transitioning young people with perinatally acquired HIV into adult care in a low prevalence setting. AIDS Patient Care STDS. 2014. doi:10.1089/apc.2013.0346.

53. Hansudewechakul R, Pongprapass S, Kongphonoi A, Denjanta S, Watanaporn S, Sohn AH. Transition of Thai HIV-infected adolescents to adult HIV care. J Int AIDS Soc. 2015;18:20651. doi:10.7448/ias.18.1.20651.

54. Bartholomew LK, Parcel GS, Kok G, Gottleib NH, Fernandez ME. Planning health promotion programs: An intervention mapping approach. 3rd ed. San Francisco, CA: Jossey-Bass; 2011.

55. IOM (Institute of Medicine). Transforming health care scheduling and access: Getting to now. https://www.nap.edu/download.php?record_id=20220. Updated 2015. Accessed August 31, 2015.

56. White House Office of National AIDS Policy. National HIV/AIDS strategy for the United States. Updated to 2020.https://www.aids.gov/federal-resources/national-hiv-aidsstrategy/nhas-update.pdf. Published July, 2015. Accessed November 8, 2015. 
Table 5.1. Characteristics of study participants $(N=27)$

\begin{tabular}{|c|c|}
\hline Characteristics & $N(\%)$ \\
\hline $\begin{array}{l}\text { Race/ethnicity } \\
\text { African American/Haitian } \\
\text { Hispanic }\end{array}$ & $\begin{array}{r}22(87) \\
5(13)\end{array}$ \\
\hline $\begin{array}{l}\text { Gender } \\
\text { Female } \\
\text { Male }\end{array}$ & $\begin{array}{l}14(52) \\
13(48)\end{array}$ \\
\hline $\begin{array}{l}\text { HIV transmission } \\
\text { Vertical } \\
\text { Transfusion } \\
\text { Sexual (abuse/child) }\end{array}$ & $\begin{array}{l}25(93) \\
1(3) \\
1(3)\end{array}$ \\
\hline $\begin{array}{l}\text { Age in years at transition } \\
\text { Mean (SD) } \\
\text { Median (range) } \\
\text { Mode }\end{array}$ & $\begin{array}{l}23(1.6) \\
24(18-25) \\
24\end{array}$ \\
\hline $\begin{array}{l}\text { Years in adult HIV care } \\
\text { Mean (SD) } \\
\text { Median (range) } \\
\text { Mode }\end{array}$ & $\begin{array}{l}4(2.8) \\
3(1-10) \\
1\end{array}$ \\
\hline $\begin{array}{l}\text { Foreign Born } \\
\text { Yes } \\
\text { No }\end{array}$ & $\begin{array}{r}5(18.5) \\
22(81.5)\end{array}$ \\
\hline $\begin{array}{l}\text { Biological mother deceased (at time of transition) } \\
\text { Yes } \\
\text { No }\end{array}$ & $\begin{array}{r}24(89) \\
3(11)\end{array}$ \\
\hline $\begin{array}{l}\text { Dependent children } \\
\text { Yes } \\
\text { No }\end{array}$ & $\begin{array}{l}14(52) \\
13(48)\end{array}$ \\
\hline $\begin{array}{l}\text { Completed GED/high school } \\
\text { Yes } \\
\text { No }\end{array}$ & $\begin{array}{r}24(89) \\
3(11)\end{array}$ \\
\hline $\begin{array}{l}\text { Currently employment (full or part-time) } \\
\text { Yes } \\
\text { No }\end{array}$ & $\begin{array}{l}17(63) \\
10(37)\end{array}$ \\
\hline $\begin{array}{l}\text { Income at or below federal poverty line at transition } \\
\text { Yes } \\
\text { No }\end{array}$ & $\begin{array}{l}11(41) \\
16(59)\end{array}$ \\
\hline $\begin{array}{l}\text { Food insecurity past } 12 \text { months } \\
\text { Yes } \\
\text { No }\end{array}$ & $\begin{array}{l}12(44) \\
15(56)\end{array}$ \\
\hline $\begin{array}{l}\text { Current relationship status } \\
\text { Married/in relationship } \\
\text { Single }\end{array}$ & $\begin{array}{l}14(52) \\
13(48)\end{array}$ \\
\hline $\begin{array}{l}\text { Current living arrangements } \\
\text { Moving around/unstable } \\
\text { With (extended) family } \\
\text { Own/shared }\end{array}$ & $\begin{array}{r}3(11) \\
10(37) \\
14(52)\end{array}$ \\
\hline $\begin{array}{l}\text { Health insurance gap past } 12 \text { months * } \\
\text { Yes } \\
\text { No }\end{array}$ & $\begin{array}{r}8(30) \\
18(67)\end{array}$ \\
\hline
\end{tabular}




\begin{tabular}{|l|r|}
\hline Health status (self-report) & $19(70)$ \\
Excellent/good & $8(30)$ \\
Fair/poor & \\
\hline Engagement in HIV care past 6 months & $18(67)$ \\
At least one visit & $9(33)$ \\
No visit & \\
\hline
\end{tabular}

*Missing one respondent reply

Table 5.2. Who/what was helpful to prepare you for transition?

\begin{tabular}{|l|c|}
\hline Felt supported by: & $\boldsymbol{n}(\mathbf{\%})$ \\
\hline Medical providers & \\
Very/quite helpful & $23(85)$ \\
Somewhat/not helpful & $4(15)$ \\
\hline Staff of the pediatric clinic & \\
Very/quite helpful & $11(78)$ \\
Unsure & $3(11)$ \\
Somewhat/not helpful & $3(11)$ \\
\hline Parents/guardians or other family members & $12(44)$ \\
Very/quite helpful & $15(56)$ \\
No reply & $10(37)$ \\
\hline Peers from the pediatric clinic & $4(15)$ \\
Very/quite helpful & $13(48)$ \\
Unsure & \\
Somewhat/not helpful & $8(47)$ \\
\hline Transition clinic attendance $(\mathrm{n}=17)$ & $3(18)$ \\
Very/quite helpful & $6(35)$ \\
Unsure & $6(75)$ \\
Somewhat/not helpful & $1(13)$ \\
\hline Attendance of support groups $(\mathrm{n}=8)$ & $1(13)$ \\
Very/quite helpful & \\
Unsure & \\
Somewhat/not helpful &
\end{tabular}


Table 5.3. Experienced problems after transition to adult HIV care

\begin{tabular}{|l|c|}
\hline Problems post-transition & $\boldsymbol{n}(\boldsymbol{\%})$ \\
\hline $\begin{array}{l}\text { It has been difficult for me to do well in adult HIV care } \\
\text { Yes }\end{array}$ & $16(59)$ \\
No & $11(41)$ \\
\hline More difficulties to take meds as prescribed & \\
Yes & $12(44)$ \\
Maybe & $1(4)$ \\
No & $14(52)$ \\
\hline More medical needs or complications & \\
Yes & $11(41)$ \\
Maybe & $1(4)$ \\
No & $15(56)$ \\
\hline Problems with medical insurance & \\
Yes & $11(41)$ \\
Maybe & $2(7)$ \\
No & $14(48)$ \\
\hline Difficulties finding supportive services & \\
Yes & $10(37)$ \\
Maybe & $3(11)$ \\
No & $14(52)$ \\
\hline Problems finding HIV provider & \\
Yes & $8(30)$ \\
Maybe & $1(4)$ \\
No & $18(67)$ \\
\hline Unmet service needs in the past 12 months & \\
0 - 2 needs & $14(52)$ \\
3 - 7 needs & $13(48)$ \\
\hline
\end{tabular}




\section{CHAPTER VI}

\section{CONCLUSIONS AND PROGRAM RECOMMENDATIONS}

Transition from pediatric to adult HIV care may lead to poor health outcomes, but few studies have examined the effects of transition and programs to improve posttransition outcomes. The purpose of the three studies comprising this dissertation was to assess health outcomes and experiences of PHIV young adults who had transitioned from a pediatric out-patient clinic in Miami-Dade County, Florida, to adult care settings between January 2003 and September 2012. The first two studies examined posttransition health outcomes, including mortality and engagement in adult HIV care. While these studies provided valuable follow-up information on important health outcomes, they contributed little to the understanding of the experiences from the perspectives of transitioned young adults. The third study explored their experiences and recommendations for improvement of the transition program.

The first study examined post-transition mortality and associated clinical and socio-demographic factors. Transition was associated with high mortality (18\%), especially in patients who were severely immunosuppressed, unemployed or less educated at time of transition. Most patients (56\%) had died in the first year posttransition. Because of the poor health status of deceased patient at transition, it is unclear whether transition had negatively impacted the disease course. Transition clinic participation was preferentially recommended to patients living in extreme poverty or with severe immunosuppression; when controlled for these factors, mortality risk was identical among transition clinic attenders and non-attenders, suggesting that this 
intervention did not impact mortality. We recommended that comprehensive programs focus on improvements in clinical care and include academic and employment services.

Continuous HIV care is essential, as even short lapses in care and treatment may have significant consequences for viral suppression, drug resistance, and HIV transmission. The second study examined a pre-requisite for HIV treatment - regular engagement in HIV care - and assessed if the transition program had achieved its goal of continuous care. Multiple measurements, including the number of kept appointments and visit constancy, showed that engagement in HIV care significantly decreased posttransition, especially among African American or Haitian and low-income participants. Compared to the last year in pediatric care, study participants were less frequently and less regularly engaged in adult HIV care in the first year post-transition. Particularly concerning was the significant increase in poorly engaged participants from 3\% in pediatric to $35 \%$ in adult HIV care. No significant changes were observed between the first and second year post-transition, suggesting that the first year post-transition was crucial to establishing a behavioral pattern. The finding that study participants kept more (regular) HIV appointments in pediatric than adult care seemed to support the effectiveness of pediatric comprehensive services to retain their patients in care. Possibly, the comprehensive coordinated primary care and psychosocial pediatric clinic services, the long-standing relationship with pediatric providers, and clinic operations, including easy access, compensated for some of the effects of HIV-infection, social marginalization, and poverty experienced by PHIV young adults. 
Engagement in adult HIV care was identical among participants and nonparticipants in the transition program. Lack of transition program success may be partially explained by a "type III error", that is a failure to detect program effectiveness because of problems in program design and implementation. As the transition program focused on influencing personal determinants and preparing patients for requirements of adult HIV care, environmental determinants that may inhibit engagement in adult care were inadequately addressed.

Despite strong agreement of the importance of a purposeful, planned transition, limited data and little consensus exists as to which transition services are needed and which intervention strategies are most effective. Successful transition programs should be based on young adult's experiences and needs, which were explored in the third study. While most participants had received a range of transition services in pediatric care, many said it was difficult for them do well in adult HIV care and reported a multitude of unmet service needs in the past 12 months. Participants had experienced transition as a loss of (emotional and instrumental) support and familiar care. Exploratory analysis suggested that social and system-related determinants shaped individual transition experiences, including poverty (limited access to resources), HIV/AIDS stigma (limited social support), and system differences between pediatric and adult care (lack of continuity of care). Consistent with socio-ecological theory, participants experienced multi-level barriers post-transition, including social isolation because of HIV/AIDS stigma, impersonal, "non-caring," relationships with adult providers, and problems accessing adult HIV care. 
Participants recommended continuation of assistance post-transition and expressed a need for patient-centered adult HIV care, which is designed to address patients' need for a personal relationship with their physicians and considers their experiences with access, including convenience and easy accessibility of services. Because of the social isolation of many PHIV young adults and the importance of social support for disease management, we proposed to transition patients in cohorts, instead of individually, and develop group-level interventions to establish social networks and facilitate mutual, ongoing support. Planning models should guide program development, implementation, and evaluation to contribute to the development of evidence-based transition programs.

Some limitations and strengths of this research are important to note. This study was a single center study of a large pediatric clinic, which required fewer resources than a multi-center study and allowed for more involvement of pediatric clinic staff and collection of data potentially of relevance for the pediatric clinic's program. However, a small scale, single-center study also carries the risk of recruiting too few participants to make meaningful comparisons and detect statistically significant differences. Limitations of this study included the small sample size, non-eligibility and non-participation of 15 of 51 patients, and limited generalizability of study results. The first two studies were based on retrospective analyses of pre-existing data available in medical and social patient records, which came with the risk of missing information on potentially relevant factors not available in established datasets (including data on substance use and mental health), and with problems to assess temporal relationships. Participants transition experiences and recommendations, as described in the third study, may have been influenced by recall 
bias. Their experiences are context dependent and may not be reflective of experiences of PHIV young adults elsewhere. An important study question was if the transition program affected transition outcomes. An experimental study design, in which study participants are randomized to intervention and control interventions, would have been superior to the observational design of this study. As little information was available regarding which specific program interventions were delivered to which participants, we were unable to assess and compare the differential effects of various components of the comprehensive transition program, with exception of the transition clinic intervention.

These studies have implications for the development of transition programs and for future research. First, although enabling and empowering youth with HIV infection to self-manage their disease is important for daily disease management, this approach may lead to a narrow focus on psychological attributes and individual behaviors, while system-level and structural barriers that may inhibit or facilitate required behaviors are ignored or inadequately addressed. The notion that adequate transition preparation will lead to the successful transition of the autonomous patient with high self-efficacy seems to be normative and based on cultural beliefs and values instead on empirical evidence. Consistent with the findings of other studies, this research has shown that many socially and economically vulnerable PHIV young adults face insurmountable environmental barriers after they transitioned to adult HIV care. A greater understanding and response to social determinants of health may pave the way to more successful transition programs.

In particular, this research suggested systemic problems in the accessibility and delivery of adult HIV care and supportive services to help HIV patients manage 
competing challenges, address unmet psychosocial needs, and facilitate the successful management of HIV disease. Our results highlighted the need for continuing improvement in the delivery of adult HIV care and supportive services in south Florida, which will require dedicated resources. While in the past decade resources for HIV/AIDS research focused on studies concerning adherence to ART medication, attention and resources should be devoted to the problem of poor engagement in care. Similar to newly diagnosed adults with HIV, our research findings indicated that the first year in adult HIV care is crucial to establish care engagement behavior in PHIV young adults.

Interventions to improve retention should focus on the first year post-transition, with extra attention for those at highest risk of poor engagement, including African-American or Haitian patients and those living in extreme poverty.

Second, study results suggested a need to re-examine current transition practices that prepare PHIV young adults individually for transition and transfer patients to adult care around their $25^{\text {th }}$ birthday. While unintended, these practices may further isolate PHIV young adults with limited personal social support and who lose the support of the pediatric team and their peers from the clinic after they had transitioned. Because of the potential importance of social support in HIV management, this research suggested to prepare and transition patients in cohorts, instead of individually, and investigate interventions to establish mutual supportive networks.

Third, program development is a complex process, and neglect in a particular phase may lead to mistakes and inadequate decisions in subsequent phases. Without a full appraisal of the problems and possible solutions, interventions may address the wrong determinants or only address some of the influential determinants and, therefore, 
will not have the desired effect. Notably, social determinants of health are intertwined. To understand what may play a role, we looked at single factors and their impact on health. However, public health programs need to use a much broader perspective to include all (modifiable) factors of importance. Social-ecological theory provides a framework for assessment of multi-level influences. Planning models should be used to systematically develop, study, adopt and evaluate innovative strategies; prospective and multi-center studies are needed to bolster evidence, and ample resources should be made available to develop evidence-based transition programs.

Finally, traditionally pediatric providers are responsible to prepare their patients for transition. As transition success is highly dependent on the capacity of adult services to facilitate transitioned patients, it is recommended that transition programs become a collaborative effort of pediatric and adult providers. Participants were a crucial source of information in this research and successful programs should be based on their needs. We suggest that PHIV young adults play a vital role in the development and implementation of transition programs. These programs should empower and support transitioning young adults to take responsibility for management of HIV disease and address structural constraints. 
APPENDICES 


\section{APPENDIX 1}

Verification letter research collaboration 


\section{Health UNIVERSITY OF MIAMI \\ Pediatrics MILLER SCHOOL

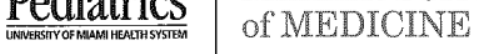

Dr. Adriana Campa

HS-IRB Chairperson

Robert Stempel College of Public Health \& Social Work

Department of Dietetics and Nutrition

11200 SW 8th Street, AHC I-450

Miami, Florida 33199

Re. Verification letter research collaboration

Miami, October 30, 2012

Dear Professor Campa,

This letter assures you that the Miami Family Care Program (MFCP) at the University of Miami has entered into an agreement with Ms Susan Biersteker, a doctoral student at F.I.U., to collaborate fully on an evaluation of our transition program for HIV-infected young adults.

Ms Biersteker, working with me and other staff members of MFCP, has developed an evaluation design, study procedures, data collection instruments, and analytical methods. Together with MFCP staff she will collect study data among former, transitioned patients of MFCP. As the principal investigator, Ms Biersteker will have the primary responsibility for data analysis and reporting of study findings, again in collaboration with MFCP. Publications of study findings will serve as her doctoral dissertation at the Robert Stempel College of Public Health \& Social Work.

A critical aspect of Ms Biersteker's responsibilities is to obtain IRB approval at collaborating institutions, FIU and UM. We fully support her in her research efforts.

Sincerely yours,

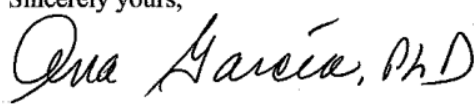

Ana Garcia, $\mathrm{PhD}$

Assistant Professor of Clinical Pediatrics

Ryan White Part D Pediatric Coordinator

University of Miami Miller School of Medicine

Pediatric Infectious Disease \& Immunology

1580 NW 10 Avenue Suite 287

Miami, $\mathrm{Fl} 33136$

Division of Infectious Disease \& Immunology

P.O. Box 016960 (D4-4) | Miami, FL 33101

Ph: 305-243-6676 | Fax: 305-243-5562 
APPENDICES 2-3

Institutional Review Board (IRB) 


\section{MEMORANDUM}

To: Dr. Consuelo Beck-Sague

$\begin{array}{ll}\text { CC: } & \text { File } \\ \text { From: } & \text { Maria Melendez-Vargas, MIBA, IRB Coordinator }\end{array}$

Date: $\quad$ October 19, 2015

Protocol Title: "Transitioning HIV-infected young adults to adult clinical care"

The Health Sciences Institutional Review Board of Florida International University has re-approved your study for the use of human subjects via the Expedited Review process. Your study was found to be in compliance with this institution's Federal Wide Assurance (00000060).

IRB Protocol Approval \#: $\quad$ IRB-14-0298 IRB Approval Date: $\quad$ 10/19/15

TOPAZ Reference \#: $\quad 102881 \quad$ IRB Expiration Date: 10/15/16

As a requirement of IRB Approval you are required to:

1) Submit an IRB Amendment Form for all proposed additions or changes in the procedures involving human subjects. All additions and changes must be reviewed and approved by the IRB prior to implementation.

2) Promptly submit an IRB Event Report Form for every serious or unusual or unanticipated adverse event, problems with the rights or welfare of the human subjects, and/or deviations from the approved protocol.

3) Utilize copies of the date stamped consent document(s) for obtaining consent from subjects (unless waived by the IRB). Signed consent documents must be retained for at least three years after the completion of the study.

4) Receive annual review and re-approval of your study prior to your IRB expiration date. Submit the IRB Renewal Form at least 30 days in advance of the study's expiration date. 
5) Submit an IRB Project Completion Report Form when the study is finished or discontinued.

Special Conditions: N/A

For further information, you may visit the IRB website at http://research.fiu.edu/irb. 


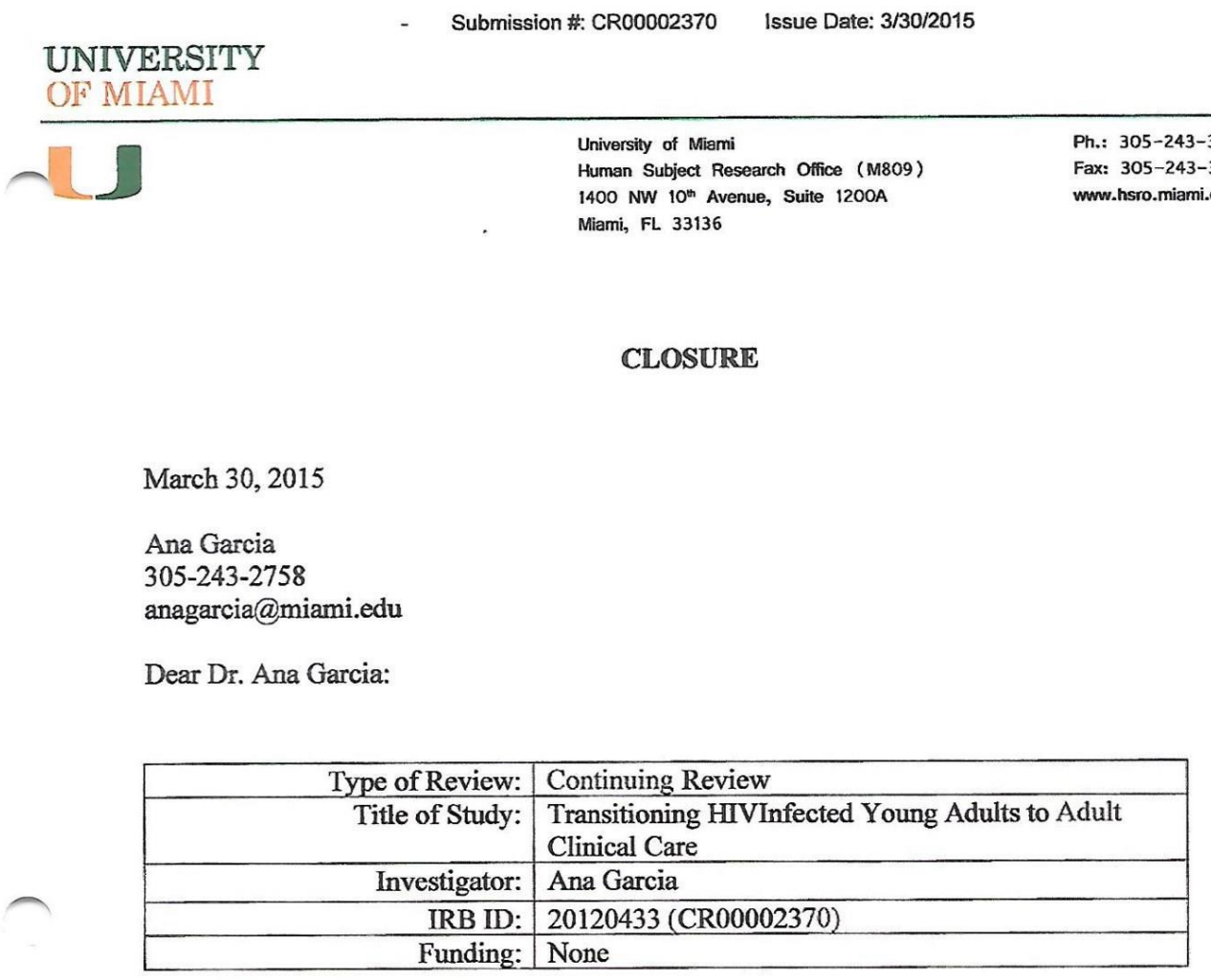

On 3/30/2015, the IRB reviewed the following submission:

The IRB acknowledges your request for closure of the study effective 3/30/2015. As part of this action:

- The protocol is permanently closed to enrollment.

- All subjects have completed all protocol-related interventions.

- Collection of private identifiable information is completed.

- Analysis of private identifiable information is completed. 
- Submission \#: CR00002370 Issue Date: $3 / 30 / 2015$

You are required to retain all records of this project for a minimum of three years following completion. Please refer to the Investigator Manual (HRP-103) for records retention policy and additional requirements.

Should you have any questions, please contact: Vivienne Carrasco, Sr. IRB Regulatory Analyst, (phone: 305-243-6713; email: vcarrasco@med.miami.edu)

Sincerely,

[This is a representation of an electronic record that was signed electronically and this page is the manifestation of the electronic signature]

Amanda Coltes-Rojas, MPH, CIP

Director

Regulatory Affairs \& Educational Initiatives 


\section{APPENDIX 4.}

Adult consent to participate in a research study 


\section{FIU}

\section{ADULT CONSENT TO PARTICIPATE IN A RESEARCH STUDY}

Evaluation of MFCP's transition program

\section{PURPOSE OF THE STUDY}

You are being asked to be in a research study. The purpose of this study is to find out how former patients of Pediatrics or the Adolescent Clinic are doing after they have transitioned to adult medical care. Your information and experiences will help us to improve the transition program.

\section{NUMBER OF STUDY PARTICIPANTS}

If you decide to be in this study, you will be one of 120 people in this research study.

\section{DURATION OF THE STUDY}

Your participation will take at most 45 minutes.

\section{PROCEDURES}

The purpose of this consent form is to help you decide if you wish to be included in this research study. Please read this form carefully. To be in a research study you must give your informed consent.

"Informed consent" includes:

- Reading this consent form,

- Having the staff explain the research study to you,

- Asking questions about anything that is not clear.

You should not join this study until all your questions are answered! If you sign this consent form you assure us that you understand what this study is about and that you voluntarily decide to participate.

We will get the information we need for this study in two different ways:

1. We will use information about your past treatment history - CD4 count/percentage, HIV RNA viral load, medical and Emergency Department visit history, HIV-transmission risk factor, and diagnosis from your medical records. From your psychosocial record, we will get demographic information (such as your gender, ethnicity, education, household income and employment). To permit your provider to release your private health information and to allow us to use your medical information for this study, we will need you to sign the HIPAA form. 
2. We will ask you to answer a survey. We will ask about your experiences with transition, what kind of problems you might have had, and how you are doing right now. You will answer the questions on a laptop computer at the Pediatrics office.

\section{RISKS AND/OR DISCOMFORTS}

You need to realize that there might be a small risk that people not authorized will find out you have participated in this study or will see the information you have provided. To limit these risks, we have agreed on ways to keep your information as safe as we possibly can. We will keep your records private and we will not ask you for your name or any other information which might identify you.

\section{BENEFITS}

One of the things we want to find out is whether you were able to get medical care and other services after transition. Ana Garcia, Barbara Messick, or another MFCP staff member will help you if this is a problem for you. They will bring you in contact with services, if you wish. Also, the reason we do this study is to improve the transition program, which will help patients who will transition in the future.

\section{ALTERNATIVES}

There are no known alternatives available to you other than not taking part in this study.

\section{CONFIDENTIALITY}

The records of this study will be kept private and will be protected to the fullest extent provided by law. In any sort of report we might publish, we will not include any information that will make it possible to identify you. Research records will be stored securely and only the researcher team will have access to the records. However, your records may be reviewed for audit purposes by authorized University or other agents who will be bound by the same provisions of confidentiality.

To help us further protect your privacy, we are applying for a Certificate of Confidentiality from the National Institutes of Health. With this Certificate, the researchers cannot be forced to disclose information that may identify you, even by a court subpoena, in any federal, state, or local civil, criminal, administrative, legislative, or other proceedings. The researchers will use the Certificate to resist any demands for information that would identify you, except as explained below.

You should understand that a Certificate of Confidentiality does not prevent you or a member of your family from voluntarily releasing information about yourself or your involvement in this research. If an insurer, employer, or other person obtains your written consent to receive research information, then the researchers may not use the Certificate to withhold that information. 
The Certificate of Confidentiality does not prevent the researchers from disclosing voluntarily, without your consent, information that would identify you as a participant in the research project under the following circumstances: disclosure of child abuse, or intent to hurt self or others.

The U.S. Department of health and Human Services (DHHS) may request to review and obtain copies of your records.

\section{COMPENSATION \& COSTS}

We will give you parking validation and pay for transportation costs you have made to come to MFCP's office. If you decide to participate in this study, you will receive $\$ 20$ in return for your time and effort. You will not be responsible for any costs to participate in this study.

\section{RIGHT TO DECLINE OR WITHDRAW}

Your participation in this study is voluntary. You are free to participate in the study or decide to withdraw your consent, at any time. Your decision will not affect any benefits to which you are otherwise entitled. We (the investigators) have the right to remove you without your consent at such time that we feel it is in the best interest.

\section{RESEARCHER CONTACT INFORMATION}

If you have any questions about the purpose, procedures, or any other issues relating to this study you may contact Susan Biersteker (principal investigator) at FIU. Susan's phone number is: (305)494-8415. Susan's e-mail is: susan.biersteker@yahoo.com.

\section{IRB CONTACT INFORMATION}

If you would like to talk with someone about your rights of being a subject in this research study or about ethical issues with this research study, you may contact the FIU Office of Research Integrity by phone at 305-348-2494 or by email at ori@fiu.edu.

\section{PARTICIPANT AGREEMENT}

I have read the information in this consent form and agree to participate in this study. I have had a chance to ask any questions I have about this study, and they have been answered for me. I understand that I am entitled to a copy of this form after it has been read and signed.

Signature of Participant

Date

Printed Name of Participant

Signature of Person Obtaining Consent

Date 
APPENDIX 5

Confidentiality Certificate Department of Health \& Human Services 


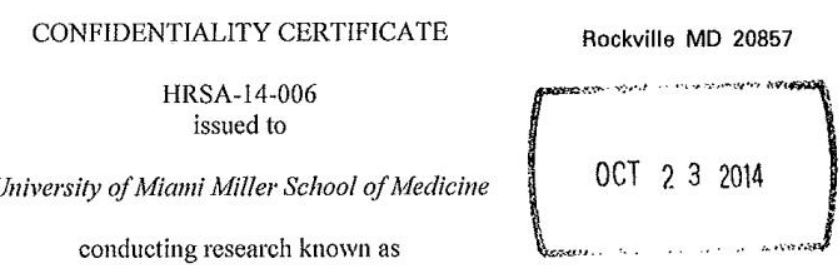

"Transitioning HIV-infected Young Adults to Adult Clinical Care"

In accordance with the provisions of section 301(d) of the Public Health Service Act, 42 U.S.C. 241(d), this Certificate is issued in response to the request of Ana Garcia, PhD, Principal Investigator, to protect the privacy of research subjects by withholding their identities from all persons not connected with this research. This research is funded by the Health Resources and Services Administration, grant \#H12HA00028.

Under the authority vested in the Secretary of Health and Human Services by section 301(d), all persons who:

1. are enrolled in, employed by, or associated with the University of Miami Miller School of Medicine, its data collecting or data processing contractors, or their collaborating service providers, and

2. have in the course of their employment or association access to information which would identify individuals who are the subjects of the research pertaining to the project known as "Transitioning HIV-infected Young Adults to Adult Clinical Care"

are hereby authorized to protect the privacy of the individuals who are the subjects of that research by withholding their names and other identifying characteristics from all persons not connected with the conduct of that research.

The study aims to assess health outcomes of transition from youth to adult primary HIV-care. It also aims to assess the impact of the Miami Family Care Program's (MFCP) transition program and other factors on transition outcomes. Study results will be used to improve MFCP's transition program. The study is an observational study; no interventions will be implemented. Using a retrospective cohort study design, the study will compare health outcomes of a cohort of patients that was exposed and a cohort that was not exposed to MFCP's transition program, for a total of about 120 patients. Health and demographic data will be abstracted from patients' medical and social records. Information regarding service delivery will be obtained from the Miami-Dade County-wide Service Delivery Information Systems. More in-depth information about factors associated with current engagement in adult primary HIV care, including but not limited to program exposure, will be obtained in a cross-sectional computer-assisted survey among all study participants. Eligible participants will be contacted by Dr. Garcia. After receiving consent, study staff will access the patient's medical records and ask eligible participants to provide answers to a standardized questionnaire administered at MFCP's office.

A Certificate of Confidentiality is needed because the study will generate sensitive information, which, if disclosed, could expose the subjects to adverse economic, psychological, and social consequences. This information may include specific substance abuse and mental health data that could lead to social 
stigmatization, discrimination, or law enforcement action. The certificate will help the researchers protect the confidentiality of this information from subpoena and other involuntary disclosures.

Confidentiality of data and protection of participant's identify will be safeguarded through various procedures. Eligible participants will be contacted by Dr. Ana Garcia and no messages about the study will be left if the call is not answered or answered by a third party. A master list with name and date of birth linked to a personal identifiable number will be kept in a locked drawer at MFCP's offices, and only the PI and key personnel of the study will have access. The list will be destroyed when the study is complete. Signed consent forms and a signed release of health information form will be also kept in a locked drawer and informed consent forms and release of health information forms will be kept for 3 and 5 years respectively. Any paper-based medical charts will be shredded after the medical chart abstraction form has been completed. Survey data will be downloaded on a secure web site and data (without personal identifiers) can only be accessed by members of the research team.

As provided in section 301(d) of the Public Health Service Act, persons so authorized to protect the privacy of such individuals may not be compelled in any Federal, State, or local civil, criminal, administrative, legislative, or other proceedings to identify such individuals.

This Certificate does not govern the voluntary disclosure of identifying characteristics of research subjects but only protects subjects from compelled disclosure of identifying characteristics. Researchers are, therefore, not prevented from the voluntary disclosure of such matters as child abuse or a subject's threatened violence to self or others; however, the consent form should indicate clearly a researcher's intention to make any such voluntary disclosure.

This Certificate does not represent an endorsement of the research project by the Department of Health and Human Services. This Certificate is now in effect and will expire on May 31, 2015. The protection afforded by this Confidentiality Certificate is permanent with respect to subjects who participate in the research during the time the Certificate is in effect.

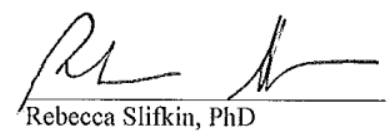

Director, Office of Planning, Analysis and Evaluation

Health Resources and Services Administration

Specific project information described within this Certificate of Confidentiality has been taken verbatim from the application. The recipient of this Certificate of Confidentiality assures that the conduct of research will comply with all HHS requirements described within 45 CFR Part 46 . 
APPENDIX 6

Data abstraction form 


\section{Chart Abstraction Form Transition Study}

Participant \# Completed by:

Date:

\section{Patient Status}

- Deceased (complete chart abstraction form)

Date (month/year) of death:

If deceased: AIDS-related causes o yes o no o unknown

- Reached and signed consent/HIPAA (complete chart abstraction form)

- Not eligible because of low cognitive functioning (no chart abstraction)

- Reached and no consent (no chart abstraction)

- Moved outside of S.Florida (no chart abstraction)

- Lost to follow-up (no chart abstraction)

\section{A. Primary Care History}

1. Before transitioning, received care at:

- Pediatric Immunology and Infectious Diseases (Pediatric Immunology)

- Adolescent Medicine's Special Adolescent Clinic (SAC)

2. Transferred to the pre-transition and/or transition clinic?

- Only pre-transition clinic at Pediatric Immunology or SAC

- Only post-transition clinic at UM/JMC

- Both pre-transition and post-transition clinic

- No

○ Unknown

3. Last medical appointment at Pediatrics /SAC

Month/year of transition:

4. Age last appointment at Pediatrics/SAC years/month

5. Total time of treatment at Pediatrics/SAC? years/months

6. Transitioned to (adult HIV care):

- Special Immunology Clinic

- Obstetric and Gynecology's Primary Care Clinic Jackson

- Clinic (other than Jackson)

- Community provider (ASO/CBO)

- Private provider

○ Unknown

\section{B. Socio-Demographics}

7. Year of birth:

8. Gender
- Male
- Female
- Transgender: $\quad$ male to female $O$ female to male 


\section{Participant \#}

\section{Race/Ethnicity}

- Black or African American, please specify:

O Haitian O Caribbean O Other

- White/non-Hispanic

- Hispanic, please specify:

O Cuban O Puerto Rican O Mexican O other

o Other

10. Foreign born?
○ Yes
- No
○ Unknown

11. HIV-transmission category

$\begin{array}{ll}\circ & \text { Perinatal } \\ \circ & \text { Blood products } \\ \circ & \text { Heterosexual } \\ \circ & \text { MSM } \\ \circ & \text { IDU } \\ \circ & \text { Unknown }\end{array}$

12. HIV status biological parents

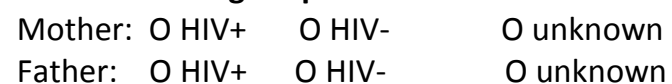

Mother deceased? 0 yes $\mathrm{O}$ no 0 unknown

If yes, age of participant when mother died:

years $\quad 0$ unknown

13. Highest level of education completed

- Did not complete high school

- High school diploma or equivalent

- Vocational/tech program after high school

- College or university (some)

- Unknown

14. Household income

- Equal or below poverty line

- $101-200 \%$ of Federal poverty line

- $\quad 201-300 \%$ of Federal poverty line

- $\quad 301-400 \%$ of Federal poverty line

- $\quad \geq 401 \% \%$ of Federal poverty line

○ Unknown 


\section{Participant \#}

15. Employment (more than one answer category possible)

- Employed

- Unemployed, looking for work

○ Unemployed, disabled/not healthy enough to work

- Enrolled in school

o Other

○ Unknown

16. Health insurance (more than one answer possible)

- Yes, please specify:

O Medicaid

O Medicare

O Ryan White

O other public funding source (than Ryan White)

O Private health insurance

- Other

- No

○ Unknown

17. Residence/neighborhood (during 12 months before transition, most of the time)

- Zone IV (Liberty City\& vicinity): 33147,33150,33138,33167, 33169, 33161)

- Zone II (Opa-Locka, Carol City): 33055,33054,33169,33179,33162,33056,33180,33160

- Zone V (Little Haiti, Brownsville, part of Liberty City): 33142, 33127, 33157

○ Zone VI (Little Havana, Overtown): 33125, 33135, 33145, 33136,33128,33130,33129,33132,33131,33109

- Zone X (Homestead, Florida City): 33031,33032,33033,33039,33034,33035

- Other

○ Unknown

18. Housing (during 12 months before transition, most of the time)

- Homeless (in the street/outdoors/shelter)

- Moved around (temporarily in someone's home)

- Lived in own or shared place

- Lived with family (f.e.: parent, guardian, grand parent, aunt/uncle, brother/sisters)

Other, please explain

○ Unknown

19. Relationship status (at time of transition)

- Married

- In relationship, but not married

- Single

○ Unknown

20. Pregnant/children or took care of anyone's children?

o Yes

- No (skip to 22)

○ Unknown (skip to 22) 


\section{Participant \#}

21. HIV status biological children

- HIV positive

○ HIV negative

○ Children have different status

o Unknown

- N/a: does not have biological child

\section{Health Status (most recent information at transition). See also: $q 24$}

22. History of diagnosed depression?

$$
\begin{array}{ll}
\text { ○ Yes } \\
\text { ○ No } \\
\text { ○ Unknown }
\end{array}
$$

23. Neurodevelopmental assessment

Age of participant $(\mathrm{m} / \mathrm{y})$ when tests were conducted:

(1). Executive functioning (D-KEFS):

\begin{tabular}{|c|c|c|c|c|}
\hline & $\begin{array}{l}\text { Baseline: Pre- } \\
\text { transition. Last } \\
\text { results at } \\
\text { Pediatrics/SAC }\end{array}$ & $\begin{array}{l}\text { Post-transition: } \underline{1} \\
\text { year after } \\
\text { transition }\end{array}$ & $\begin{array}{l}\text { Post transition: } \\
\underline{2 \text { years after }} \\
\text { transition }\end{array}$ & $\begin{array}{l}\text { Post transition: most } \\
\frac{\text { recent }}{\text { information (i.e. }} \\
\text { currently) }\end{array}$ \\
\hline \multicolumn{5}{|l|}{$\begin{array}{l}\text { Clinical category } \\
\text { HIV disease } \\
\text { staging }\end{array}$} \\
\hline \multicolumn{5}{|l|}{ CD4 count } \\
\hline \multicolumn{5}{|l|}{ Viral load } \\
\hline $\begin{array}{l}\text { Non-compliance } \\
\text { to ART? }\end{array}$ & $\begin{array}{l}0 \text { yes } \\
0 \text { no } \\
0 \text { unknown } \\
\text { O ART not } \\
\text { prescribed }\end{array}$ & $\begin{array}{l}0 \text { yes } \\
0 \text { no } \\
0 \text { unknown } \\
\text { O ART not prescribed }\end{array}$ & $\begin{array}{l}0 \text { yes } \\
0 \text { no } \\
0 \text { unknown } \\
\text { O ART not prescribed }\end{array}$ & $\begin{array}{l}0 \text { yes } \\
0 \text { no } \\
0 \text { unknown } \\
\text { O ART not prescribed }\end{array}$ \\
\hline
\end{tabular}

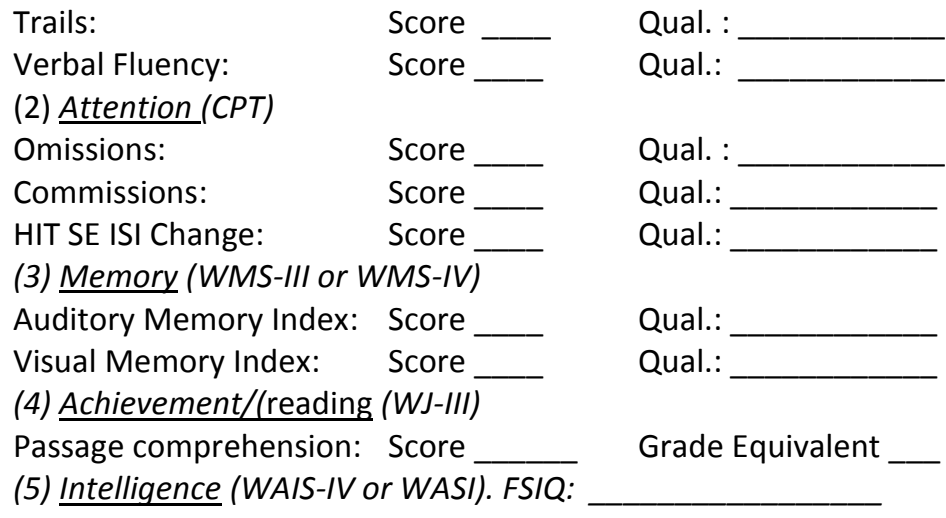

24. CD4 count, viral load and adherence to ART 


\section{Participant \#}

25. Number of made \& kept appointments with HIV provider

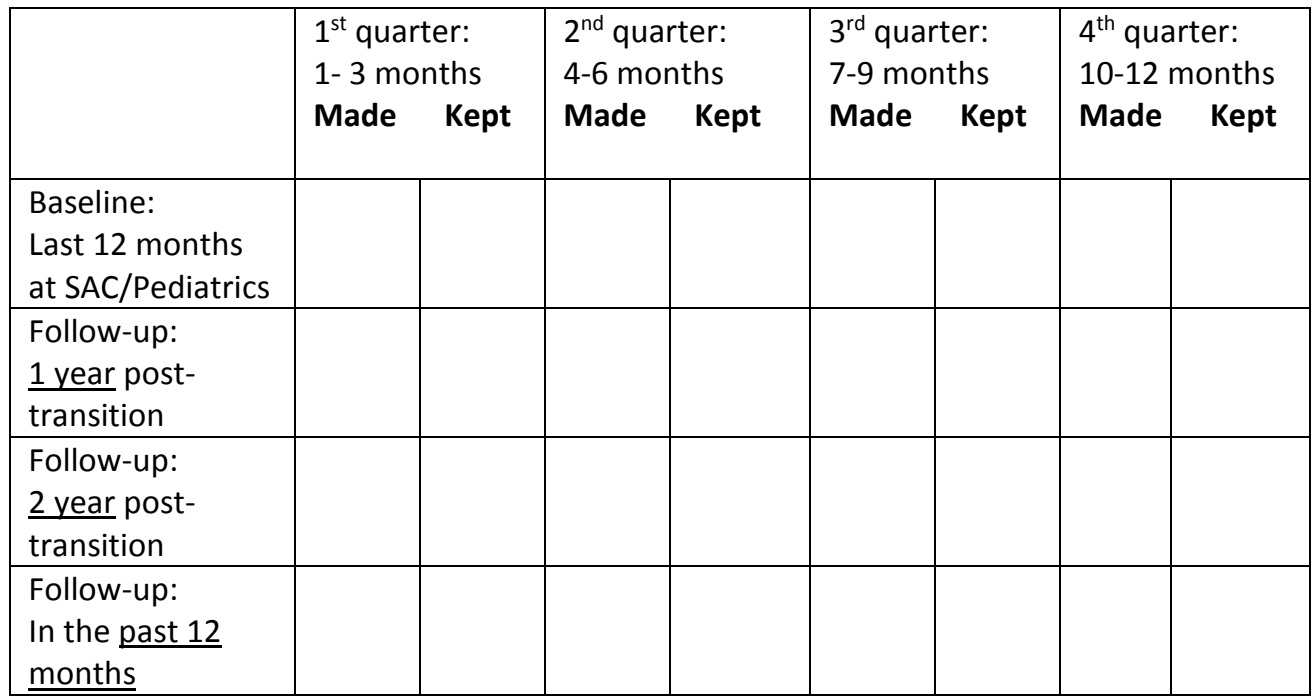

26. Number of made \& kept appointments with case manager

\begin{tabular}{|l|l|l|}
\hline & Made & Kept \\
\hline $\begin{array}{l}\text { Baseline: } \\
\text { last 12 months at }\end{array}$ & & \\
SAC/Pediatrics & & \\
\hline $\begin{array}{l}\text { Follow-up: } \\
\text { 1 year post-transition }\end{array}$ & & \\
\hline Follow-up: & & \\
2 year post-transition & & \\
\hline $\begin{array}{l}\text { Follow-up: } \\
\text { In the past 12 months }\end{array}$ & & \\
\hline
\end{tabular}

\section{Total number of E.R. visits \& hospital admissions}

\begin{tabular}{|l|l|l|}
\hline & E.R. & Hospital \\
\hline Baseline: & & \\
Last 12 months at SAC/Pediatrics & & \\
\hline Follow-up: & & \\
1 year post-transition & & \\
\hline Follow-up: & & \\
2 year post-transition & & \\
\hline $\begin{array}{l}\text { Follow-up: } \\
\text { In the past 12 months }\end{array}$ & & \\
\end{tabular}




\section{Participant \#}

28. General remarks (do not include private information) 


\section{VITA}


VITA

\section{SUSAN BIERSTEKER}

Born in Heerhugowaard, The Netherlands.

$1975-1979$

B.A. Education.

Bijzondere Neutrale Academie, Den Helder, The Netherlands

$1979-1980$

Teacher Elementary Education

$1981-1984$

B.A. Behaviorial Sciences

University of Amsterdam, Amsterdam, The Netherlands

1982-1986

Teacher Illiteracy Courses

Amsterdam, The Netherlands

$1984-1987$

Degree of Doctorandus (Drs) in Behaviorial Sciences

University of Amsterdam, Amsterdam, The Netherlands

1986- 1987

Counselor

Hubertus Huis, Amsterdam, The Netherlands

$1988-1994$

Coordinator Dutch National HIV/STD Prostitution Policy

Foundation for STD Control, Utrecht, The Netherlands

1990

International EIS Course in Epidemiology (Certificate)

Emory University and Centers for Disease Control and Prevention (CDC)

$1995-2001$

Founding Board Member and Program Director

South Beach AIDS Project, Miami Beach, Fl.

2003-current

Program Planning and Evaluation Consultant

Behavioral Research and Evaluation Consultants, Miami, Fl.

2009-current

Doctoral Candidate Health Promotion and Disease Prevention

Florida International University, Robert Stempel School of Public Health \& Social Work, Miami, Fl. 


\section{PUBLICATIONS AND PRESENTATIONS}

Biersteker, S. Trends in HIV/AIDS and Homelessness. Institute of Homeless Studies: The Treatment for Ending Chronic Homelessness. Oral presentation, Goral Gables, Fl., September 27, 2005.

Biersteker, S. Short-term Impact Evaluation of a Syphilis Social Marketing Campaign. Poster presented at ISSTDR 16th Biennial Meeting, Amsterdam, The Netherlands, July 13, 2005 (with Darrow WW).

Biersteker, S. Evaluation of the South Florida Syphilis Social Marketing Campaign. Poster presented at National STD Prevention Conference, Jacksonville, Florida, May 8-11, 2006 (with Darrow WW, et al).

Biersteker, S. Effectiveness of a Faith-Based Inpatient Substance Abuse and HV/AIDS Program for Homeless Men. Poster presented at the 8th Congress of European Federation of Sexology, Prague, Czech Republic, June 7, 2006. Sexologies 2006;15: S27 (with Darrow WW, Cawley P).

Biersteker, S. Development of an HIV-prevention program for in-treatment homeless men: The importance of assessing feasibility and fidelity. Poster presented at the XVII International AIDS Conference, Mexico City, Mexico, 2008 (with Darrow WW, Cawley P, Mims F, Campbell A).

Biersteker S, Darrow WW. (2010). Dogs are talking. What are they saying? Who is listening? Sexually Transmitted Diseases; 37(8):530.

Darrow, WW, Biersteker, S. et al. 'Hooking up' on the Internet, 'club drug' use and risks for acquiring syphilis among men who have sex with men in an international resort area. Oral presentation at $13^{\text {th }}$ International Union against Sexually Transmitted Infections Asia Pacific Conference, Chiang Mai, Thailand, July 7, 2004.

Darrow WW, Biersteker S, Geiss T, et al. (2005) Risky sexual behaviors associated with recreational drug use among men who have sex with men in an international resort area: Challenges and opportunities. Journal of Urban Health; 82(4): 601-609.

Darrow, WW, Biersteker, S. Development and Evaluation of an HIV-Prevention Program for Homeless Men. Presentation at the $2^{\text {nd }}$ Annual Institute of Homeless Studies Symposium, Miami, Fl. February 5, 2008.

Darrow WW, Biersteker S. (2008). Short-term impact evaluation of a social marketing campaign to prevent syphilis among men who have sex with men. American Journal of Public Health; 98 (2): 337-343. 